Portland State University

PDXScholar

Dissertations and Theses

Dissertations and Theses

$1-1-1978$

\title{
Social Control Theory and Delinquency
}

Michael David Wiatrowski

Portland State University

Follow this and additional works at: https://pdxscholar.library.pdx.edu/open_access_etds Let us know how access to this document benefits you.

\section{Recommended Citation}

Wiatrowski, Michael David, "Social Control Theory and Delinquency" (1978). Dissertations and Theses. Paper 857.

https://doi.org/10.15760/etd.857

This Dissertation is brought to you for free and open access. It has been accepted for inclusion in Dissertations and Theses by an authorized administrator of PDXScholar. Please contact us if we can make this document more accessible: pdxscholar@pdx.edu. 
SOCIAL CONTROL THEORY AND DELINQUENCY

by

MICHAEL DAVID WIATROWSKI

A dissertation submitted in partial fulfillment of the requirements for the degree of

\author{
DOCTOR OF PHILOSOPHY \\ in \\ URBAN STUDIES
}

Portland State University

1978 
TO THE OFFICE OF GRADUATE STUDIES AND RESEARCH:

The members of the Committee approve the dissertation of Michael David Wiatrowski presented October 25, 1978.
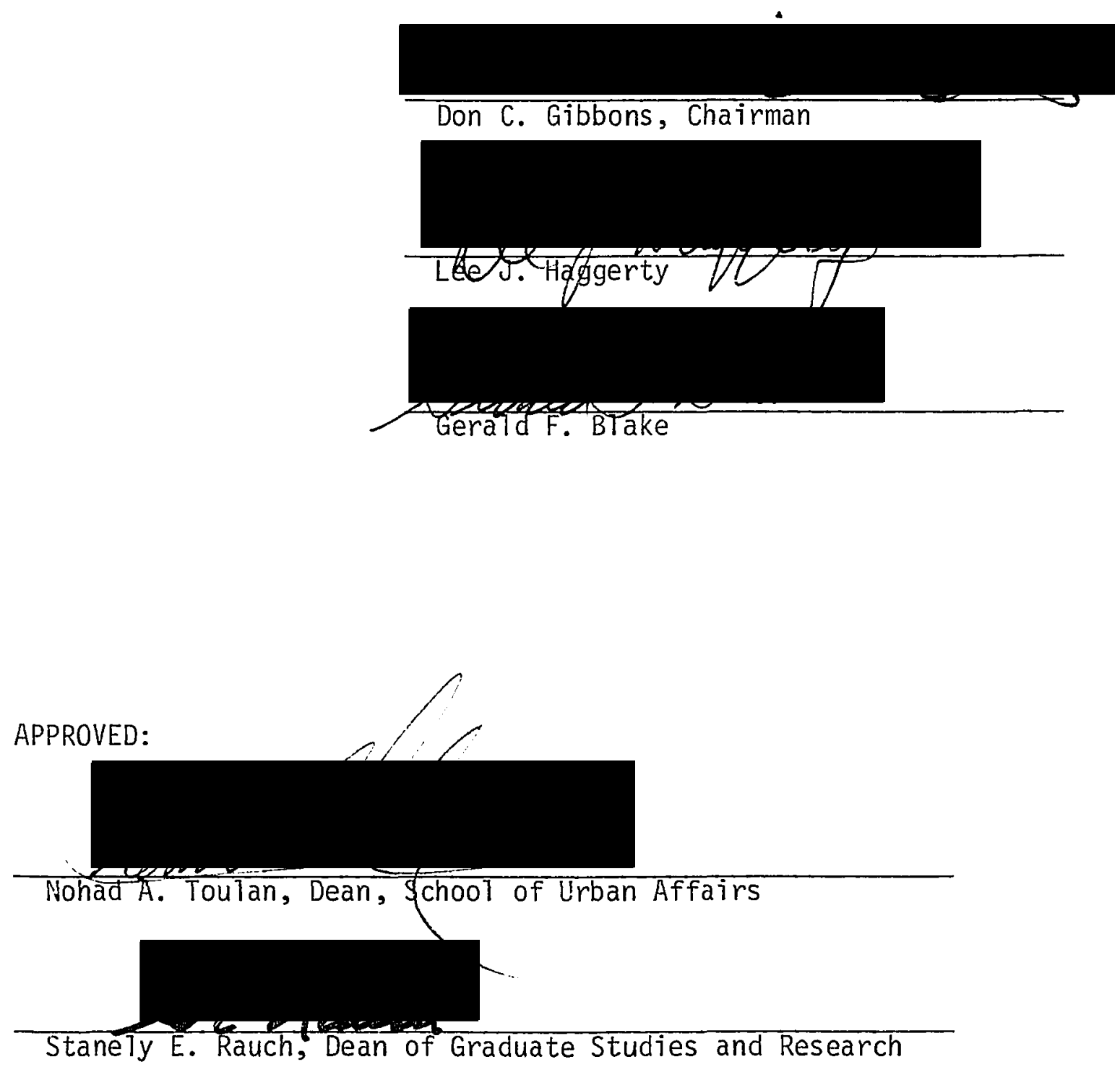
AN ABSTRACT OF THE DISSERTATION OF Michael David Wiatrowski for the Doctor of Philosophy in Urban Studies presented October 25, 1978.

Title: Social Control Theory and Delinquency.

APPROVED BY MEMBERS OF THE DISSERTATION COMIITTEE:

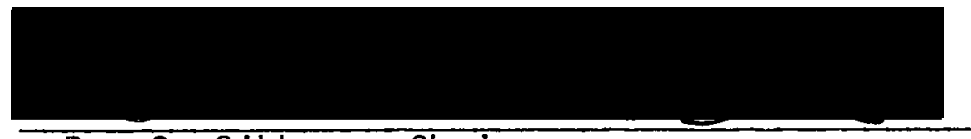

Don C. Gibbons, Chairman
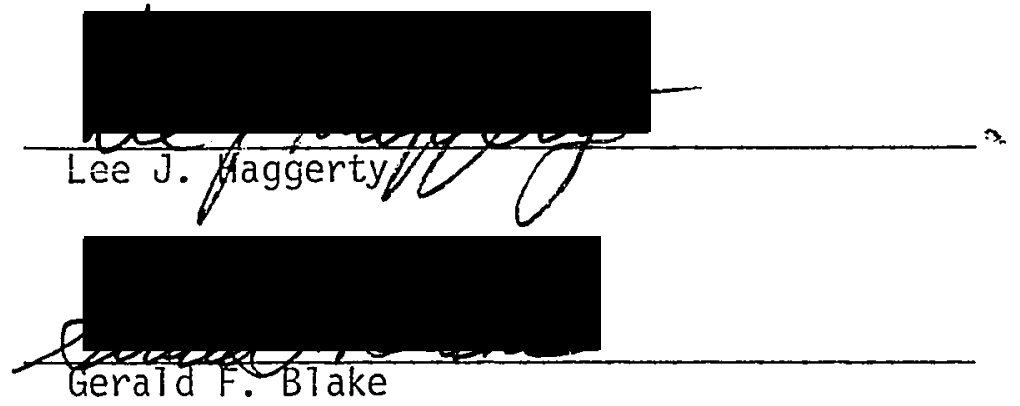

The concept of social control has been used in sociology since the foundations of the discipline were laid almost a hundred years ago. At the turn of the century social control developed two distinct orientations. The concept has referred to the process of socialization or how individual behavior is regulated in primary group relations, and alternatively, to how the large macrosocial institutions such as education, religion, law and the political system maintain order in society. 
Early research in social control focused on the development of inventories of societal means of social control. Changing standards of science, however, forced an abandonment of that perspective and research became more directly concerned with the socialization process. Most recently, social control arguments have centered upon the primary group aspects of socialization and the relation of that socialization to delinquency and have been unattentive to larger social institutions and secondary group factors that also influence behavior.

The version of social control theory developed by Travis Hirschi in Causes of Delinquency (1969) has been shown to be an exemplary model of social research. He claimed that in early childhood many youths form a bond to society which prevents some of them from becoming involved with delinquency while others who fail to form a bond become delinquent. Hirschi's theory was strongly supported by the research he conducted which showed that delinquency involvement was inversely related to the strength of an individual's relationship to society.

Despite the importance of Hirschi's research there is mounting evidence that various institutional experiences such as tracking and grading in school operate as contingencies experienced by adolescents which affect their ability to pursue the legitinate careers which is central to Hirschi's thesis and which may force some youths into patterns of delinquent behavior. Similarly, youngsters who come from different positions in the class structure may vary in their likelihood of obtaining access to high status positions or conversely participating in delinquency if they fail. Yet the impacts of educational policies and the effects of social class background have not been incorporated into social control arguments. 
This dissertation extends the explanatory model developed by Hirschi. First, it argues that the socialization levels reached by youngsters in primary group socialization are sometimes altered by subsequent experiences. Secondly, it contends that those changes are related to school experiences and social class backgrounds of youths. Finally, it avers that those changes increase or decrease the likelihood that adolescents will become involved in delinquent behavior.

The data for this research was obtained from the llarion County Youth Study, an ongoing survey of a panel of male youths who were high school juniors in 1964. A twenty-five percent random sample of the panel in 1967 comprised the group used in this research. The group's 1964 responses were identified, and this served as the basis for the data ana?ysis.

The first part replicated Hirschi's contentions that the bond was formed in the family. One element, not formed in 1964, emerged prior to the youth's graduation. Secondly, this research diverged from Hirschi's contention that social class was not related to the levels of bond achieved by youths or delinquency. Delinquency and two of the four elements of the bond were found to be related to social class. Third, the social bond was found to be moderately unstable and change was somewhat related to the educational and social background of the youth. Finally, these changes in bond and secondary group factors were translated into significant variations in the delinquency rates for the youths who comprised the analysis groups. 
TABLE OF CONTENTS

PAGE

LIST OF TABLES ................................ vii

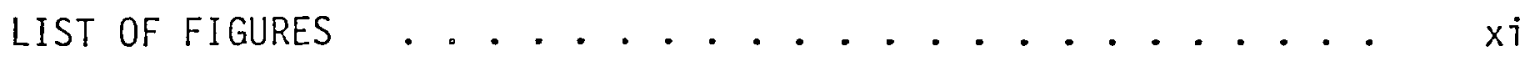

CHAPTER

I INTRODUCTION ........................ I

Overview of the Research ....... 3

II THE DEVELOPMENT OF SOCIAL CONTROL THEORY . . . . . 5

The Early History .......... . . 5

Merton and Social Structure ....... 13

Labeling Thoery ............... 15

Primary and Secondary Deviation ...... 16

Containment Theory and Social Control .... 22

Sociai Control Theory and Causes of Delinquency 33

Conclusions .............. . . . 4 47

II THE RESEARCH PROBLEM AND METHODOLOGY . . . . . . 50

Introduction .............. 50

Research Procedures ......... 51

The Social Bond and Delinquency . . . . . 52

Changes in the Social Bond and Delinquent Behavior ............. 54

The Causal Ordering of Variables ..... . 54

Research Model ............ 60 
CHAPTER

PAGE

Description of Analysis Groups .......

Initial Level of Social Bond, Social Class and Delinquency Involvement . . . . . . .

Explaining the Changes in the Social Bond . . 64

Methodology . . . . . . . . . . . 66

Data Collection . . . . . . . . . 67

Educational and Delinquency Involvement Data . 68

Description of Longitudinal Data Collection

Procedures............ . 68

Operationalization of the Concepts . . . 69

Attachment .............. . 71

Commitment . . . . . . . . . . 72

Involvement . . . . . . . . . . 73

Belief............... . . . . 74

Del inquency . . . . . . . . . . 75

Education .............. . . 76

Social Class Background . . . . . . . . 79

Data Presentation . . . . . . . . 80

Conclusion . . . . . . . . . . . 82

Data Conventions ......... . . . 82

Missing Data............. . 83

IV LEVEL OF BOND AND DELINQUENCY, BOND AND SOCIAL CLASS, AND CHANGES IN BOND AND DELINQUENCY . . 84 Attachment to Parents . . . . . . . . 84 
Commitment to Conventional Goals . . . . .

Involvement in Conventional Activities . . . .

Belief in the Social Value System . . . . 92

Discussion . . . . . . . . . . . . 95

Social Class in Relation to Social Bond and

Delinquency Involvement . . . . . . . 96

Social Class and Bond . . . . . . . . 98

Changes in the Bond ......... 103

Changes in Attachment ......... 106

Changes in Commitment ......... 110

Changes in Involvement.......... 113

Summary ................. 116

$\checkmark$ EXPLAINING THE CHANGES IN THE LEVEL OF BOND . . . . 118

Changes in Attachment ......... 119

Changes in Commitment . . . . . . . 123

Changes in Involvement . . . . . . . . 127

Summary ............... 131

Changes in the Level of Bond and Delinquent Behavior ............ . . 132

Changes in the Level of Attachment and the Relation to Delinquency ........ 133

Changes in the Level of Commitment and the Relation to Delinquency ........ 138

Changes in the Lever of Involvement and the Relation to Delinquency ........ 144

Bel ief and the Effects of Social Class and Educational Practices ......... 149 Conclusion ................. 153 
VI CONCLUSIONS ....................... 156

Replication of Causes of Del inquency . . . . 156

Level of Bond and Delinquency and Social Class 157

Changes in the Level of Bond . . . . . . 158

Explaining the Changes in the Level of Bond . 161

Changes in the Level of Bond and Delinquency. 163

Summary .................. 164

APPENDIX ............................... 166

REFERENCES ........................ 170 


\section{LIST OF TABLES}

TABLE

PAGE

I Evaluation of Alternative Causal Models . . . . .

II Average Number of Self-Reported and Official

Delinquency Acts by Father's 0ccupation

White Boys Only . . . . . . . . . . . .

II Delinquency Involvement by Lever of Attachment,

Marion County Youth Study .......... 86

IV Self-Reported Delinquent Acts by Mother's Level of

Supervision, Causes of Delinquency (in Percent) • 86

$\checkmark$ Official Delinquency Involvement by Level of

Commitment, Causes of Delinquency (in Percent) . 88

VI Delinquency Involvement by Level of Commitment,

Marion County Youth Study . . . . . . . . 90

VII Participation in Delinquency by Level of Involvement, Marion County Youth Study . . . . . . . . .

VIII Level of Self-Reported Delinquency and Level of

Invol vement, Causes of Delinquency . . . . . .

IX Level of Delinquency Involvement by Level of Belief, Marion County Youth Study . . . . . . . . .

$X \quad$ Level of Delinquency Involvement by Level of Belief, Causes of Delinquency (in Percent) . . . . . . . 
XI Level of Self-Reported Delinquent Acts by Occupation of Father (in Percent), Causes of Delinquency . . . 97

XII Delinquency Involvement by Father's Socioeconomic Status, Marion County Youth Study . . . . . .

XII Father's Socioeconomic Status and Level of Attachment, Marion County Youth Study . . . . . . . . . 99

- XIV Father's Socioeconomic Status and Level of Belief, Marion County Youth Study . . . . . . . . .

XV Father's Socioeconomic Status and Level of Commitment, Marion County Youth Study ........... 101

XVI Father's Socioeconomic Status and Level of Involvement, Marion County Youth Study ........... 101

XVII Changes in Level of Attachment From 1964 to 1967 . . 107 XVIII Delinquency Involvement by Initial (1964) and Subsequent (1967) Level of Attachment ......... 109

XIX Changes in Level of Commitment from 1964 to 1967 . . 110 XX Delinquency Involvement by Initial (1964) and Subsequent (1967) Level of Commitment. . . . . 112 XXI Changes in Level of Involvement From 1964 to 1967 . 114 XXII Delinquency Involvement by Initial (1964 and Subsequent (1967) Level Involvement . . . . . 115 XXIII Initial (1964) and Subsequent (1967) Level of Attachment and Social Class............. 120 
TABLE

XXIV Initial (1964) and Subsequent (1967) Level of Attachment

and Grade Point Average . . . . . . . . . . 122

XXV Initial (1964) and Subsequent (1967) Levels of

Commitment and Socioeconomic Status . . . . . 124

XXVI Initial (1964) and Subsequent (1967) Level of

Commitment by Grade Point Average . . . . . . . 126

XXVII Initial (1964) and Subsequent (1967) Level of

Involvement and Socioeconomic Status . . . . . 128

XXVIII Initial (1964) and Subsequent (1967) Levels of

Involvement and Grade Point Average . . . . . . 130

XXIX Delinquency Involvement by Changes in the Level of

Attachment by Grade Point Average . . . . . . . 135

$X X X$ Delinquency Involvement by Changes in the Lever of

Attachment by Socioeconomic Status . . . . . . 137

XXXI Delinquency Involvement by Changes in the Level of

Commitment by Grade Point Average . . . . . . . 140

XXXII Delinquency Involvement by Changes in the Level of

Commitment by Socioeconomic Status . . . . . . 143

XXXIII Delinquency Involvement by Changes in the Level of

Involvement by Grade Point Average . . . . . . . 145

XXXIV Delinquency Involvement by Changes in the Level of

Involvement by Socioeconomic Status . . . . . . 148

XXXV Percent Officially Delinquent and Level of Belief

(1967) and Socioeconomic Status . . . . . . 150 
TABLE

PAGE

XXXVI Percent Officially Delinquent and Level of Belief

(1967) and Grade Point Average . . . . . . . 152

XXXVII Correlations Between Delinquency and the Elements of the Bond................. 157

XXXVIII Correlation Between Social Class and Delinquency and Elements of the Bond ........... 158

XXXIX Correlation Between Elements of the Bond in 1964

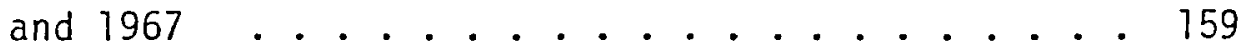

XL Correlation Between the Level of Bond in 1964 and 1967 Controlling for Social Class and Grade Point Average 160

XLI Percent of Youths who Changed Their Level of Bond by Social Class and Grade Point Average Controlling For the Initial Level of Bond in 1964 . . . . 162

XLI I Del inquency Involvement by Level of Attachment From the Marion County Youth Study . . . . . . . 168

XLIII Delinquency Involvement by Level of Commitment From the Marion County Youth Study . . . . . . . 168

XLIV Delinquency Involvement by Level of Involvement From the Marion County Youth Study ........ 169 
LIST OF FIGURES

FIGURE

PAGE

1. Means of Societary Control, as Listed in Ten Current

Treatments of the Topic......... 9

2. A Typology of Modes of Individual Adaption. . . . . 14

3. The causal Structure of Differential Association Theory 38

4. The Causal Structure of the Glueck's Formulation of

Social Control Theory .......... 39

5. The Causal Structure of Hirschi's Formulation of

Social Control Theory .......... 39

6. A Revised Formulation of Hirschi's Social Control Theory 40

7. Social Control Theory as Formulated by Hirschi in

Causes of Detinquency ......... 52

8. Level of Bond Determining Delinquency . . . . . . 55

9. Delinquency Determining the Lever of Bond . . . . . . 55

10. Changes in Bond Causing Subsequent Delinquency . . . 57

11. Second Level of Bond Occurring as a Consequence of

Delinquency ................ 57

12. Revised Model of Social Control Theory . . . . . 61

13. Level of Parental Attachment and Its Relation to

Delinquency and Delinquent Values ...... 71 
CHAPTER I

\section{INTRODUCTION}

A host of causal perspectives has been employed by sociologists in their search for the mainsprings of delinquent behavior. The social control approach, represented by the theorizing and research of Walter C. Reckless, Travis Hirschi, and others, is one relatively recent entrant into the theoretical field. Current social control notions in delinquency analys is are linked, at least tenuously, to broader social control perspectives that have been central to sociological analysis from the beginnings of the discipline. These broad social control interests have evolved from an original concern with "social order," that is, with how societies order social relations to a more narrow interest in how individuals are socialized into the ongoing social structure.

The discussion that follows provides an overview of the development of the concept of social control and indicates some of the major problems which inquiry in that substantive area has faced. As will be seen, social control theory has gradually drifted from the "social order" question to emphasis upon socialization processes. Most recently, social control arguments have become centered upon delinquent behavior, with relatively little attention being devoted to conformist conduct or to patterns of deviance other than juvenile 
lawbreaking. Social control views applied to delinquency have focused on the primary group aspects of socialization and the relation of that socialization to delinquency and have been relatively inattentive to the importance of larger social institutions and secondary group factors that also influence behavior.

At the same time, there is mounting evidence that various institutional experiences, such as tracking, grading and ability grouping in modern school systems operate as contingencies experienced by adolescents which affect their ability to pursue legitimate careers and which may also force some youths into patterns of delinquent behavior (Schafer and Polk, 1967 and Polk and Richmond, 1972). Similarly, youngsters who come from differing positions in the social class structure also may vary in their likelihood of obtaining access to high status positions or conversely of participating in juvenile delinquency. Yet, the impacts of educational policies and the effects of social class background have not been incorporated into social control arguments.

One of the more promising varianis of sociai control theory has been deveToped by Travis Hirschi. In Causes of Delinquency (1969) he claimed that many youths form a bond to society in early childhood which prevents them from becoming involved in del inquent behavior, while others who fail to form such a bond do become delinquent. Hirschi's theory was strongly supported by the research he conducted which showed that delinquency involvement was inversely related to the strength of an individual's relationship to society.'

${ }^{1}$ Hirschi's work studied a sample of mâle youths in Richmond County, California and is not generalizable to females. 
This dissertation extends the explanatory model developed by Hirschi. First, it argues that the socialization levels reached by youngsters in primary group socialization are sometimes altered by subsequent experiences. Secondly it contends that those changes are related to school experiences and social class backgrounds of youths. Finally, it avers that those changes increase or decrease the likelihood that adolescents will become involved in delinquent behavior. The research reported here extended the model developed by Hirschi and included an examination of the effects of nonprimary group factors on socialization, and was intended to strengthen social control theory in terms of its ability to explain delinquent behavior.

\section{OVERVIEW OF THE RESEARCH}

The model of social control theory developed by Hirschi has provided important insights into the causes of delinquent behavior. However. it has been argued that nonprimary group factors which include educational grading policies and social class ${ }^{\top}$ background shou?d be consiciered in terms of how they affect the individual's relationship to society. These two variables should be particularly important in high school because it is there that youths leave the family and enter a milieu whose purpose is to prepare them for higher education and entry into adult social roles.

I In this study a number of terms will be used to represent the concept of different positions in the class structure. Blue collar, working class and lower SES will refer to the lower positions in the class structure while white collar, middle class will be used to refer to the higher positions in the class structure. 
In the research reported here, data were obtained from a study of a panel of high school students which was surveyed first as sophomores and later as seniors. It was therefore possible to determine if the Tevels of social bond exhibited by them remained constant, as Hirschi's theory would suggest, or if it changed over the three year period. For those whose level of band changed, it was possible to see how much of the change was accounted for by the structural variables which were introduced into the analysis. Finally, it was possible to determine if these changes resulted in different delinquency rates for those groups whose level of bond changed or remained constant, for those who either did poorly or well in school, and for those who came from a blue as opposed to white collar background. To the extent that the level of bond did change and was affected by social class background and grade point average, then, it will be necessary to augument Hirschi's formulation of social control theory with a more dynamic model which can account for the changes in the level of bond.

Before explicating the hypotheses and research methodology of this study, a detailed examination of social control theory is in order. Chapter II takes up the historical development of the concept, along with current versions of social control theory applied to juvenile delinquency. 
CHAPTER II

THE DEVELOPMENT OF SOCIAL CONTROL THEORY

EARLY HJSTORY

One of the central organizing questions in the study of society has been how social organizations achieve regularity in social relations. An impetus for the development of sociology as an academic discipline has been the recognition that there are features of social life which operate at a higher Ievel from those factors which regulate individual behavior. Janowitz has noted that utilitarianism as a model for individual behavior cannot account for social behavior.

Social control has been an expression of the outlook that held that the individualistic pursuit of economic self interest can account for neither collective social behavior nor the existence of a social order, and does not supply an adequate basis for the achievement of ethical goals (Janowitz, 1975:83).

The questions involving social behavior which sociologists initially sought to answer were directed toward the nature of social organizations as collectives of individuals. It was therefore necessary to address two corollary questions. The first dealt with the structure of social organizations, and the second studied how regularity or order in the social relations of that organization are maintained.

An examination of the history of academic sociology in the United States revealed that much theoretical attention was directed toward the interrelated questions of social structure and social order. 
The portion of the field dealing with order and the means by which it is maintained was usually called "social control." The study of social structure has been approached through a variety of evolutionary, structural, conflict, and Marxist perspectives, while the study of social order too, has changed with respect to both the content of the field and the manner in which the area has been studied.

Although social-structural questions have remained in the forefront of American academic sociology, the study of the means by which social order is maintained has had a less consistent history. This unevenness was due to changes in perceptions of the importance of social control and the methodological problems which the field of social control has encountered.

One of the pioneering uses of the term "social control" reflected the early connections of sociology to social philosophy. George Vincent, writing in the first volume of the American Journal of Sociology, defined social control as ". . . the art of combining social forces so as to give society at least a trend toward an ideal" (1896: 490). The "social forces" and "ideal" reflected the evolutionary social philosophical foundations which sociology later abandoned in its move toward scientific status. The first shift in emphasis within the field of social control was the result of the difficulties inherent in operationalizing and studying vague, imprecise factors such as "social forces" and "social ideals."

By the early part of the twentieth century, theoretical and empirical inquiry on social control had taken two separate directions, 
represented by the thinking of E. A. Ross and C. H. Cooley. In his seminal work, Social Control (1901), Ross stated ". . . it is the purpose of this inquiry to ascertain how men of the West-European breed are brought together, and to associate their efferts with that degree of harmony we see about us" (Ross, 1901:3). In discussing the basis for collective enterprises, Ross focused on what he thought were the genetically inherited characteristics of West-European citizens which impelled members of the race into collective behavior as well as the means by which social control was carried out in social organizations. His enumeration of sympathy, sociability, and the sense of justice as characteristics of Western man was accompanied by an extensive cataloging and description of the means of social control. Attention to the characteristics of Western man was later dropped by Ross and others due to the problems which all evolutionary theories of society confront when describing Western civilization as the height of intellectual, social and cultural development.

In his discussion of the means of control, Ross initially stressed the importance of consensus in social structure and social hierarchies in achieving and legitimizing social control. In so doing this he provided a basic direction for a generation of scholars who did not succeed in going much beyond his basic formulations. Those who followed Ross continued to overemphasize the importance of consensus in social relations in maintaining the stability of societies (Landis, 1956; Parsons, 1951; and LaPiere, 1954). Yet towards the end of his career, Ross repudiated his earlier position on the importance of consensus in society. He observed that a hierarchy implies that those 
who are in superardinate positions may use their power to achieve their goals. The use of power is legitimized by those in subordinate positions who arcept their place in society. His discussion of class was somewhat archaic, yet it captured the essence of conflict theories of a later age which held that descriptions of societal structure, social roles and statuses alone were not adequate to represent the complexity of social relations.

Ross's book was described by Eubanks in The Concepts of Sociology as ". . . the leading reference on the subject of social control" $(1932: 220)$. He stated that those who wrote subsequent to Ross were indebted to his methodology, described as ". . . principally that of delineating, largely by picturization the diverse types of situations in which constraint is effected" (Eubanks, 1932:220). Eubanks also went on to note the 1 imitations of Ross's approach.

Description is, of course, essential to analysis; but of recent years the pictorial element has tended to become subordinated to the more critical dissection of concrete materials themselves, and their resolution into component elements (Eubanks, 1932:220).

Eubanks also developed an important discussion of representative works in the field of social control. His book was a major synthesis and review of central sociological concepts that had appeared up to that time. He noted the preoccupation of theorists with the "means of social control," as the following list from his book illustrates (see Figure 1). The number accompanying each means of control indicates the number of authors from the ten whose books were used who cited that particular means. The plethora of means of social 

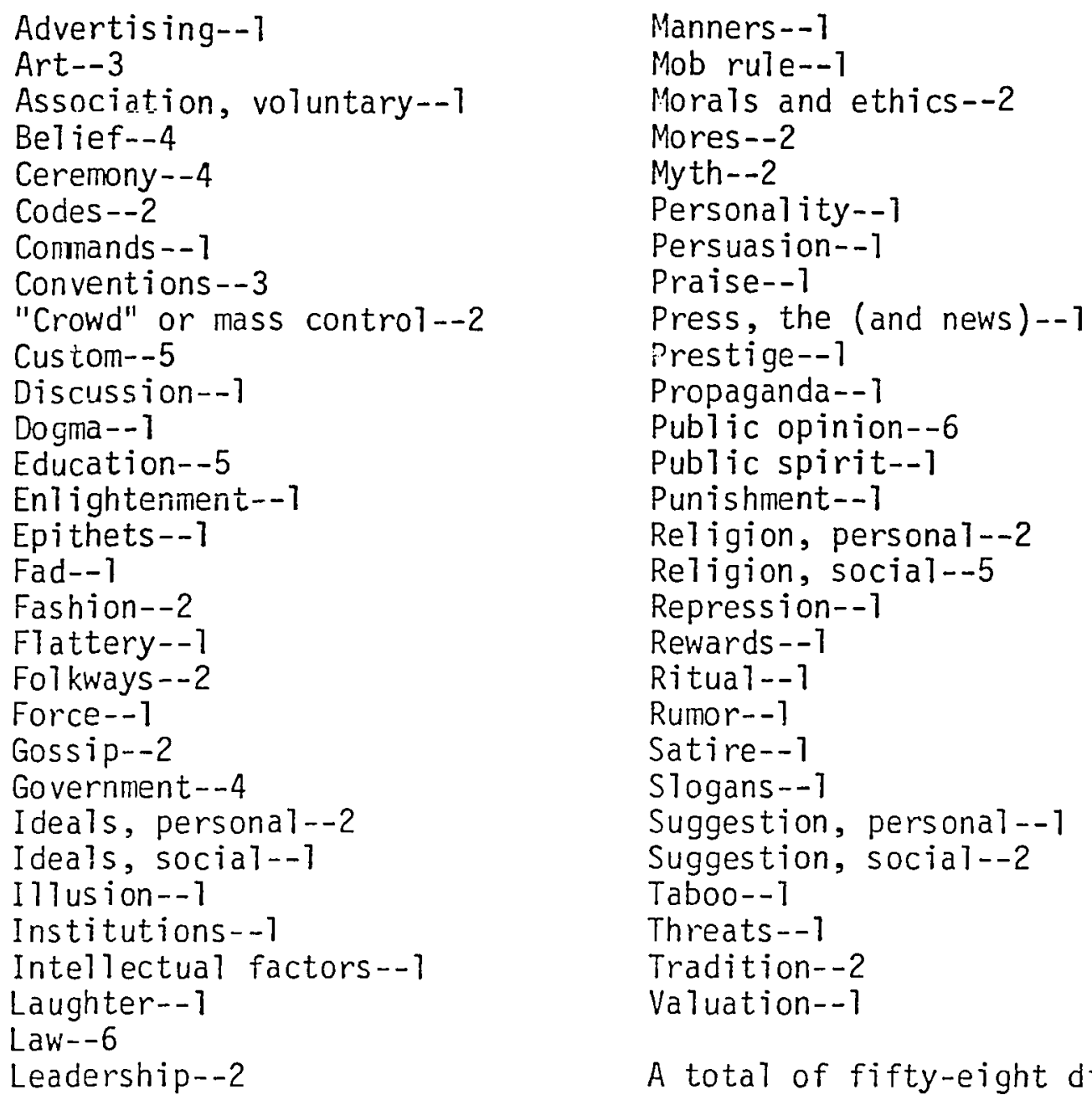

A total of fifty-eight different "means"

Al1port, Social Psychology, Chap. 15.

Bernard in Davis, Barnes, et al., Introduction to Sociology, pp. 467-483.

Blackmar and Gillin, Outlines of Sociology, Parts III and IV. Bogardus, Social Psychology, Chaps. 29, 30, and 31 .

Eldridge, in Davis, Barnes, et al., Introduction to Sociology, pp. 609-639.

Ellwood, The Psychology of Human Society, Chap. 13.

Hayes, Introduction to the Study of Sociology, Part IV.

Lumley, Means of Social Control.

Park and Burgess, Introduction to the Science of Sociology, Chap. 12.

Ross, Social Control.

(Eubanks, 1932:221)

Figure 1. Means of societary control, as listed in ten current treatments of the topic. 
control for which only one or two citations are given indicates that writings in this era consisted primarily of developing new lists of the means of social control. To what extent does the writing of Ross and of his successors qualify as social theory? An answer was offered by Eubanks when he characterized Ross's methodology as primarily being that of description, with the implication that description is not theory.

By the mid 1930s, sociological theorizing had moved well into the tradition of grand theory and the explanation of macrosocial phenomena. The potential in the lines of thinking developed by Ross had been exhausted, and some of his ideas were carried to misleading conclusions. Writings on the subject of social control overemphasized the importance of consensus in social hierarchies as the basis for legitimizing diverse methods of social control and excluded discussion of the coercive aspects of control. Ross himself had stated in his memoirs that consensus had been overemphasized as the means by which the stability of a society was maintained, arguing that the law's sometimes represent something other than the public will. In reflecting upon his book, Social Control, Ross stated:

Not only do most laws at their passage reflect the outcome of struggle behind the scenes among pressure groups, but the same holds true in trends of public opinion and the deliverances of organized religion. Sooner or later the alert, well led elements organize in order to mold social requirements to their wishes. The content of the code of social requirements, as well as the strictness with which obedience is extracted reveals an incessant tug-of-war among spokesmen of contending groups (Ross, 1936:47). 
It is apparent that Ross, too, recognized the limitations of the structural approach which he had emphasized in the study of social control. Importantly, he argued in his memoirs that there was a qualitative difference between laws and other means of social control. He questioned the mainstream position that laws mirrored the values of the social structure behind which stood the force of the state should those values be violated. He asserted that the potential existed for laws to be written which did not always represent social consensus, but instead were an outcome of the struggle of competing interest groups. In so doing, Ross anticipated by some thirty years a central concern of sociologists writing from the conflict perspective.

Charles H. Cooley's Human Nature and the Social Order (1902) was published a year after Ross's Social Control (1901). Cooley was interested in the process of socialization through which the individual acquires his personality structure. The study of primary group associations was deemed to be important because while the individual is a part of a larger social structure, his life is most directly affected by the small group associations with which he is surrounded. The importance of primary group associations in socialization was largely ignored after Cooley for almost half a century. LaPiere observed though, that by the mid-1950s the insights developed by Cooley were again a major contribution to the study of social 1 ife and "constituted somewhat of a major revolution in the study of social control" $(1954: 10-24)$.

In a 1925 essay in the International Journal of Ethics, George Herbert Mead stated that "social control depends, then, upon the degree to which individuals are able to assume the attitudes 
of others who are involved with them in common endeavors" (1925). On this point, in a short review of macrosociology and social control, Janowitz reported that through the 1940 s attention to the concept of social control was shifting from the structural perspective with its focus on the means of control to a more restricted meaning in which social control was described as the "process of socialization leading to conformity" (1975:95). The dead end to which the study of the means of social control had led accounts, at least in part, for the emergent research emphasis upon the interaction of the individual with his or her social environment. Janowitz believed that fruitiess preoccupation with the study of the means of social control served to notify researchers that more specific and delimited topics of research which were amenable to empirical study and hypothesis testing should be developed. Social control theory was therefore more narrowly defined and reformulated as the process of socialization leading to conformity of behavior.

In the sections to follow, it will be seen that the study of social control shifted in emphasis a number of times over past decades. The early writers were largely concerned with the structural and socialpsychological aspects of control and paid little attention to the specific study of deviant and delinquent behavior which society sought to control. But a later generation of theorists was interested in studying deviance and delinquency, and at first were inattentive to control issues. Merton's anomie formulation concerning deviance is a case-in-point. Merton was largely responsible for the initial development of a model for structurally analyzing deviant behavior. Later, 
labeling theorists endeavored to examine the forms of social control, particularly as they contribute to the deveiopment of deviant and delinquent personality structures. For example, Lemert's formulation of labeling theory challenged many of the tenets of Merton's argument. Finally, social control perspectives have emerged most recently that have narrowed the concern from deviance even more sharply to delinquency. The works of Travis Hirschi and Walter Reckless are prominent examples of this kind.

\section{MERTON AND SOCIAL STRUCTURE}

Through the middle of the twentieth century, structural analysis continued to be important in sociological theory although it was not concerned directly with control issues. The work of Robert Merton (1957) on anomie has proved to be a benchmark from which a number of versions of social control theory emerged. Merton described a relatively simple model of society comprised of culturally defined goais and social structure. The first is founded on the ostensibly egalitarian nature of the cultural goals of American society which revolve around economic success and upward mobility and are equally disseminated throughout the social class structure. However, with the social structure, the means of achieving those goals are not equally distributed. Those who subscribe to those culturally defined goals but who are unable to reach them by vir 'e of their class position in society are then forced to engage in adaptive patterns of behavior. Merton presented a typology of modes of individual behavior 
which, with the exception of conformity, represented major patterns of deviant behavior (Figure 2).

\section{Cultural Goals Institutionalized Means}

$\begin{array}{rlcc}\text { I } & \text { Conformity } & + & + \\ \text { II } & \text { Innovation } & + & - \\ \text { III } & \text { Ritualism } & - & + \\ \text { IV } & \text { Retreatism } & - & - \\ V & \text { Rebellion } & \pm & \pm\end{array}$

$+=$ Acceptance $;-=$ rejection; $\pm=$ rejection of prevailing values and substitution of new values

Figure 2. A typology of modes of individual adaptation.

Innovation involved using deviant or illegal means such as burglary to obtain money. Ritualism described those who appear to strive for goals which are not within their power to achieve. Retreatists are those who reject the goals and the means of achieving them, substituting in their place drug use, alcoholism and so forth. Rebellion was illustrated by those who reject the goals and means and who substitute and strive for alternative illegitimate social goals.

It should be noted that Merton's theory was directed towards explaining broad patterns of deviant behavior and that those who followed him (Cohen, 1955, and Cloward and Ohlin, 1960) adapted the theory to explain delinquent behavior. Additionaliy, Merton was not directly concerned with social control processes. Instead, his inquiry was directed at examining the societal forces which break down patterns of normative behavior and cause deviance. Merton's theory was painted with broad strokes, and those who took exception to his major tenets went on to develop labeling theory. 
LABEL ING THEORY

Labeling theory represents a theoretical perspective which arose in reaction to the work of Merton and other functional theorists. The two perspectives can be contrasted along a number of dimensions. First, the model of society shared by labeling theorists contains a social value system which is considerably more complex and diverse than that described by Merton. Also, labeling theorists viewed the origins of the deviant act or behavior as being more complex than simply the disjuncture between social goals and the means of achieving those goals. Finally, whereas Merton was relatively silent about social control processes, labeling theorists argue that social reaction is of crucial importance in creating deviant identities.

Lemert has articulated a relatively detailed version of labeling theory which focuses on a broad range of deviant behavior. His analys is was developed in reaction to some of the claims which underlie the social structural approach to social structural approach to social control theory. The conception of society depicted by the structuralfunctionalists was markedly different than that outlined by Lemert. From the structural perspective, societies are bound together by a set of common social values which are universally accepted by the members of that society. Conformity is encouraged by a wide variety of institutions which have the purpose of discouraging unwanted types of benavior thought to be harmful to the health of that society. Integration or socialization of individuals into society is a major source of social control. Societal values are viewed as universally 
accepted and important in legitimizing official and unofficial societal reaction against undesired types of behavior.

Lemert reacted to the overly-simplified representation of the social system depicted by the structural functionalists. Lemert and Merton represents these two dimensions. Lemert argued that the social value system is considerably more diverse than depicted by Merton. Lemert also held that an individual becomes a member, not of a large societal structure, but instead is affiliated with a small number of groups such as delinquent gangs, peers, social groups and clubs, friends, work mates, deviant subcultures and so forth which represent a wide range of interests. In describing this situation Lemert noted:

Instead of seeing the individual as a relatively free agent making adaptations toward a consistent value order, it is far more relaistic to visualize him as "captured," to a greater or lesser degree, by the claims of various groups which he has given his allegiance. It is in fact that these claims are continually being pre-emptively asserted through group action at the expense of other claims, frequently in direct conflict, that we find the main source of pressures on individuals in modern society, rather than in "cultural emphasis on goals" (Lemert, 1967: 20).

\section{PRIMARY AND SECONDARY DEVIATION}

Lemert argued that delinquent or deviant activities arise from polygenetic circumstances. Moreover, he contended that individuals initially do not see themselves as delinquent or deviant persons.

Primary deviation is assumed to arise in a wide variety of social, cultural, and psychological contexts, and at best has only marginal implications for the psychic structure of the individual (Lemert, 1967:17). 
Lemert stated that primary deviation ".. does not lead to symbolic recognition at the level of self regarding attitudes and social values" (Lemert, 1967:17). However, once an individual integrates the effects of repeated contacts with official agencies of social control into his personality structure and proceeds to exhibit behavior which is consistent with the newly acquired criminal identity, secondary deviation develops:

Secondary deviation is deviant behavior, or social roles based upon it which becomes a means of defense, attack, or adaptation to the overt and covert problems created by the societal reaction to primary deviation (Lemert, 1967:17).

Lemert's conception of primary and secondary deviation emphasized that primary deviation arises from diverse sources, many of which are of little interest to the theorist. Lemert stressed the study of stabilized or secondary deviance, and in particular emphasized the role of social control influences in the development of deviant personality structures. He rejected the use of symbolic interactionism as a model Which overly psychologizes the actions of social control agencies (1974:462). Instead he offered an empirical solution to the unproductive inquiry which had come to characterize social control. He stated that social control could be defined in terms of behavioral social reaction to deviant behavior and that isolation, segregation, penalties, and supervision could be studied as manifestations of social control. The manner in which social reaction is imposed could then be examined far more systematically and objectively than had been previously possible. 
Law and Social Reaction

The processes by which laws arise which serve as the basis for social reaction have been discussed in both social-structural and labeling theories. In the first, laws are viewed as representing the values of a social system codified into legislation which has the force of the state behind it. Labeling perspectives, on the other hand, hold that laws arise from a process in which the values of a group or coalition of groups come to prevail over the values of other groups. As a result, the values which come to be written into law do not represent value consensus within a social system. Hopkins found a degree of validity in both propositions (Hopkins, 1975). In evaluating the explanatory power of the two positions, he felt that certain laws, such as those protecting life and property, probably have a high degree of social support behind them, while other laws may be the work of interest groups which have worked to insure their passage. Some scholars, have identified "moral crusades" in which groups and coalitions of groups representing diverse interests come together for the passage of a particular legislative agenda (Gusfield, 1963). Therefore it appears that both positions are partially accurate.

Labeling theorists deny that behavior is intrinsically deviant. Labeling theory, instead, is concerned with the process by which individuals are designated "deviant" by the social reaction process and have integrated that label into their personality structure. Theorists of this persuasion have reordered the traditional hypothes is: that deviant behavior elicits social reaction and have replaced it with 
the counter proposition that social reaction is instrumental in producing deviant identities (Lemert, 1967:18). Social reaction thus is seen as a cause instead of an effect of deviance. Yet as with most everything else in labeling theory, this proposition remains virtually untested. The processual development of secondary deviance in reaction to social control efforts has been difficult to document. Finally, labeling theorists have been unable to account for differing outcomes, such that certain people who are processed by control agencies manage to refuse to integrate the deviant label into their personality structure while others in the same situation come to view themselves as deviant (Bordua, 1969:53).

Labeling Theory and Organizational Analysis

One byproduct of the labeling perspective has been that in studying social reactions, authors have sought to examine in depth the organizations which deal with deviant behavior. Organizations such as the police, courts and correctional institutions are depicted as operating in an environment which is considerably more complex than traditional organizational analysis would lead one to believe. Bittner's study of the police in their "peace keeping" function on Skid Row (1967), Sudnow's description of the operation of a public defender's office (1965), Wald's discussion of the conflict between custody and treatment in juvenile correctional institutions (1960) and Cicourel's examination of the legal processing of juveniles in court (1968) are important examples of this tradition. They go beyond the official statistics and in-house propaganda of organizations and reveal very complex situations to which criminal justice agencies respond. 
Schur (1971) has noted at least three important aspects of this research. First, organizations operate according to informal norms which develop in response to the demands placed upon them. For example, according to Bittner (1967), a law enforcement officer may have the authority to arrest those who are publically intoxicated, but in so doing he may place a demand upon scarce jail facilities as well as disrupt the life of the drunk. Therefore, when a decision has to be made, the conflicting requirements that he enforce the law yet keep drunks out of jail have to be resolved. Second, organizations' employees may have to respond to pressures not normally considered by those drawing up organizational charts. Pressure groups, public opinion, the media, legislatures, and citizen groups comprise the environment in which an organization operates and must be considered when decisions are made. Finally, Schur noted that organizations may operate with a multiplicity of ambiguous or conflicting goals. The conflict between treatment and custody in correctional institutions is in often-cited yet very important example of a problem organization nembers may have to resolve.

Yet, despite the promise which the labeling perspective would seem to have in terms of studying institutionalized forms of social control and the effect of those control actions on personalities of individuals, several authors have indicated that it has not lived up to its promise (Davis, 1975:186; Gibbons and Jones, 1975:130-141). In Davis's sumary of the contributions of labeling theorists, she stated that the perspective concentrates on ex post facto analys is as 
indicated by the concern with categories of individuals who already have been defined as deviant (Davis, 1975:185-186). Little empirical work has been done on the process by which individuals acquire the deviant labels given by social control organizations. Also, little attention has been given by labeling theorists to explaining the factors relating to individuals rejecting the deviant label and not integrating the effect of the social reaction processes into their personality structures. Davis found the methodology of the perspective to be unsystematic, describing it as "ethnographic and overly restrictive sociology" with the result being the "inadequate development of concept or hypothesis testing, due to the penchant for insightful, impressionistic observation" (Davis, 1975:186).

The major proposition of this perspective asserts that societal reaction in the form of labeling, which stigmatizes deviants leads to an altered identity and necessitates a reconstruction of the self. This premise has not been adequately demonstrated empirically, as the research focus is on those social persons and categories already known to have been labeled. Little testing of alternatives to this conception of labeling as causing a reconstruction of self has been done, nor is there a systematic search for negative cases in rilost studies (Davis, 1975:186).

Labeling theory has been influential in directing attention to the role which social control agencies play in processing deviants. Yet it is important not to overstate that evidence because the studies concentrated only on those who received deviant label. The perspective has severe conceptual and methodological problems which appear to be insurnountable. Until the research uses fiore valid designs in studying individuals in interaction with social control agencies, the promise of labeling theory as an approach to social control theory will remain unfulfilled. 


\section{CONTAINMENT THEORY AND SOCIAL CONTROL}

The special relevance of a social control perspective has been noted in different theories which reflect the sociai-psychological and social-structural approaches to crime and delinquency. Theorists of the Chicago school of sociology developed a unique posture toward the study of the way order is maintained in social organizations. The foundations of "containment theory" can be found in this work. These persons noted that rural societies shared certain characteristics of stability along with a high degree of coordination and integration of the activities of society's members. Social control in rural societies took place largely through informal methods rather than through the use of formal legal codes. In contrast to the idyllic life in the countryside, existence in the city was considerably nore complex. A variety of forces ranging from the complexity of human interaction to the rich, division of labor along with rapid social change and high mobility prevented the kinds of relations which bound members of a rural society together from developing in the city. Robert Park, who was a founder of the Chicago school of sociology, noted that the forces which regulated 1 ife in the countryside did not exist in the city and thus, he argued, "social control was the central fact and central prob7em of society" (Turner, 1967:IX).

Part of the methodology developed by the Chicago school was to study the social ecology of a city and note those areas which had the highest crime rates and in which many broken homes along with other measures of social pathology were located. Where those phenomena 
coincided, conclusions were drawn about the disorganized nature of social life in those areas. This evidence was then used to argue that those communities no longer exerted effective social control over the ir members.

Despite what would seem like overpowering social and cultural inducements toward delinquent and criminal activities in certain parts of the city, Reiss (1951) noted that not all persons who were in these "socially disorganized" areas got into trouble with the law. Noncriminals and nondelinquents in high crime areas were not accounted for in existing ecological theories. If social-structural factors are strong enough to drive many individuals toward a life of crime, then personality factors must be operating to insulate other, noncriminal persons from these criminogenic environmental influences. Reiss termed these factors "personal controls" and defined them as the ability of the individual to resist values in his immediate environment which are at variance with the norms and laws of the larger dominant society (1951:196). Delinquency was identified as the "behavior consequent to the failure of personal and social controls to produce behavior in conformity with the norms of the social system to which legal penalties are attached" (Reiss, 1951:196). Reiss defined social control as the ability of social groups to make rules and norms effective. He also viewed personal control as the ability of persons to refrain from responding to norms which conflict with the rules and norms of society. Reiss concluded that delinquency can result from any of three sources: the absence of internalized norms of behavior; a breakdown in established control; or the absence or conflict in social rules or techniques for enforcing standards of behavior. 
Reiss's work was not entirely adequate because he did not infer the existence of personal controls independently of the delinquent behavior which he sought to explain. But, this research was important in that several authors who followed him operationalized and studied the relationship of certain aspects of personal controls to law breaking behavior.

The most important subsequent advance in the area of personal controls was made by Reckless and his associates who investigated the manner in which personality and environmental factors interact to produce delinquency. Their concern is sumiarized below:

Although the existence of the non-delinquent in a high delinquency area has been tacitly recognized by sociologists, social workers and others, the greatest emphas is has traditionally been placed on the study, treatment and prevention of the small quota of boys in a high delinquency area who experience contact with the police and juvenile court (Reckless, Dinitz and Murray, 1957:18).

The task which Reckless and his associates confronted was that of explaining why certain youths refrain from delinquent activities despite living in disordered areas. Their study ". . . focuses on those aspects of the socialization process which enable persons, even in areas of highest delinquency, to internalize non-deviant attitudes and behavioral patterns" (1957:18). The authors hypothesized that positive socialization experiences coming from well-integrated, warm, stable family relations operate to "insulate" some youths from involvement in criminality. Initially a group of 196 Caucasian boys were nominated by 30 sixth grade teachers in Columbus, Ohio, as being "good boys" with positive self-concepts and therefore insulated against delinquency. Further study revealed that 16 of the youths had del inquency records and were therefore eliminated from the study as 
not being insulated. Finally, 55 other youngsters were eliminated because a member of the family other than the youth had been in contact with either the criminal court or the civil court because of domestic relations problems, or because the researchers failed to contact the individual.

The 125 boys who remained to participate in the study were administered two instruments. One measured social responsibility, delinquency proneness, and, finaliy, occupational desires and aspirations, while the other sought to assess the youth's conception of self, along with family and interpersonal relations.' The scores for the sample ranged from a low of 4 to a high of 34 out of a possible 54 points on the delinquency proneness scale, a result which the authors believed justified the selection of the youths as "good" boys. The mean score on the social responsibility scale was 28.86 out of a possible 42 points with a range of 12 to 40 . The correlation between the two scales was -.61, indicating " a significant and negative relationship between delinquency vulnerability and social responsibility" (Reckless, Dinitz and Murray, 1957:22). It should be noted that the wide range of scores would seem to indicate that the group of boys chosen were not very homogeneous along the dimensions which were measured.

The delinquency proneness and social responsibility scales were taken from the Gough California Psychological Inventory which had ". . . been widely used with delinquent and non-delinquent populations and found to have predictive value with reference to delinquent behavior. . . The essential purpose of the delinquency proneness scale is to measure the effectiveness of the socialization process as regards delinquent conduct" (Reckless, Dinitz and Murray, 1957:19). However, it should be noted that the validity of the CPI has been questioned on the basis that it does not measure self-concept. For example, Tangri and Schwartz (1965) note that questioning the adolescents as to whether the police are corrupt indicates little about how they perceive themselves. 
The authors began with the speculation that the existence of a nondeviant, harmonious, stable family setting was important for most $0:$ the boys in the study and served to insulate them from delinquent norms and companions. The results indicated that many lower class families may be more cohesive than sociologists previously believed.

In another article using the same population and instruments, Reckless, Dinitz and Murray (1956) introduced "self-concept" as the variable which insulated youngsters against delinquency (1956). They did not indicate how the youth acquired his good "self-concept," although they hinted that it was the result of effective socialization or contact with a significant other, such as a settlement house worker, priest, or teacher. Finally, they felt that there is reason to believe that a "well developed conception of self" is the component which keeps middle and upper class boys who live in better neighborhoods out of delinquency.

Four years after the initial study conducted by Reckless and his associates, an attempt was made to locate the 125 boys to look at their delinquency involvement and to determine if any changes in attitudes or self-concept had taken place (Scarpitti, Murray, Dinitz and Reckless, 1960:555-558). A total of 103 boys, of whom 99 were still in school were located. Of the 103 boys, 4 had come to the attention of the police, each for only one offense. The 103 boys were again given the series of tests they had taken four years earlier. The mean scores were lower on the delinquency vulnerability scale in 1959 than in 1955, indicating that they were even less prone to delinquency at this later date. The families of the "insulated" boys 
remained cohesive and the orientation of the youths towards completing school remained unchanged. The authors felt that the continuation of the boys in conventional behavior was due to the internalization of a favorable self image. They argued that because of the stable family relations, positive high school aspirations, and "isolation from the purveyors of deviant values, it may be predicted that the good boys will persist in their law abiding behavior" (Scarpitti, Murray, Dinitz and Reckless, 1960:558).

The work of Reckless and his associates on the role of "selfconcept" in self control has not gone unchallenged. Schwartz and Tangri observed that the interpretations of the scores of the boys in the 1957 study by Reckless, Dinitz and Murray and the 1960 study by Scarpitti, Murray, Dinitz and Reckless were questionable. The lack of a control group of officially processed delinquents made it impossible to assess whether the two groups would actually differ with respect to the measures used in the study. It cannot be concluded that the nondelinquents had a more positive level of self-concept than delinquent boys in the absence of a delinquent comparison group (Schwartz and Tangri, 1965:923). Additionally, Schwartz and Tangri attacked the idea that the boys integrate their teacher's and parent's assessments of their worth into their self-concepts. Finally, they believed that the concept of self as used by Reckless was vague. They describe it as

The indiscriminate collation of items from the CPI (California Personality Inventory) and questions asked of mothers, sons and teachers, all treated as self-concept, (which) does not produce a meaningfur definition of the term (1965:923). 
In an extension of their earlier article, Tangri and Schwartz (1967) offered some further comments on the use of the self-concept variable by Reckless and his colleagues. The line of inquiry begun by Reckless was faulted for methodological as well as theoretical inadequacies. Tangri and Schwartz noted that in the 1959 follow-up study, the inability to locate the 31 youths who could not participate in the study may have biased the results. They stated that the question of why poor self-concept should leave a youth more vulnerable to delinquency was not addressed. Additionaliy, they argued that Reckless did not explain why the carriers of delinquent norms who are in the minority should have more impact on the youths than the carriers of prosocial norms who far outnumber the delinquents. Tangri and Schwartz observed that the definition of a high delinquency area as an area with a rate of at least 40 officially processed delinquents per thousand population means that as many as 96 percent of the residents in the area may not have come into contact with the juvenile justice system. Therefore, many persons riay not encounter delinquents against whom they need to be insulated.

The criticisms of the research of Reckless and his associates were further developed by James Orcutt (1970) who detailed some additional conceptual weaknesses in this work. He argued that Reckless was originally concerned with boys in high delinquency areas who were handicapped by disordered home backgrounds yet who managed to steer a course away from delinquent behavior. But, the emphas is on studying the youth who comes from a criminogenic milieu was not pursued. Orcutt observed that the boys who comprised the nondelinquent group 
came from good homes and tended not to have delinquent companions. As a result, it is difficult to call them vulnerable to delinquency in the sense originally advanced by Reckless. This research can thus be faulted for being unclear and inconsistent in terms of the conceptual framework which the studies followed. Orcutt also concurred with Schwartz and Tangri (1965:923) in noting that the concern with "good boys" and insulating factors was replaced by the "self-concept" variable. He commented that:

Reckless and his associates have avoided the messy problem of explaining away the troublesome findings of their exploratory study by subsuming the other so called causes of delinquency under the master concept of self (Orcutt, 1970:387).

Finally, Orcutt observed that the concept of "self" has been used extensively in social-psychological research, but that the items which were used by Reckless were substantially different from those used in most other research studies (1970:38).

Reckless and Dinitz (1972) attempted to employ their work in the area of self-concept as the basis for a delinquency prevention program. The inner city 7 th grade classes located in a high delinquency area of Columbus, Ohio, were divided into experimental, control and comparison groups. The experimental groups miet for three hours a day with the same teacher who acted as a positive role model. The hypothes is was that the inner city youth who was on the threshold of adolescence needed to internalize nodels of behavior and perceptions of self that develop into inner controls. The results of the study showed that the experinental group did not differ significantly from the control and comparison group on the basis of the outcome variables of drop out rates, attendance, grades, school achievement, and delinquency rates. 
Additional7y, the teachers were not accurate in their predictions of which students would become delinquent. In the previous studies conducted by Reckless, teachers nominated youths who were thought to be insulated against delinquency. The implication of this finding is that teachers do not have any special insight into who potential delinquents are or why they become that way.

The results of the Reckless and Dinitz study are fairly conclusive. Their intervention strategy had little effect on the outcome measures. It follows that the self-concept variable as they have formulated it seems unrelated to delinquency.

In a reanalysis of the data collected by Travis Hirschi, Gary Jensen (1973) claimed to have dealt with the major problems which were discovered in the series of studies conducted under Reckless's aegis. Delinquency was measured through the use of self-report data, and inner containment or self-concept was measured with respect to self control or the ability to stay out of trouble with the law. These factors were then combined with a measure of comitment to conventional moral beliefs. The findings regarding delinquency and containment variables were in the direction predicted by jensen, but the relationships were not very strong. When control variables were introduced which measured factors such as the amount of parental support, social class, and numbers of delinquent friends, relationships either did not emerge in the direction predicted or were inconclusive with respect to Reckless's theory. For example, the greater the amount of education of fathers, the lower the self-esteem and selfcontrol exhibited by black delinquents (garma $=-.56$ and -.54 ). 
Ostensibly the boy with an educated father should have a more positive role model than the youth with the less-educated father. In contrast, the education of the father apparently did not affect the self-control or self-esteem of white youngsters.

Confronted with inconclusive findings which did not support his thesis, Jensen opted for renewed emphasis on the importance of socialstructural variables. He concluded:

Thus, it may very well be the case that some elements of inner containment are less important for delinquency involvement the greater the adversities of family, class and neighborhood (Jensen, 1973:468).

He then went on to suggest that there may be environmental factors which are important in explaining delinquency and that the continued use of inner containment concepts is of marginal utility. He noted that "we can seriously question any conclusions that inner containment acts as a buffer among boys who have experienced the same environments" (Jensen, 1973:468). Then, in a rather quixotic phrase, Jensen stated:

A more appropriate conclusion would be that variable inner containment processes can be explained by variable external control processes, but that such internal control can come to operate independently or in combination with external controls (Jensen, 1973:469).

This assertion seems to indicate that Jensen found problematic the interaction between psychological and structural variables, and that empirical work should probably focus on studying external or social control.

Marshall (1973) attempted to cover the same ground as Jensen, except that $h$ is hypotheses concerning the relative inportance of internal and external containnent were explicitly stated. Thus he began at the place where Jensen (1973) ended. The research attempted 
to compare officially processed delinquents with nondelinquents in: relation to inner and outer containment variables. One object of the study was the development of a scale measuring delinquency proneness which would differentiate "major delinquents from their controls, and the minor delinquents from their controls, or the major delinquents from a]1 others" (Marsha11, 1973:228). The controls were youths who were matched with the delinquents but who had not been judged to be delinquent themselves.

The research specifically intended to assess the relative contributions of inner and outer containment to delinquency. Delinquents and nondelinquents with low delinquency proneness scores were first compared, using two modified versions of the instruments developed by Reckless. The differences between the two groups were primarily that the delinquents were lower on school achievenent, attendance, and class background and that they dated more. The groups were similar in terms of father's occupation, socio-economic status, and peer activities. As a result, the author felt delinquent or nondelinquent behavior was due more to external circumstances than personal characteristics (Marshal1, 1973:231).

Among youths with high delinquency proneness scores, the nondelinquents were similar to those with low delinquency scores in objective home and school situations. Additionally, líarshall noted that the delinquents and nondelinquents with high delinquency proneness scores were attitudinally similar and were equal with respect to peer orientation. He therefore observed that external constraints were operating to keep the nondelinquents from engaging in gang type 
activities. In assessing his evidence, Marshall observed that the males were similar with respect to inner controls, but varied widely in relation to external characteristics. Those with low external constraints had higher delinquency rates. Marshall felt that this result was due to the power of external pressures over which the youth had no control which caused an increase in delinquency (1973:233). He concluded that the problem of predicting delinquency has yet to be resolved using the approach developed by Reckless. The prediction scale was effective for only a small portion of the sample. In sunmary, he noted:

Social pressures toward antisocial behavior therefore seem to be dominant, and often act in the absence of personal inclinations toward such behavior (Marshall, 1973:235). The central thrust of this study is that influences appear in the social structure which compel persons toward delinquent behavior and which override or are more important than personality factors.

SOCIAL CONTROL THEORY AND CAUSES OF DELINQUENCY

Travis Hirschi took the tattered remnants of social control theory which survived after the wrok of Reckless and the labeling theorists and reformulated them into a theory which he tested using survey research techniques. He dispensed with the $i$ deas of inner and outer containment and the labeling process. Instead, he theorized that delinquency results when an individual fails to become bound to the social order, or when the bond which a person forms becomes attenuated, freeing the individual to engage in law breaking behavior. 
The four elements of the bond which Hirschi believed are related to socialization are attachment, commitment, involvement and belief. Hirschi stated that the attachment of an individual to others is the "essence of internalization of norms" (1969:18). He pointed out that the extent to which the internalization of norms occurs has usually been inferred indirectly from observations about the amount of delinquent behavior in which the individual engages. Whereas Reiss (1951) and Nye (1958:5-7) used essentially a tautological explanation by inferring the lack of internalized norms from the delinquent behavior which they sought to explain, Hirschi proposed that the relationship between delinquency and attachment should be measured directly by studying the extent to which attachments to significant others have been developed (Hirschi, 1969).

The next element of the bond which Hirschi discussed was commitment. Commitment was described as the investment which a person makes in conventional behavior which would be losi if he or she were to decide to break the law (Hirschi, 1969:20). Commitment is measured by positive attitudes towards work, education and adult life. Education is the means through which access is gained to positive adult roles. On the other hand, Hirschi described lack of comitment as an alternative situation in which youths refrain from working on their education through which they can achieve high status adult work roles. If adolescents are heavily involved with some of the superficial hedonistic aspects of adult life such as having a car, dating, smoking or drinking, they will be less comitted to education with its associated rewards. 
Involvement, the next element of the bond, was related to incapacitation of the individual by engaging him or her in prosocial behavior so that he or she is unavailable to participate in law breaking behavior (Hirschi, 1969:21). Hirschi quoted William James as saying:

Not that I would not, if I could, be both handsome and fat and well dressed and a great athlete, and make a million a year, be à wit, a bon vivant, and a lady killer, as well as a philosopher, a philanthropist, a statesman, warrior, and African explorer, as well as a "Tone poet" and a saint (Hirschi, 1969:22).

Hirschi then went on to note

The things that William James says that he would like to be or do are within the realm of conventionality, but if he were to include illicit action he would have to eliminate some of them as simply impossible (1969:22).

Involvement, then is the behavioral side of commitment.

The final element of the bond is belief. Hirschi's formulation of social control theory "assumes the existence of a conmon value system with the society or group whose norms are being violated" (1969:23). The position taken by him on the existence of a set of core social values stood in contrast to that of the proponents of cultural deviance theory who argue that there are many value systems in society. Hirschi, in effect, maintained that delinquents recognize that their deviant behavior is wrong. From a cultural deviance perspective, delinquents would not acknowledge that their behavior was wrong, for they would simply be acting consistently with their deviant value system. Delinquency would therefore simply be a label placed on the youth by an agency which is empowered to impose its rules. 
Hirschi endeavored to deal with the contentions of strain theorists who argued that status pressures are exerted on individuals, causing them to break the law. Strain theorists, as represented by Merton (1957), Cohen (1955) and Cloward and Oht in (1960), claim that individuals react to the disparity between a cultural system which stipulates societal values and a social system which sicructurally restricts access to the means to reach those universal values. The tension between those two conditions causes the individual to engage in a variety of adaptive behaviors which serve to reduce the tension. Both cultural goals and socially prescribed means can be adhered to, rejected, or replaced with new goals or means of reaching those goals by the individual.

Hirschi's argument was that it is unnecessary to search for special motivations or pressures which induce a person to engage in criminal behavior. He also disagreed with Sykes and Matza (1957) who advanced the thesis that delinquents use "techniques of neutralization" which free them from the restraining effects of social norms in order to be at liberty to engage in 1 aw breaking behavior. He argued:

We therefore follow the implicit logic of control theory and remove these moral ohstacles by hypothesis. Many persons do not have an attitude of respect towards the rules of society; many persons feel no moral obligation to conform regardless of personal advantage. Insofar as the values and beliefs of these persons are consistent with their feelings, and there should be a tendency towards consistency, neutralization is unnecessary; it has already occurred (1969:25).

Hirschi's point was that if allegiance to a belief system has not been developed, or if those ties are weakened for whatever reason, the individual is then free to behave without regard to that belief system. 
Those who embrace the social value system will participate in conforming behavior, while those who do not will be more likely to become delinquent. Thus, the extent to which people deviate is a function of the level of belief.

Hirschi's study contained substantial support for his thesis that attachment, commitment, involvement and belief do covary with the incidence of delinquent behavior. Also, he contrasted social control theory against strain and cultural deviance theories in his data analysis. Social control theory was consistently able to explain relations between variables which the other theories could not account for. Thus the support which accrued to social control theory was at the expense of the other two theories.

An important replication of Hirschi's study was conducted by Hindelang (1973), substantially supporting the results reported in Causes of Delinquency. Using a sample of male and female respondents from a rural area of New York, Hindelang found that the elements of the bond were inversely related to involvement in delinquent behavior. The one exception was that instead of a positive relationship between attachment to mother and attachment to peers, that relationship was reversed in Hindelang's study. However, Hindelang did not feel that this relationship was important in explaining delinquency, although Hirschi stated that strong parental attachments should work to keep youths from becoming involved with delinquent peers.

There has recently been a movement in the literature towards testing and interpreting alternative theoretical models of delinquency through a conrron data base (Liska, 1969). Through testing alternative 
models, it is possible for a researcher to demonstrate the comparative superiority of one theory over another. The resuit of this type of activity should be to eliminate from consideration those theories which do not receive empirical support.

Hepburn's (1976) test of differential association or cultural deviance theory, the Glueck's version of social control theory, and Hirschi's social control theory fell in the mode of analysis advocated by Liska. Hepburn's research centered around the differing causal ordering of four variables which appear in these three theories: 1ack of family support, delinquent definitions, delinquent associates and delinquent behavior. In differential association theory a weak family socialization process results in the youth failing to acquire prosocial norms and consequently associating with other delinquents and acquiring delinquent definitions before becoming involved with delinquent behavior (Figure 3 ).

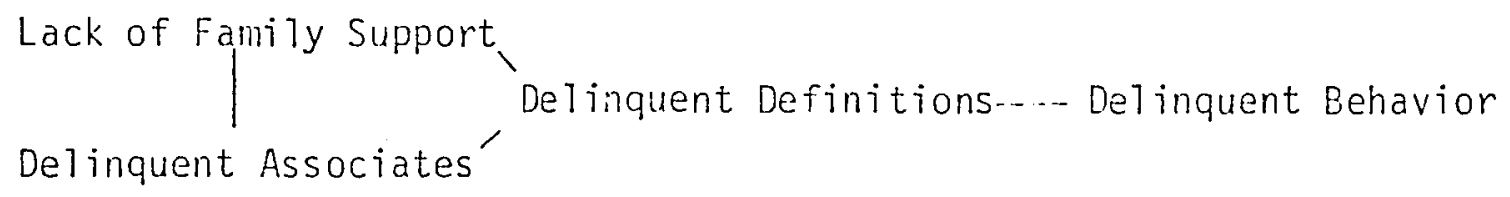

Figure 3. The causal structure of differential association theory.

The version of social control theory offered by the Gluecks was unilinear. It posits that delinquency arises when youths fail to acquire appropriate supervision and dominant social values in the family. This results in the adolescents learning antisocial values which manifest themselves in delinquent behavior. Having become involved in delinquent behavior, the youngster then comes to 
associate with other delinquents. As the Gluecks (1950:164) put it:

"birds of a feather flock together." This sequence is depicted below:

$\begin{array}{ll}\text { Lack of } & \text { Delinquency_ Delinquent_- Delinquent } \\ \text { Family Support } & \text { Definitions - Behavior }\end{array}$

Figure 4. The causal structure of the GTueck's formulation of social control theory

The final theory tested by Hepburn was Hirschi's version of social control theory. Hirschi also concurred with the others that delinquency arises in family interaction where if youths fail to internalize normative behavior and develop stakes in conventional behavior, they become liable to the acquisition of delinquent norns. Hirschi, however, differed from the Glueck's by stating that "delinquent behavior and delinquent associates are independent effects of delinquent definitions and delinquent behavior is the effect, not the cause of delinquent associates" (Hepburn, 1976:451). This model is presented below:

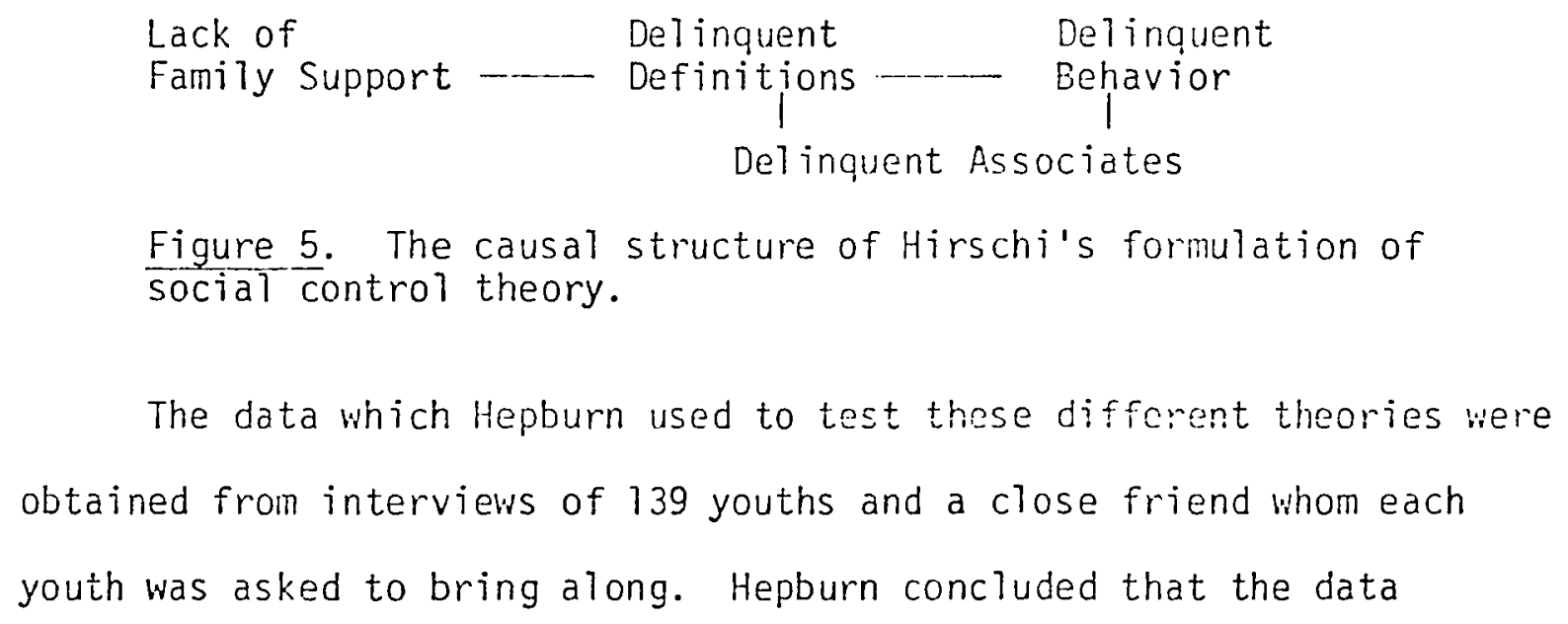

The data which Hepburn used to test these diffcrent theories were obtained from interviews of 139 youths and a close friend whom each youth was asked to bring along. Hepburn concluded that the data supported Hirschi's theory. 
It could be argued that not all youths with poor family relations are likely to become delinquent. Hepburn sought to strengthen Hirschi's theory by differentiating between those youths with poor family socialization and who were willing to become involved with delinquent behavior and those to whom delinquent behavior is not important. By this characteristic which Hepburn termed "constraint," he found that he was more accurately able to predict the delinquency involvement of those youths who were not controlled or otherwise were free to deviate. This new variable "constraint" was included in Hirschi's theory as follows:

Lack of Family Support Constraint_- Delinquent Behavior Delinquent Definitions- Delinquent Associates

Figure 6. A revised formulation of Hirschi's social control theory.

Another test of social control theory (Rankin, 1976) used survey research techinques to compare Hirschi's (1969) theory with that of Reckless. Rankin matched measures of Hirschi's elements of the bond (attachment, commitment, involvement and belief) to Reckless's inner and outer containment theory. After analyzing the data from a sample 385 interviews of male youths, Rankin concluded that there was little support for either Hirschi's or Reckless's version of social control theory. In fairness to Hirschi, it should be noted that Rankin directly tested Reckless's theory and then inferred that the results did not support Hirschi. 
In another respect Rankin's research was questionable. He used the number of delinquent companions as a measure of attachment. Hirschi was quite specific about the role which parental attachment plays in determining whether a youth will have delinquent companions. Rankin measured the level of the independent variable (attachment) from what Hirschi would consider a dependent variable (number of delinquent peers) and this would invalidate the interpretation which he attached to his findings.

Hirschi's research and these additional studies revealed extensive support for the hypotheses which he presented. He felt that variation does exist between the elements of the social bond and delinquent behavior and found evidence that the higher the level of bond which youths formed, the more likely they were to be engaged in conventiona 7, law abiding behavior.

\section{Social Control Theory and Social Structure}

There are several important issues concerning the version of social control theory formulated by Hirschi winch need to be examined further. Most theoreticians who have taken a social-psychological approach to the study of social control have not adequately considered the effects of secondary group factors or institutional and social-structural forces in the explanation of social behavior.

\section{High School Experiences}

An unspoken postulate of those persons putting forth socialpsychological theories is that an individual's behavior and access to social roles is determined by the extent to which that person has been adequately socialized. Yet important nonprimary group 
experiences do affect young people and seem to influence their ability to compete for social roles. First, the events which occur in high school are perhaps the most important forces shaping the lives of young people in adolescence. While Hirschi considered the attitudes of youths towards school as a factor in educational success or failure, the alternative proposition must be considered, namely that there are practices such as grading, tracking, and ability grouping which can be influential in determining hnw well the youths will perform academically.

Educational tracking practices were developed to assist in the functional allocation of scarce educational resources. Intelligence tests were to be administered so that youths with low ability would be subjected to a curriculum which would prepare them for employment cominensurate with their abilities. Gifted youths who could progress at a much facter rate than normal students would be educated in a manner which would maximize their intellectual potential.

There are three questions which arise regarding tracking as an educational policy. First, do those students who are in the "college prep classes" learn more than if they had been placed in classes with students of lesser ability? Secondly, do those youngsters in vocationally-oriented classes perform at a level which is cominensurate with their abilities, or do they have potential which is not being utilized because of the lower expectations which are associated with those classes. Finally, does tracking lead to a more efficient allocation of educational resources? Do those who occupy the higher positions in the social class structure show more intelligence than 
those in lower positions, or have those positions been obtained on the basis of factors other than ability?

While it has been difficult to find evidence that supports the "functional effectiveness" of tracking (Schafer, Olexa and Polk, 1972: 51-54), the data do suggest that it has harmful effects on the selfconcepts and aspirations of those not in the "college prep" track (Polk and Richmond, 1972; Schafer and Polk, 1967; and Schafer, 01exa and Polk, 1972). It is also possible that tracking sets into motion a self-fulfilling prophecy where teachers significantly underestimate the abilities of vocationally-oriented adolescents and accordingly lower the quality of the instruction which they provide them. The youths who are in the classes for "slower" students often perceive the lower quality of instruction and the stigma of being in vocational classes and feel that investments of time and energy will have smaller payoffs than if they were in college preparatory classes. They therefore become less committed to school and to conventional occupations having high educational standards which they cannot achieve. Delinquency then becomes a viable alternative for juveniles who have had access to rewarding conventional behavior closed off due to their vocational track position.

Social Class and Social Mobility

Another problem which should be addressed regarding the issue of educational tracking is the relation between objective measures of ability (IỌ test scores) and occupational success. In a thorough review of the literature on the subject, Bowles and Gintis (1976:294296) noted that intelligence scores have very low correlations with 
measures of economic success. A more important predictor of economic success seems to be the socioeconomic background of the youth's parents. In attempting to determine whether "intelligence" or social class of the parents accounts for the economic success of their children, Gintis and Bowles (1976:120), held IQ constant and observed that "the reduction in the relationship is practically nil. Evidently IQ--whether inherited or not--plays a negligible role in passing economic status from parent to child" $(1976: 120)$. Thus the arguments advanced by those who advocate tracking as a means of efficiently allocating scarce educational resources may be erroneous. The social class of the adolescent's parents rather than IQ appears to be a much better predictor of the social class position which is eventually achieved.

If social roles are not allocated primarily on the basis of intelligence, but on the basis of parental background, then the manner in which this mechanism operates should be examined. Research in this area seems to indicate that the ability of parents to send their children to college is important in the intergenerational transmission of socioeconomic status.

. . fully 80 per cent of 1965 high school seniors who graduated did not attend college in 1967 if their family income was under $\$ 3,000$ as compared to only 13 per cent of those with family incomes of $\$ 15,000$ or more (Anderson, 1974:140). Similarly, after controlling for IQ, Bowles and Gintis (1976:31) reported in their study that youths from families in the top socioeconomic decile received 4.9 years more education than those in the bottom decile. The disparity of education levels attained by menters 
of different social classes clearly indicates that the social class background of the sample in the study was important in facilitating access to both higher education as well as entry to a higher level in the social class structure.

Social Roles and Social Control Theory

A critical examination of Hirschi's conception of the social order to which individuals are bonded revealed that it is underdeveloped along another dimension as well. The availability of the roles into which individuals are socialized was left unexamined by Hirschi. It is one thing for a role to be available and vacant and for someone to fail to become sufficiently socialized to be able to fill that role. It is another matter if the role does not exist, or if its legitimacy is questioned and subsequently rejected by a person. An implicit assumption in social control theory is that an adequate number of acceptable social roles exist. Janowitz (1975) noted that social control deals with the ability of a social group or society to engage in self-regulation without resorting to coercion. Social control theory invoves a structural-functional model of social order, in which the social system is regarded as a persisting, well-integrated configuration, all of the elements of which contribute to the functioning of the whole and in which value consensus is the primary means of social control. It is clear in Hirschi's discussion of the relation of bond to the value system that he took for granted the ready availability of socially-desirable roles and niches for all who aspire to them. However, if the roles or social niches into which individuals are socialized or integrated are in scarce supply, control would then 
have to be far more coercive than if roles were easily available. Since Hirschi did not discuss coercive means of control, he must have assumed that there is an adequate number of social roles existing in the social structure.

It is important to realize that economic roles are finite in number. Hirschi and others who took a social-psychological approach to the study of social control neglected two aspects of economic role structures. First, in a dysfunctional economic system which may not be creating an adequate number of roles as indexed by the numbers of underemployed and unemployed youths, the potential effects of social institutions which are not operating well are borne by the individual. This observation would indicate that there is some utility in pursuing an institutional approach which attempts to determine the effects of dysfunctional social institutions. Secondly, in stressing the importance of economic roles it is possible to determine whether primary group socialization is the only determinant of the position in society which an individual will attain, or whether that attainment is influenced by other factors which are outside of existing formulations of social control theory. The research in this thesis centered on the effects which social class background and educational tracking had in determining access to economic roles. In contrast, the model developed by Hirschi focused on the attitudes which youths develop toward valuing and achieving high status occupations through the skills formed in family socialization. While the initial primary group socialization may be important, it is also possible to view suciai class background and educational success as affecting that initial 
level of social bond and therfore being a determinant of the position which a person achieves in the social structure.

\section{CONCLUSIONS}

This review of studies in the area of social control has drawn attention to several facets of interest. Social control research and theory initially reflected the broad concern with how societies maintained social order. Subsequent research focused on narrower research topics and smaller units of analys is which represented more productive lines of inquiry. Also, studies in later years moved from an emphasis on the social psychology of conformity to the study of deviant behavior, and, finaliy, to an emphasis on delinquent behavior.

The initial work in the area of social control primarily consisted of enumerating the various methods which are in societies to induce conformity. These studies were later shown to be largely descriptive and did not qualify as theory. The first major reorientation in the study of social control theory was in response to Merton's formulation of anomie theory. Merton was primarily concerned with the societal forces which disrupt social control and cause broad patterns of deviant behavior. Labeling theory emerged in reaction to the criticisms of the model of structural analysis developed by Merton and those who followed him. In labeling theory, value pluralism, the varied causes of primary deviation, and the role of social control agencies in defining and organizing deviant identities were emphasized. White the research on social control agencies and organizational responses to deviance proved to be valuable, the lack of research on the processes involved in the development of deviant identities by deviant 
actors was an important shortcoming of the perspective. The review of Reckless in the area of containment theory suggested that his research was of questionable validity. Hirschi's variant of social control theory stresses the role of primary group socialization in preventing delinquency. He found considerable support for the major propositions in the theory he formulated. Finally, a number of studies were examined which dealt with certain other versions of social control theory as well as expansions of earlier works.

While Hirschi conducted research on the components of the social bond which he regarded as the essence of social control, he said littie about the nature of the social structure into which individuals are socialized and how access is gained to social roles. He viewed the development of the social bond as the process whereby youngsters assimilate social values and learn how to gain access to legitimate social roles. In the family the youths learn the value of education and its importance in attaining high status occupational roles. However, beyond the mere formation of appropriate attitudes, adolescents must invest time and energy in pursuit of those aspirations. Finally, the individuals must embrace the social value system and evaluate his behavior against the standards of that value system.

The implication of social control theory is that the bond is fixed in primary group interaction prior to adolescence. By the time a youth enters high school the attitudes which have been formed should then be translated into conforming behavior with the adolescent gaining access to legitimate social roles.

Hirschi contended that young people enter adolescence with their social bonds formed to varying degrees. By contrast, this thesis argues 
that experiences of adolescents within the secondary educational system and variations in parental social class backgrounds influence the process through which individuals are socialized. After the bond is initially formed, educational practices and life options available to youths from different positions in the social class structure can affect the level of bond, thereby facilitating or hindering the competition for social roles. In particular, being from a white collar background or in a college preparatory track should reinforce an initially high level of bond, or increase it if it was initially low because of the benefits which accrue to individuals in those positions. Conversely, students who are in a vocational track or who are doing poorly in school, or who come from a blue collar background would have relatively fewer opportunities to continue the investments in a college education or prepare themselves for positions such as a banker or lawyer. The result is that the initially high level of bond would be expected to decrease, while for those whose level of bond was low, it would be expected to remain low.

In the study reported here, the work of Hirschi was used as a basis for a more dynamic model of social control theory than he originally developed. The behavior of the social bond was looked at over time and related to differential delinquency involvement. Additionally, the impact of nonprimary group factors on delinquency was studied. Chapter III outiines a research design which examines the effect of education and social class ties on the relation of the individual to society. 


\section{CHAPTER III}

\section{THE RESEARCH PROBLEM AND METHODOLOGY}

\section{INTRODUCTION}

The two previous chapters discussed the development of the social control perspective and reviewed the relevant research regarding it. It was noted that while social control theory once centered broadly on the social institutions which regulate individual behavior, it later came to be more directly concerned with the relationship of the person to society. The work of Hirschi on the social bond was shown to be a significant advance in the area of social control theory. Yet, it is also true that those taking a social-psychological approach to studying delinquency have been relatively silent on a number of issues. First, they have viewed the individual's relationship to society as fixed in primary group interaction. Secondly, social structural and social institutionai forces have not been considered in terms of how they might affect a person's relationship to society. In the research reported here, the social control theory developed by Hirschi was examined to determine whether the social bond is static or dynamic, whether it is affected by social class and educational achievement, and finally how those changes in the social bond, if they exist, are related to delinquent behavior.

The argument of this study, in contrast to that of Hirschi, was that the level of bond can change over time, resulting in greater or 
lesser likelihood that a youth will engage in delinquent behavior, depending on the current level of social bond. This research examined two structural factors which were thought to produce the hypothesized changes in the level of bond. School tracking as measured by the youth's grade point average and parental social background may operate while the youth is in high school to differentially affect those adolescents whose level of bond was either initially high or low, depending upon the manner in which life options are opened or closed for juveniles. These factors which were not considered by Hirschi may change the level of bond which had been previously formed, depending upon the nature of the interaction, resulting in changes in the likelihood that a youth will become delinquent.

\section{RESEARCH PROCEDURES}

This analys is began with the hypothesis presented by Hirschi about the relation of the elements of the social bond to delinquency. Using data obtained from a longitudinal panel study of male youths, this study examined the effects of changes in the leve? of bond between two time periods (Time 1 in 1965 and Time 2 in 1967) on participation in delinquent behavior. Next, attention turned to whether the levels of bond which were initially formed had any relation to social class. Finally, changes in the level of bond were examined in relation to grade point average and parental social class background to determine if those factors at least partially explained the changes in the level of bond and subsequent delinquent behavior. 
THE SOCIAL BOND AND DELINQUENCY

Before moving on to a more detailed consideration of the research design, some further explication of the research problem is required, starting with a more extensive discussion of Hirschi's social control theory and the hypotheses which were studied here. From a social control perspective, deviance can result from either the failure of the social bond to be established or a subsequent attenuation of those ties to society. The research which has been done on social control theory has primarily focused on youths who represent failures in socialization rather than those who have had experiences which theoretically could result in a weakened social bond. The problem is that studies such as Hirschi's which have only one measure of the social bond have been unable to distinguish between those delinquents who were initially bonded and whose bond was weakened and those whose socialization was never completed. The model developed by Hirschi can be viewed below:

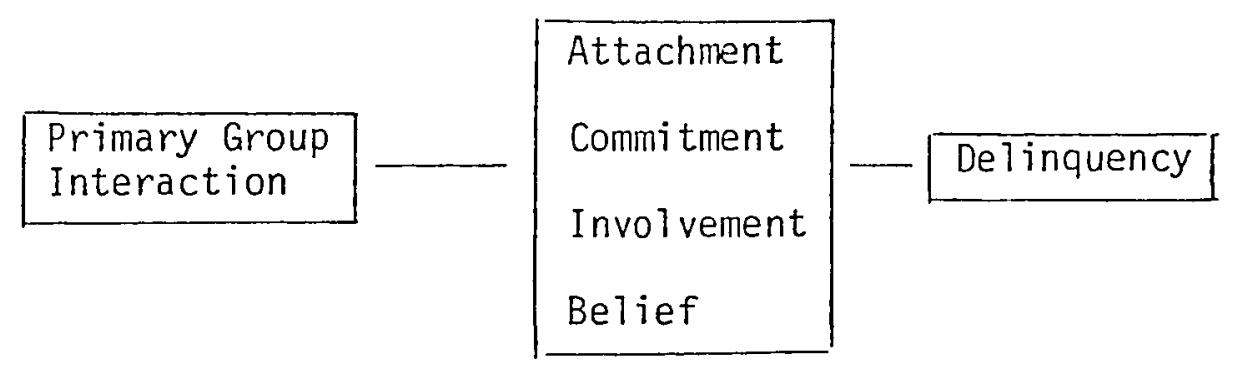

Figure 7. Social control theory as formulated by Hirschi in Causes of Del inquency.

Hirschi treated each element of the social bond as equally important in terms of how it relates to delinquency. Therefore, four hypotheses from Hirschi's study were identified regarding the relation of each element of the bond to delinquency. 
The first hypothesis held that the more successful or higher the quality of the parent-child interaction, the less likely that the youth will become involved with delinquent behavior. This parent-child interaction is viewed as a central part of attachment. Therefore

$\mathrm{H}_{7.1}$ The greater the attachment of the youth to his parents, the less likely he will become delinquent.

The next hypothesis examined the relation between commitment to educational goals and delinquency. Commitment to the goal of going to college should have the effect of orienting youths toward prosocial activities such as work and study and so forth. Those youngsters should be less involved in essentially idle activities such as cruising around in a car, smoking, dating and so forth, which do not represent an investment in the adolescent's future. If so, the following hypothesis can be stated.

$\mathrm{H}_{1.2}$ The greater the commitment to achieving a college education, the less likely the youth will become delinquent.

Involvement represents a measure of the time and energy which young people invest in conventional behavior, particularly in attaining socially desirable and approved goals. Investments in homework and other conventional activities as opposed to delinquent behavior are crucial aspects of this element of the bond. Therefore:

$\mathrm{H}_{1.3}$ The greater the involvement of the youth in homework, the less likely he or she will be to become delinquent.

Finally, belief plays an important role in social control theory in that it represents an indication of the extent to which an adolescent subscribes to the normative order of society. Juveniles who accept the 
legitimacy of the law, therefore, should be less likely to become involved with delinquency. Belief is represented as follows.

$\mathrm{H}_{1.4}$ The greater the belief of a youngster in the social value system the less likely he or she will become involved in delinquent behavior.

\section{CHANGES IN SOCIAL BOND AND DELINQUENT BEHAVIOR}

As previously noted, Hirschi considered the level of the bond to be stable, or at least did not seriously entertain the possibility that bond, using the measures which he described, could change over time. Also, the survey which he conducted did not allow for his sample to be followed over time to determine if the changes in the level of bond did occur. Nonetheless, the possibility exists that a person's social bond can change due to ceriain experiences which in turn could be related to different rates of delinqeuncy involvement.

\section{THE CAUSAL ORDERING OF VARIABLES}

Unfathoming or determining the causal ordering of the variables was an important problem in this research. The issue arose in two parts of the analysis. The first part dealt with the replication of Hirschi's research, in which this study attempted to overcome the shortcomings of his cross-sectional research design in Causes of Delinquency and $i$ ts consequent limitations upon his causal interpretations. The second part dealt with determining the ordering of the variables in an expanded argument, in which changes in the level of bond were examined in relation to delinquency involvement. 
Let us begin with the work of Hirschi. He assumed that participation in delinquency was a consequence of the level of bond formed by the adolescent. This hypothesized causal process is presented below:

Early Socialization - Level of Bond - Delinquency

Figure 8. Level of bond determining delinquency.

However, a plausible case could be made that the causal process is reversed, with delinquency and the attendant difficulties associated with peer, parental and educational reaction producing low bond while successful adjustment leads to high bond. The alternative model is shown below:

De? inquer:y - Defective Social Reiations - Lever of Bond Figure 9. Delinquency determining the level of bond.

The causal order problem in cross-secticnal research should now be clear. When measurements of the level of bond and of delinquency occur at the same time, it is difficult to determine which of the two arguments above is more plausible.

Because the research reported here was based on a panel study, it was possible to determine at the time the population was initially surveyed in 1964 that none of the sophomore boys had been officially adjudicated delinquent. Delinquency occurred subsequent to the initial measurement of the level of bond. In this respect this research design was stronger than that of Hirschi, for he could not be sure of the causal ordering of the variables in his study. Results turned up in this study showing low level of bond in 1964 was related to subsequent del inquency. 
The second issue developed as a result of the expanded conceptual framework in this research. This argument held that initial levels of bond sometimes become altered as a result of changed social circumistances of youths, thereby leading to changes in the rates of delinquent behavior. The direction of this relationship is from initial bond, to subsequent bond, to delinquency.

In attempting to determine whether changes in the level of bond might be related to delinquency, the time-order problem reemerged due to the manner in which delinquency was measured. With the level of bond assessed first in 1964 and later in 1967, and with delinquency operationalized as any officially recorded act occurring between 1964 and 1967, two plausible interpretations of the findings were possible. Consistent with the general hypothes is above, the level of bond may have changed first and may have affected the likelihood the youngster would become delinquent. Alternatively, it is possible that delinquency during the three year time period produced the second level of bond, such that the relationship is actually from initial bond, to delinquency, to subsequent bond. This is, of course, a markedly different pattern than the one utilized in this study.

Putting the matter in a somewhat different fashion, with the data on delinquency and bond that were available for analys is in this research, all that can be said with complete assurance is that bond changed sometime between 1964 and 1967, and that involvement in delinquent behavior also occurred sometime during the same time period. This uncertainty about the time ordering of variables could be resolved by having a large series of longitudinal observations on bond level and 
delinquency, taken at close intervals, but those kinds of data are rarely if ever available and were not obtainable from the Marion County Youth Study.

The two alternative formulations regarding the relationship between bond levels and delinquency are shown in Figures 10 and 11 below.

Mode 1 I

Lever of Bond (1964) - Level of Bond (1967) - DeTinquency (1964-1967)

Figure 10. Changes in bond causing subsequent delinquency.

Model II

Level of Bond (1964) - Delinquency - Changed Level of Bond Figure 11. Second level of bond occurring as a consequence of delinquency.

As indicated above, the orienting framework for examination of bond and delinquency in this research is captured in Figure 10. It is also the case that the investigator was interested in exploring a more detailed version of Figure 10, in which the effects of intervening influences of social class and educational policies upon bond levels, and subsequentiy, upon delinquency were to be examined. However, this expanded formulation is based on the same logic as Figure 10, and assumes that the outcome of the intervening factors operating upon bond is delinquency. Accordingly, it became crucial in the research reported here to bring to bear any evidence that could be marshalled in order to adjudicate between Figure 10 and Figure 11. 
Despite the difficulties which exist in interpreting differing orderings of variables in cross sectional data, there is at least one method of resolving the problem. This method is based on Liska's (1969) proposal that a common data base should be used to test competing sociological theories, allowing the elimination or rejection of those theories which are not supported by the data. In the following section, the models described in Figures 10 and 17 were evaluated. This was done by treating the level of bond in Figure 10 and delinquency in Figure 11 as intervening variables. In the section which follows, a Pearsonian Correlation Coefficient (Pearson's R) was computed for each of the zero-order correlations and a partial correlation coefficient (Loether and McTavish, 1974:300) was also computed to examine the effects of the intervening or test variables. In this case, only one of the two models will be supported by the data when the relationship between the independnet and dependent variable is reduced to zero, while the relationship which is not reduced will be rejected as a causal model. According to the rationale presented in The Logic of Survey Analysis (Rosenberg, 1968:54-66), the relationship between the independent and dependent variable should be reduced to zero if the indicated test factors are intervening variables. The reduction simply indicates that the independent variable operates on the dependent variable through the intervening variable.

For the three different measures of bond available in both 1964 and 1967 (Table 1), the partial correlation of the 1964 and 1967 measures of the bond with delinquency controlled were not appreciably reduced below the zero-order correlations, indicating that delinquency is implausible as an intervening factor between the bond levels at the 


\section{TABLE I}

EVALUATION OF ALTERNATIVE CAUSAL MODELS

Mode $\mathrm{I}$

Attachment 1. Attachment (1964)-2. Attachment (1967)-3. Delinquency

$$
\begin{aligned}
& r_{13}=.125 \\
& r_{13.2}=.064
\end{aligned}
$$

Model II

1. Attachment (1964)-2. Delinquency-3. Attachment (1967)

$$
\begin{aligned}
& r_{13}=.299 \\
& r_{13.2}=.281
\end{aligned}
$$

Model I

Commitment 1. Commitment (1964)-2. Commitment (1967)-3. De inquency

$$
\begin{aligned}
& r_{73}=.002 \\
& r_{13.2}=-.076
\end{aligned}
$$

Mode1 II

1. Commitment (1964)-2. Delinquency-3. Comnitment (1967)

$$
\begin{aligned}
& r_{13}=.594 \\
& r_{13.2}=.595
\end{aligned}
$$

Model I

Involvement 1. Involvement (1964)-2. Involvement (1967)-3. Delinquency

$$
\begin{aligned}
& r_{13}=.271 \\
& r_{13.2}=.167
\end{aligned}
$$

Model II

1. Involvement (1964)-2. Del inquency-3. Involvement (1967)

$$
\begin{aligned}
& r_{73}=.415 \\
& r_{13.2}=.666
\end{aligned}
$$


thio times. However, for each measure of the bond, the correlation between the initial level of bond and delinquency involvement dropped to near zero when bond in 1967 was partialled out, indicating that Model I is more plausible as a causal model than is Model II for each of the three measures of the bond.

The analyses presented here by no means completely resolve the issue of the causal ordering of the variables, but they were consistent with the model specified in Figure 10. However, because of the nature of this partial support and the thrust of the theoretical arguments presented in Chapter I, the model presented in Figure 10 was used in subsequent analysis. Obviously, the most desirable procedure in future research would be to collect repeated measures of bond levels and delinquency involvement for much shorter periods of time and eliminate this important issue in the research design.

\section{RESEARCH MODEL}

This research, by virtue of its panel nature, was able to examine changes in the level of bond over time. Chapter I pointed out that in adolescence, as youths compete for adult social roles, their opportunities to make investments in conventional behavior are affected by their social class position and their academic performance. These in turn affect the initial level of bond resulting in a changed relationship to society therefore affecting the likelihood that youths would become delinquent. An expanded model is presented below which was used in the discussion of the hypotheses which follow. 
Level of Bond in 1964

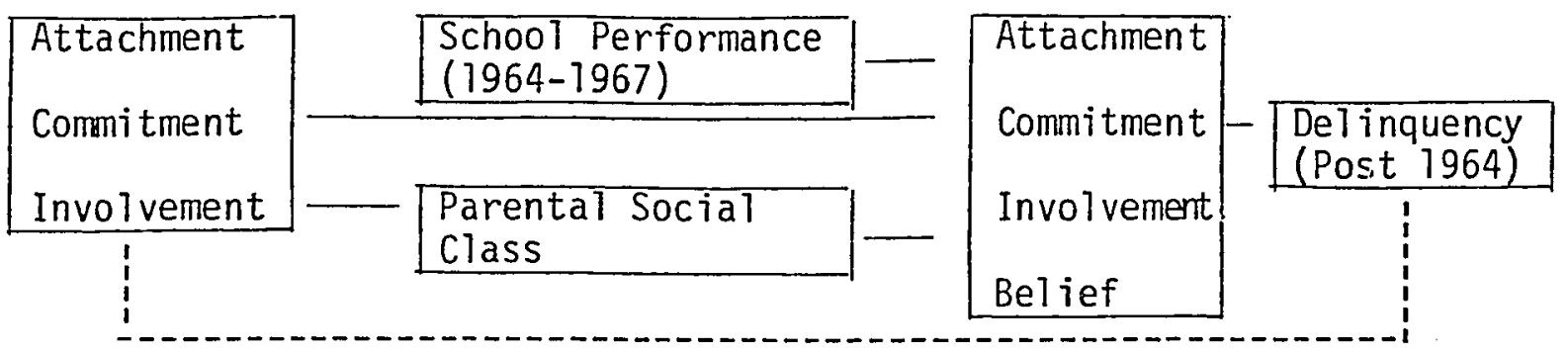

Figure 12. Revised model of social control theory.

Hirschi's research, as stated previously, examined only the relation between the level of bond at one point in time and delinquency. If his model were applied to this study, it would be represented by the link between the bond in 1964 and post-1964 delinquency. The model used here expanded the framework through the addition of several more variables. These are measures of parental social class for 1967 , school grade point average for 1964-1967 as a measure of school track, and a measure of the level of bond in 1967 .

There was one other possible relationship which was not examined primarily because it was not consistent with the theoretical framework used in this research. This was the relationship between educationa? performance and the level of bond in 1967. It could be argued that bond is an important determinant of school performance, and Hirschi would probably concur. This research treated that relationship as existing in the opposite direction. Primarily because of the evidence noted in Chapter 1 which indicated that educational policies such as grading, tracking and ability grouping are important determinants of the adjustments which adolescents make toward school, those external factors are thought to affect the youth's initial relationship to society. 
Hirschi also argued that no significant relationship between the initial level of bond and social class exists. By contrast, the present study assumes that such a relationship between bond and socioeconomic status does exist. Additionally, this study assumed that socioeconomic status is also a measure of the parents' ability to assist their children in entering college. Since Hirschi stressed the critical nature of upward social mobility and orientation toward higher education, this study has treated social class in adolescence as an intervening influence which facilitates or hinders access to higher occupations and leads to changes in the initial level of bond.

\section{DESCRIPTION OF ANALYSIS GROUPS}

In the parts of the study which dealt with changes in the level of bond, there were four subsamples, or analysis groups, which served as the basis for the data analysis. These subsamples were identified by whether the level of bond changed or remained stable between 1964 and 1967. The first was made up of persons whose level of bond remained high in 1964 and 1967; the next of those whose 1evel of bond fell from high to low (group 2); one in which bend remained low (group 3) and one in which bond increased from low to is ? croup 4). The size of these groups was dictated by the initial level of bond and subsequent change or stability in that level of bond. For those whose level of bond was initially high and then decreased, the anticipated result was increased delinquency participation when compared to those whose level of bond remained uniformly high. Secondly, those whose level of bond was initially low and then increased were expected to show less delinquency involvement than those whose level of bond remained low. 
$\mathrm{H}_{2.1}$ Youths whose level of bond was high at Time One and low at Time Two will have greater contact with the juvenile justice system than those whose level of bond was initially high and remained so in 1967.

$\mathrm{H}_{2.2}$ Youths whose level of bond was $10 \mathrm{w}$ in 1964 and high in 1967 will have less delinquency involvement than those whose level of bond was low for both years.

INITIAL LEVEL OF SOCIAL BOND, SOCIAL CLASS AND DELINQUENCY INVOLVEMENT

Hirschi did not consider the relationship between delinquency and social class to be important. He presented the following table dealing with official and self-reported measures of delinquency involvement $(1969: 74)$.

\section{TABLE I I}

\section{AVERAGE NUMBER OF SELF-REPORTED AND OFFICIAL DELINQUENCY ACTS BY FATHER'S OCCUPATION WHITE BOYS ONLY}

$\begin{array}{lccc}\begin{array}{l}\text { Father's } \\ \text { Occupation }\end{array} & \begin{array}{c}\text { Self-Reported } \\ \text { Acts }\end{array} & \begin{array}{c}\text { Official } \\ \text { Offenses }\end{array} & \begin{array}{c}\text { Number of } \\ \text { Boys }\end{array} \\ \text { Lower } & .81 & .32 & 124 \\ \text { Upper-Lower } & .68 & .28 & 112 \\ \text { Lower-Middle } & .83 & .27 & 300 \\ \text { Middle } & .88 & .24 & 128 \\ \text { Upper-Middle } & .61 & .22 & \frac{241}{.26} \\ \text { Total Sample } & \overline{.76} & & \end{array}$

Hirschi noted that there was a small relation between social class and delinquency. Even so, he concluded that:

in sum, there is in the present sample no important
relation between social class as traditionally measures
and delinquency. We do find a small group at the bottom
of the class hierarchy whose children are more likely to be 
delinquent, and at the other extreme, we find that the sons of professionals and executives are consistently less likely to be delinquent. The percentage point differences and/or the number of cases in extreme categories are, however, small, so small, in fact, that we need not control social class in subsequent analysis (1969:75).

These findings are important because Hirschi stated on the basis of this information that:

I sha11 occasionally examine relations within socioeconomic status categories if the hypothesis in question is class specific, and I shall occasionally examine relations between social class and independent variables, but it should be kept in mind throughout the analys is that al ternative explanations involving social class cannot, in the present data be true (Hirschi, 1969:75).

In the theoretical framework developed in this research, social class was hypothesized to be an important factor. The following two hypotheses were explored.

$\mathrm{H}_{3.1}$ There will be no relationship between socioeconomic status and delinquency.

$\mathrm{H}_{3.2}$ The initial level of attachment, commitment, involvement and belief will not be related to social class.

\section{EXPLAINING THE CHANGES IN THE SOCIAL BOND}

Finally, this study examined several explanations for the hypothesized changes in the level of bond and how those changes relate to delinquency. The discussion presented in the first chapter concerning educational policies and parental social class background indicated that those factors are important in determining the types of roles which are obtained by individuals in the social class structure. This study contends that grading, as a measure of educational tracking, and 
parental class background can either mediate or exacerbate the effects of an initial level of bond. By the time youths approach adolescence and enter high school, they are becoming involved with a milieu which is substantially different from that of the family. At this point in the lives of young people, the effects of educational policies and parental class background can be viewed as either optionopening or option-closing. In this study it was possible to develop a number of specific comparisons which examined the effects that doing well in school versus doing poorly, or being a youth with a blue collar as opposed to white collar background, have on changes in bond. From this discussion a number of summary hypotheses which reflect the differential effects of these factors were examined.

$\mathrm{H}_{4.1}$ Youths from a white collar background will be less likely to show a decline in the level of bond if it was initially high and will be more likely to show an increase if it was initially low than their lower class counterparts.

$\mathrm{H}_{4.2}$ Youths with a high grade point average will be less likely to show a decline in the level of bond if it was initially high and more likely to show an increase if it was initially low than their lower GPA counterparts.

In conclusion, these changes in the level of bond and their relation to social class background and grade point average were examined to determine how they affected the likelihood that a youth would become delinquent.

$\mathrm{H}_{5.1}$ Youths with a white collar background and good school performance will be less likely to be involved in delinquency than 
youths with a blue collar background and poor school performance. Furthermore, regardless of whether the level of bond increased or decreased between Time One and Time Two, high socioeconomic status youths and youths with better grades will have less delinquency involvement than adolescents with either a low socioeconomic status background or poor grades.

\section{METHODOLOGY}

The data for the research were derived from the Marion County Youth Study. Dr. Kenneth Polk, from the University of Oregon, is the director and primary researcher of that study. Data for this dissertation research were obtained on cards from the extensive set of information which has been collected over the past 14 years from the panel of youths who have participated in the study since 1964.

The Marion County Youth Study involves a relatively unique approach to examining the problems which confront male youths. The title, "Maturational Reform and Rural Delinquency" served to announce at least two major research foci: (a) a concern for investigating the processual nature of adolescence and behavior and (b) to do so in a nonmetropolitan area. A panel of 1,227 male youths who were sophomores in 1964 were surveyed in that year and have since been surveyed each following year with the exception of one to study the rajor societal and social-psychological forces which come into their lives as they mature.

In 1964, larion County, Oregon, had a population of 139,301 persons, two-thirds of whom were classified as urban residents. Salem 
is the largest city of any size in the county and had a population of 62,861 in 1964. While this population is "urban," it is rather dissimilar to many other urban areas in that it was racially homogeneous, with less than .2 percent of the population being black. The major economic activities of the area are food processing, government, agriculture, forestry and manufacturing.

\section{DATA COLLECTION}

In December 1964, a nineteen-page questionnaire was administered to 1,227 male sophomores enrolled in the eighteen high schools in Marion County. The questionnaire, which was composed of extensively pre-tested items, surveyed the youngsters about their attitudes and behaviors in relation to a wide range of adolescent concerns. The youths who were not contacted during the initial survey attempts were subjected to a series of follow-up surveys with the result that the study included 93 percent of the population who were sophomores in the Marion County High Schools (Koval, 1967).

Special attention was given to coder training to insure the accuracy and uniformity of the data processing. The steps have been described as follows:

\footnotetext{
- . procedures for coding and processing of the data were consistent with the detail and care which went into the other phases of the research. (1) Coders were screened, trained, and supervised. (2) The data were independently double-checked, key punched, and verified. (3) All aspects of the data processing were closely monitored in order to eliminate sources of error between the questionnaire completion and the data analys is phase. (4) Special computer programs with logical validity checks (i.e., scanning for duplicate identification numbers) provided further insurance that unnecessary errors were eliminated (Koval, 1967).
} 


\section{EDUCATIONAL AND DELINQUENCY INVOLVEMENT DATA}

The initial survey did not inciude data in a number of important areas for youths participating in the study. It was therefore necessary in a follow-up phase of the research conducted in 1967 to obtain information on school absences, individual course grades, total grade point average, I.Q. test scores, and quantitative and general vocabulary scores for the Iowa Standard Achievement Test (Frease, 1969:38).

When the population in the study graduated from high school in 1967, data concerning delinquency involvement were collected from both the Marion County Juvenile Court and the Linn County Juvenile Department. The criteria for classifying a male as delinquent were quite specific in that the adolescent had to have been

.. referred to the juvenile court and treated as a delinquent by that agency. Age 18 or high school graduation, whichever came last seemed to be the criteria for referral to and disposition by the juvenile department (Frease, 1969: 40).

The information concerning delinquency excluded traffic offenses, dependency, and "information only" listings in the juvenile court records. Nonetheless, excluding those items, 303 of the original 1,227 boys were adjudged to be delinquent by those standards (Kelley, 1969:58).

DESCRIPTION OF LONGITUDINAL DATA COLLECTION PROCEDURES

Inasmuch as the Marion County Youth Study is an ongoing research project, all members of the sample have been contacted annually, with the exception of one year. Each year the members of the study are 
contacted to determine if their addresses on file are correct and are given a short questionnaire. In 1967, 25 percent of the total pane? was randomly selected and given a more extensive survey to probe research interests in greater detail. This 25 percent random sample has been followed separately from the total population. In the research presented here, the 1964 responses from the 196725 percent random sample was extracted from the data set and this comprised the information on which this study was based.

A major problem with survey research in general but which is critical in panel studies is that members drop out of the study. If some panel members drop out, the possibility exists that the remaining sample will be biased. The original study population was divided into two groups: those who finished high school and those who did not. In 1967 there were 127 high school dropouts and 1,100 high school graduates. Youths who chose not to participate in the study were compared along three dimensions to those who continued to participate: class background, grade point average, and delinquency participation. This analysis showed that the non-participants did not differ significantly from the participants (B1ake, 1973:220).

\section{OPERATIONALIZATION OF THE CONCEPTS}

The items which were derived from the Marion County Youth Study to operationalize the concepts identified in Hirschi's formulation of social control theory were not entirely comparable to those used in Causes of Delinquency. Because Hirschi collected the data which he used in his study, he was able to achieve a level of precision in his 
measures which was not possible in this study. Therefore, this research did not attempt a point by point replication of Hirschi's study. At the same time, this analysis did investigate aspects of social control theory which Hirschi did not consider. It should be noted that while he measured some of his concepts with indexes comprised of several variables, for the most part he used single items as measures of variables. The items selected for this study can therefore be criticized on the grounds that they are not entirely valid al though they closely approximate the measures used by Hirschi. In two areas this research is confronted with a serious problem of generally weak measures of variables which are introduced as test factors. These are the use of parental social class to describe the variation in life chances in gaining access to legitimate, high status social roles, and the use of total high school grade point average as a measure of school track or more broadly, institutional reaction toward the youth. It is obvious enough that not all middle status youths take advantage of opportunities that are differentially available to them, while some other youngsters from relatively comfortable backgrounds may nonetheless be cut off from opportunities. Conversely, not. all working class youths may be similarly disadvantaged by virtue of shared class position. Even so, social class is correlated with opportunities for success and upward mobility and can be used as an indicator of the latter, in the absence of more specific, detailed information on individuals and their life-chances. 
ATTACHMENT

Hirschi argued that successful family interactions are the basis for the formation of attachment (Hirschi, 1969:83-89). In family interaction youngsters come to prize the opinions of others and should therefore adopt attitudes which are consistent with those of their family members. One such value is the attachment to school. Hirschi averred that this attitude is substantially formed in the family where youths have learned to respond to teachers as significant others. Finally, Hirschi argued that youths who have unsuccessful family interactions will tend not to value their family's opinions. Thus, a pattern of unsuccessful interpersonal relations precedes involvement with delinquent peers and in social control theory is independent of delinquent values. This sequence is depicted as follows:

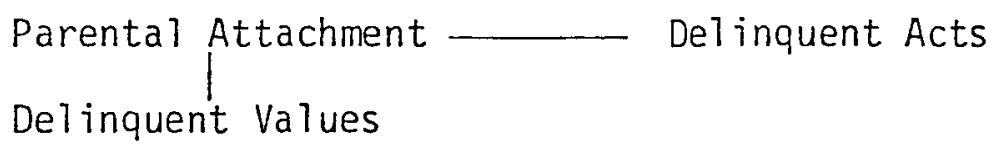

Figure 13. Level of parental attachment and its relation to delinquency and delinquent values.

The factor which precedes involvement with non-delinquent peers and with the formation of positive attitudes toward school is a pattern of successful family relations. Many adolescents therefore learn to behave in a manner which is consistent with familial values and act as if they are under their parent's supervision. Hirschi noted that the parents of youths with good family relations know whom their children are with and where they are going and

- . are much less likely to have committed del inquent acts than those who at least sometimes, feel that they have moved beyond the range of parental knowledge or interest (1969:89). 
To measure parental supervision, Hirschi used the responses to the questions "Does your mother (father) know where you are when you are away from home?" and "Does your mother (father) know whom you are with when you are away from home?" (1969:88-89). Those items were strongly correlated with delinquency, such that males with low degrees of supervision were more likely to become delinquent. The strength of this relationship served as the basis for the selection of a similar item from the Marion County Youth Study. The item used was "My parents usualiy know where I am and what I am doing." The responses of "Agree Strongly" and "Agree Somewhat" were treated as a high level of attachment and "Disagree Strongly" and "Disagree Somewhat" were treated as a low level of attachment.

\section{COMMITMENT}

Conmitment, like attachnent contains a number of underlying dimensions. It designates values which persons have toward conventional behavior. Conmitment means that youths must come to value education and a high status occupational career if they are to participate in productive social roles. They must come to perceive education as the means through which a career is gained. The adolescents then will proceed to invest time and energy into school and will choose not to risk that investment with its potential rewards by the stigma and blocked opportunities which are associated with being caught participating in delinquent activities.

In Hirschi's work, educational aspirations occupied a central place in the formation of commitment. Youths who have high educational 
aspirations and who work for future rewards are markediy different from those who are presently having fun. Hirschi noted that ". . . the higher the student's educational aspirations... the less likely he is to commit delinquent acts" $(1969: 171)$. In the present study the question "What do you think about going to college?" was used to measure educational aspirations in 1964. The responses "I want to and plan to go"; "I want to go but don't know if I will"; and "I want to go, but don't think I will" were treated as high commitment. The responses "I don't want to go and am sure I won' $t$ "; "I don't want to go but don't know if I will"; "I don't want to go but will probably go anyway"; and "I have not thought about it" were classified as low commitment. In 1967, the question "I expect to go to college" was used to measure commitment. A "Yes" represented high commitment and a "No," low conmitment.

\section{INVOLVEMENT}

Involvement was unique among the elements of the bond in that it was the only behavioral, as opposed to attitudinal variable. Even so, involvement appeared to relate to attitudinal measures such that youths who are committed to conventional activities also should be involved in those activities. Hirschi was emphatically clear that involvement does not refer to activities which are tedious and time consuming. Attempts to incapacitate youths through recreation and youth centers have not been productive because delinquent acts are not tremendously time consuming (Hirschi, 1969:1870191). Instead, he argued, the quality of what the youth is doing is more important. His contention 
was that the willingness of youngsters to devote time and energy to school work is an important measure of the correspondence between valuing educational goals and achieving those goals. Hirschi found that adolescents who spent more time on homework were less likely to become involved in delinquent behavior than those who spent little time. In the Marion County Youth Study this same factor was isolated through the response to the question which measured the number of hours per week spent doing school work at home. In this research up through six hours per week was treated as low involvement and seven or more hours of homework as high involvement. These amounts of time correspond to Hirschi's measures of low and high involvement.

\section{BELIEF}

Control theorists assume that there is a set of core values which represent society's standards for behavior. But in contrast to the strain theorists who also assume that there is a set of core societal values, and also posit deviant motives on the part of delinquents. Hirschi did not look for special motivations to explain why some youths break the law. Instead he simply contended that "there is variation in the extent to which people believe they should obey the rules of society" (1969:26). This variation determines the extent to which they believe that their behavior should be bound by those rules. Youths who are more bound by rules will be less likely to engage in law breaking behavior than those who are less bound.

The item used to measure belief in Hirschi's study was the statement "I have a lot of respect for the Richmond police." The 
logic for choosing that item was "Lack of respect for the police presumably leads to lack of respect for the law" (Hirschi, 1969:202). In the present study, belief was measured by the statement "From what I know the police treat you fairly," since it assessed a similar aspect of the youth's perception of the moral validity of the law as represented by the actions of a social control agent. For this item, "Agree Strongly" and "Agree Somewhat" were treated as a high level of belief and "Disagree Strongly" and "Disagree Somewhat" as a low level of belief. Although this item is very similar to the one used by Hirschi, it was not an ideal measure of belief. Persons might agree that laws are just even though they feel that the police are corrupt or enforce the laws improperly. Therefore, this item may have measured belief in an indirect and potentially misleading manner.

\section{DELINQUENCY}

The measure of delinquent behavior used in Causes of Delinquency was patterned after the self-report delinquency scale developed by Nye and Short and used by Dentler and Monroe and others (Hirschi, 1969: 54-57). Self-report studies have been responsible for challenging at least two major assumptions in many delinquency theories. First, they have called into question the idea that delinquency almost exclusively is a lower class phenomena, and secondly, challenged the thesis that delinquents are fundamentally different than nondelinquents. These studies have shown that most youths have engaged in the activities which the scales use to define delinquency and that the behaviors are not restricted to the lower class. Self-report studies in effect 
show that official data on delinquency do not accurately reflect the incidence of juvenile law breaking in the social system.

Close examination of the instruments used to measure delinquency reveals that serious problems exist with the validity of self-report studies. The scales which are used to measure delinquency usually represent a truncated scale of offense seriousness. The items which are used on these scales are concentrated upon minor delinquent acts such as stealing items worth 1 ess than $\$ 2$ and incidents of adolescent misbehavior such as fist fighting which may not even be against the 1aw. In addition to not focusing on serious acts of delinquent behavior, some of these scales do not measure offense frequency. Thus the youth who is adjudicated delinquent may have repeatedly broken the law resulting in his or her apprehension while the nondelinquent may have broken the law only once or twice and then ceased that behavior. In contrast, the self-report scales would treat both youths as equally del inquent.

In attempting to develop valid measures of delinquent behavior, Hirschi's scale included items ranging from petty larceny, grand larceny and auto theft, to assault and battery. While these offenses might seem serious criminal activities, enough ambiguity exists in their definitions that youths taking small amounts of property technically would have committed a Tarceny and might so indicate that on the instrument while those who have gotten into minor fights might report themselves to have engaged in assault. Some youths may treat their peccadilloes as indicative of serious criminal behavior when this is not the case, while others may only admit to truly serious delinquent acts. 
While the items in Hirschi's instrument appear to represent serious criminal behavior, at least some of the incidents which were reported by youngsters might frequently not be treated as crimes by the police. The question then exists as to whether official data or selfreport data are better measures of delinquent behavior. While selfreport studies have been useful in correcting some of the biases in official offense statistics, Nettler's comments suggest that official data do have validity for representing the actual incidence of serious delinquent behavior.

An evaluation of these unofficial ways of counting crime does not fulfill the promise that they would provide a better enumeration of offense activity (1974:98).

Official measures of delinquency were collected in 1967 for the period 1964 through 1967 and used in the Marion County Youth Study to avoid the ethical and legal implications that might arise in safeguarding the confidentiality of self-report data. In this study delinquent behavior which came to the attention of the juvenile justice system was used to measure delinquency and thus provide a valid index of serious delinquent behavior in Marion County. Adolescents who came into contact with the juvenile justice system after the first questionnaire was administered in 1964 were classified as delinquents while those who did not come into contact with the juvenile justice system were treated as nondelinquents.

\section{EDUCATION}

The discussion of the literature in Chapter I revealed that the practices of the school system of dividing students into college 
preparatory and non-college preparatory tracks were harmful because those students who were in the vocational tracks came to see themselves as failures. If participation in higher education can be viewed as option opening, from a social control perspective, then becoming enmeshed in a non-college course of study may have the effect of limiting the student's life options. The argument regarding the dimension of commitment was that youths who make investments in conventional behavior such as education would be less likely to become delinquent. Tracking differs from commitment in that the latter represents the youth's attitude toward education while the former refers to the actions taken by the educational system toward the student. Thus, the education system can be characterized as sometimes closing off the opportunities to make investments in conventional behavior which social control theory holds to be important.

The measure of school tracking used in this study posed a serious problem. School tracking was measured directiy in the Marion County Youth Study by the question "What is the major emphasis of your studies?" However, only 770 out of 1,227 adolescents responded to the question (Blake, 1973:46). The nonresponse rate could therefore present considerable difficulty in inferring the effects of school track on the youngsters. This difficulty was resolved by noting that school track was highly correlated with grade point average (Tau c $=.46$, B7ake, 1973:70). So, because of the higher response rate on $i t$, the latter item was used as a measure of the effect of educational policies on the youth. Grade point averages which were between 2.0 and 4.0 were treated as high GPA, while a GPA of 1.99 or below was classified as 
low because admissions policies would presumably prevent those youths from attending college.

\section{SOCIAL CLASS BACKGROUND}

The final area which was deemed to be theoretically important was that of the social class background of the youth. Social class was thought to manifest itself along two related dimenstions. First, it can be argued that there are class related opportunities for conventional behavior (Gordon, 1974:73). White collar parents can assist their children in gaining access to educational and occupational structures through appropriate socialization and through contacts in the area of employment. Thus youths from a middle class background will have more opportunities for prosocial behavior than their biue collar counterparts. Secondly, class background results in class related variations in the way in which parents can assist their children in attending college. With most high status occupations demanding college preparation, white collar youths have a distinct advantage over their lower class counterparts. The thrust of the argument here is that while Hirschi stated that commitment and involvement in conventional behavior are components of an investment which is risked if a youngster decided to participate in delinquent behavior, adolescents may not all have equal opportunities to make those initial investments. If the opportunities for conventional involvements and commitments are low or limited by social class, then correspondingly there should be a relation between that lack of opportunity and delinquency.

In this study, the social class background of the youngsters was measured by the occupations of their fathers. The measure of social 
class used in the Marion County Youth Study is the Hollingshead scale. This scale was modified and validated to include items which represented the wood products industry of the area because the more nationally oriented scale did not include those items which are a major source of employment in the Marion County area (Frease, 1969). In the revised scale the categories of high executive, business manager, and administrative personnel and minor professionals were classified as middle class or white collar occupations. Those who were unemployed, clerical and sales, skilled workers, semi-skilled workers, unskilled workers, farmers and loggers were classified as having low socioeconomic status or blue collar occupations.

\section{DATA PRESENTATION}

The data analysis in this study was conducted primarily through

two methods, (a) the use of percentages and (b) a nonparametric measure of the strength of association, gamma. Percentage analys is was used because it is readily interpretable as a "rate" of a characteristic. Gamma was used to summarize the data in a table as one easily interpretable figure and could also be used with ordinal data to compare tables with different numbers of rows and columns. Gamma additionally has a direct proportionate reduction of error interpretation similar to Pearson's R, but for ordinal data (Loether and McTavish, 1974: 212-214; Costner, 1965).

The interpretation of gamma is straightforward and is defined below. 
The numerical value of gamma, disregarding the sign, gives the percentage of guessing errors el iminated by using knowledge of a second variable to predict order. The sign of gamma indicates which of two possible predictions of order is more accurate: a positive sign indicates that a prediction of same order on the predicted variable, as on the predictor variable, is more accurate, while a negative sign indicates that a prediction of reverse order is more accurate. Thus, the numerical value of gamma represents the degree of association, while the sign represents the association as predominantly negative or positive. A positive sign indicates that the variables increase together, whereas a negative sign indicates that, as one variable increases, the other decreases (Mueller, Schuessler and Costner, 1970:288).

In this research, gamma was used to measure the extent to which knowledge about elements of the social bond, social class and so forth improves the ability to predict the likelihood the youth will become delinquent or to predict subsequent levels of bond over simply guessing.

Garma was employed in the partial tables to indicate the relationship between three or more variables (Loether and McTavish, 1974:299). Rosenberg's Logic of Survey Analys is (1968) provides the basic rationale for analyzing tabular multivariate data. Gamma provides a more easily interpretable summary of the content of a table than the percentage analysis used by Rosenberg. The original correlation between two variables can be compared when a third variable is introduced as a control. Changes in the strength of association then describe the influence of the third variable.

Tests of significance were not used in this research because the assumptions associated with their use were not met. The purpose of tests of significance is to provide a guide about the certainty with which inferences from a sample to a population can be made (Kerlinger, 1973). In the Marion County Youth Study, the researchers attempted to 
contact an entire population, the sophomore class, and succeeded in surveying 93 percent of it. Additionally, it would be difficult to state that the Marion County group represents a random sample of youths of counties in Oregon or the Pacific Northwest, therefore further limiting the validity of the use of tests of significance.

\section{CONCLUSION}

The methodology of this study built upon the foundation developed by Hirschi. The issues which were raised as research problems such as the relationship between bond and social class, changes in the level of bond, and the effects of structural and nonprimary group factors reflect changes which took place in the extension of the social control perspective developed in this research. The methodology which was used to investigate those research problems made certain allowances due to the weak measures of the variables and the problems of operationalizing the concepts in this research. Yet, the more dynamic model also enabled the researcher to investigate the processual nature of adolescence and delinquent behavior in a manner which Hirschi could not accomplish.

\section{DATA CONVENTIONS}

In analyzing the data it was necessary to develop a set of conventions or standards to describe the percentage differences and measures of strength of association found in the research. A conmon fallacy found in social research is the selective use and description as "strong" of relationships which support one's hypotheses, while similar relationships which are not supportive are characterized as 
"smal1," or are simply not reported. To be consistent, in this study percentage differences of less than 10 percent wi 11 be considered sma11, while differences greater than 10 percent will be considered significant. Similarly, in describing gamma, relationships of .25 or less will be considered small, while relationships stronger than .25 will be considered significant.

\section{MISSING DATA}

The number of cases on which this research was based is 307 . In examining the frequency distributions along the different variables used in the analysis, the responses of the youths could be coded as "don't know" or "did not answer." While these categories were not included in the research, it should be noted that it is possible that the nonresponse rate due to those coding categories may account for some of the percentage differences which occurred. 


\section{CHAPTER IV}

\section{LEVEL OF BOND AND DELINQUENCY, BOND AND SOCIAL CLASS, AND CHANGES IN BOND AND DEL INQUENCY}

The findings of this study are presented in two chapters. The first examines the relationships between the strength of the social bond and participation in definquent behavior and then compares them with those reported in Causes of Delinquency. Chapter IV also examines the data relating social c? ass to delinquency, along with the changes in the level of bond and delinquency. Chapter $V$ discusses explanations for the changes in the level of bond that were observed. Also, the relationships of those changes to rates of delinquent behavior, controlling for social class and grade point average, are examined.

\section{ATTACHMENT TO PARENTS}

If there is a basic foundation upon which Hirschi's statement of social control theory rests, it is upon the element of attachment. In primary group interaction, youths come to acquire both a set of skills which are important in interpersonal relations and attitudes and values toward such socially desired objectives as education and social mobility. Concern about how others evaluate one's behavior is a learned social attribute which is central to this element of bond. Youths who are concerned will not risk the reproach of others, a 
potential cost which is incurred should they participate in delinquent behavior. Hirschi stated that the result of successful parent-child interaction is the establishment of sensitivity to direct and psyciological supervision with the latter being more important. He observed that

So called direct control is not, except as a limiting case, of much substantive or theoretical importance. The important consideration is whether the parent is psychologically present when temptation to commit a crime appears. If in the situation of temptation, no thought is given to parental reaction, the child is to this extent free to comit the act (Hirschi, 1969:88).

Due to the small sample size of the present study, a dichotomous measure of attachment was used. Paralleling Hirschi's research, low levels of attachment were found to be related to delinquency (Table III). The data from the Marion County Youth Study show that 28.4 percent of the youths with low attachment in 1964 became delinquent while 17.8 percent of the high attachment boys were involved in delinquency. The percentage differences for Hirschi's data (Table IV) were greater. It can be seen that 63 percent of those males with high supervision were nondelinquents compared to none of those who were low on supervision. Similarly, 55 percent of those with low supervision committed two or more delinquent acts contrasted to only 12 percent of those with high supervision.

In order that the two studies could be compared, a measure of the strength of association was computed for the corresponding element of Hirschi's study. In Causes of Delinquency the relationship between attachment and delinquency was important and yielded a gamma of .294 while in the study reported here the comparable measure was .292. 
TABLE III

DELINQUENCY INVOLVEMENT BY LEVEL OF ATTACHMENT,
MARION COUNTY YOUTH STUDY 2

$\begin{array}{lcc} & \text { Level of Attachment (1964) } \\ \begin{array}{l}\text { Delinquent } \\ (1967)\end{array} & \text { Low } & \text { High } \\ \text { Yes } & 28.4 & 17.8 \\ \text { No } & 71.7 & 82.2 \\ \text { Total } & 100.7 & 100.0 \\ \text { N } & (127) & (146) \\ \text { Gamma }=.292 & . & \\ & \end{array}$

I am and what I am doing."

${ }^{2}$ Attachment 1964, Delinquency 1967.

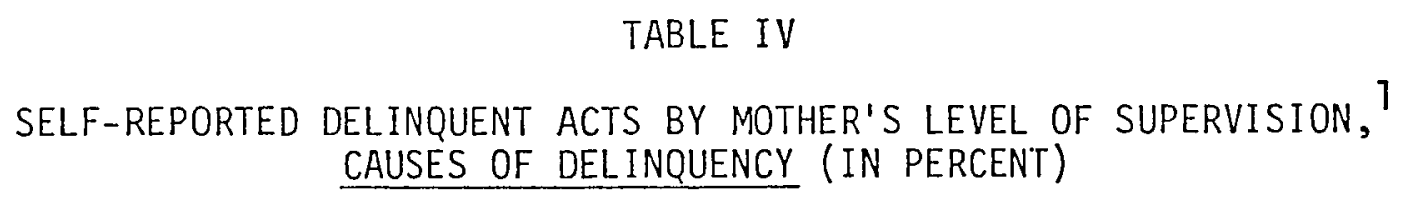

\begin{tabular}{|c|c|c|c|c|c|}
\hline \multirow{3}{*}{ Self-Reported Acts } & \multicolumn{5}{|c|}{ Mother's Level of Supervision } \\
\hline & \multicolumn{3}{|l|}{ Low } & \multicolumn{2}{|r|}{ High } \\
\hline & 0 & 1 & 2 & 3 & 4 \\
\hline Two or more & 55 & 41 & 29 & 20 & 12 \\
\hline One & 45 & 31 & 26 & 21 & 26 \\
\hline None & 0 & 28 & 45 & 59 & 63 \\
\hline Totals & 100 & 100 & 100 & 100 & 101 \\
\hline$N$ & $(110)$ & $(29)$ & $(236)$ & $(252)$ & $(698)$ \\
\hline \multicolumn{6}{|l|}{ Gamma $=.294$} \\
\hline
\end{tabular}


In the latter case, by knowing the level of attachment, error in predicting delinquency could be reduced by more than 29 percent, while it could be reduced by a similar amount with the same information in Hirschi's study. Thus these two studies were in close agreement, for both showed an inverse relation between the level of attachment and de 1 inquency.

\section{COMMITMENT TO CONVENTIONAL GOALS}

According to Hirschi, commitment directs youths toward the rewards of society and to the concommitant realization that those rewards are at risk should they engage in deviant behavior. When looking at the level of commitment of a youngster, it is important to understand how the types of activity associated with low and high commitment relate to conventional and delinquent behavior. If a youngster becomes involved extensively with a wide range of adolescent activities such as dating, drinking, smoking and driving around in a car, then he or she will be less likely to become associated with what Hirschi called thie "comnitment to conventional lines of activity" such as pursuing educational and high status occupational goals. On the other hand, many youths with a high level of commitment will defer the gratifications which are inherent in drinking and dating and so forth and instead become oriented towards valuing and achieving socially desired goals.

A fundamental characteristic of American society is that rewards are differentially distributed. Social control theory hypothesizes that educational attainment is the primary means through which the most 
desired positions in the social class structure are attained. Youths who are achievement oriented would be less likely to risk losing that goal and its attendant benefits by participating in delinquent behavior. Hirschi found a significani relationship in which those who had college aspirations were less likely to become involved in delinquency than those who did not exhibit those aspirations. In Hirschi's study, 33 percent of those who did not want to go to college became delinquent compared to 23 percent of those who wanted some college. Only 14 percent of those who wanted to graduate were delinquent. The correlation between commitment and delinquency in Hirschi's study was gamma $=.377$ (Table V). Thus error in predicting delinquency could be reduced by 37.7 percent in that study by knowledge of the youths' educational aspirations.

\section{TABLE $Y$}

OFFICIAL DELINQUENCY INVOLVEMENT BY LEVEL OF COMMITMENT, 1 CAUSES OF DELINQUENCY (IN PERCENT)

Lever of Comunitment

Low Medium High

Delinquent Less than College Some College College Graduation

Yes 33

23

14

No

67

77

86

Total

100

100

100

N

(246)

Gamma $=.377$

1

Measured by "How much schooling would you like to get eventually?" 
In marked contrast, the present research found no relationship between educational aspirations in 1964 and dleinquency (Table VI, gamma = $-.002)$. It should be noted that many youths in the Marion County Youth Study did change their minds about college attendance as they approached graduation. It is clear though that this element of the bond was not developed in early life in primary group interaction as predicted by Hirschi. Its later emergence may be related to either practices with the educational system or the youth's social class background. Regarding commitment as indexed by the decision or desire to go to college, of some considerable interest is the fact that about 75 percent of all the youngsters questioned as high school sophomores were already motivated to attend college.

\section{INVOLVEMENT IN CONVENTIONAL ACTIVITIES}

Hirschi attempted to reconcile several conflicting ideas about delinquent behavior in terms of the notion of involvement in conventional activities. Some observers of delinquency have argued that participation in activities such as recreation can operate to prevent youths from becoming delinquent. Yet, available evidence indicates that these ideas are probably naive (U.S. Department of Health, Education and Welfare, 1960:21). Hirschi cited the work of Kvaraceus and Mitler in noting:

As preventive, "keeping youth busy," whether through compulsory education, drafting for service in the armed forces, providing fun through recreating, or early employment, can, at best, only temporarily postpone behavior that is symptomatic of more deep-seated or culturally oriented factors (Hirschi, 1969:39). 
TABLE VI

DEL INQUENCY INVOLVEMENT BY LEVEL OF COMMITMENT, 1
MARION COUNTY YOUTH STUDY 2

Level of Commitment (1964)

\begin{tabular}{|c|c|c|}
\hline $\begin{array}{l}\text { Delinquent } \\
(1967)\end{array}$ & Low & High \\
\hline Yes & 23.4 & 23.7 \\
\hline No & 76.6 & 76.3 \\
\hline Total & 100.0 & 100.0 \\
\hline$N$ & (64) & (194) \\
\hline \multicolumn{3}{|c|}{ Gamma $=-.002$} \\
\hline $\begin{array}{c}1 \\
\text { Meas } \\
\text { col lege?" }\end{array}$ & by "Wha & 6 about \\
\hline
\end{tabular}

Hirschi's own arguments were considerably more complex. He went beyond the notion of incapacitation and argued that youngsters who make substantive investments toward future goals will be less likely to risk those investments by engaging in delinquent behavior. Involvement in school-related activities, such as clubs and social organizations, was of crucial importance to Hirschi's thesis. He noted that time spent on homework "... affects the student's performance in school and may operate on delinquency through its effects on attachment and commitment to school" (Hirschi, 1969:192).

Although the ranges of the amounts of time spent on homework were comparable in both studies a smaller percent of the Marion County youths were delinquent (Table VII) than those in Hirschi's study (Table VIII). 
TABLE VII PARTICIPATION IN DEL INQUENCY BY LEVEL OF INVOLVEMENT,
MARION COUNTY YOUTH STUDY ${ }^{1}$

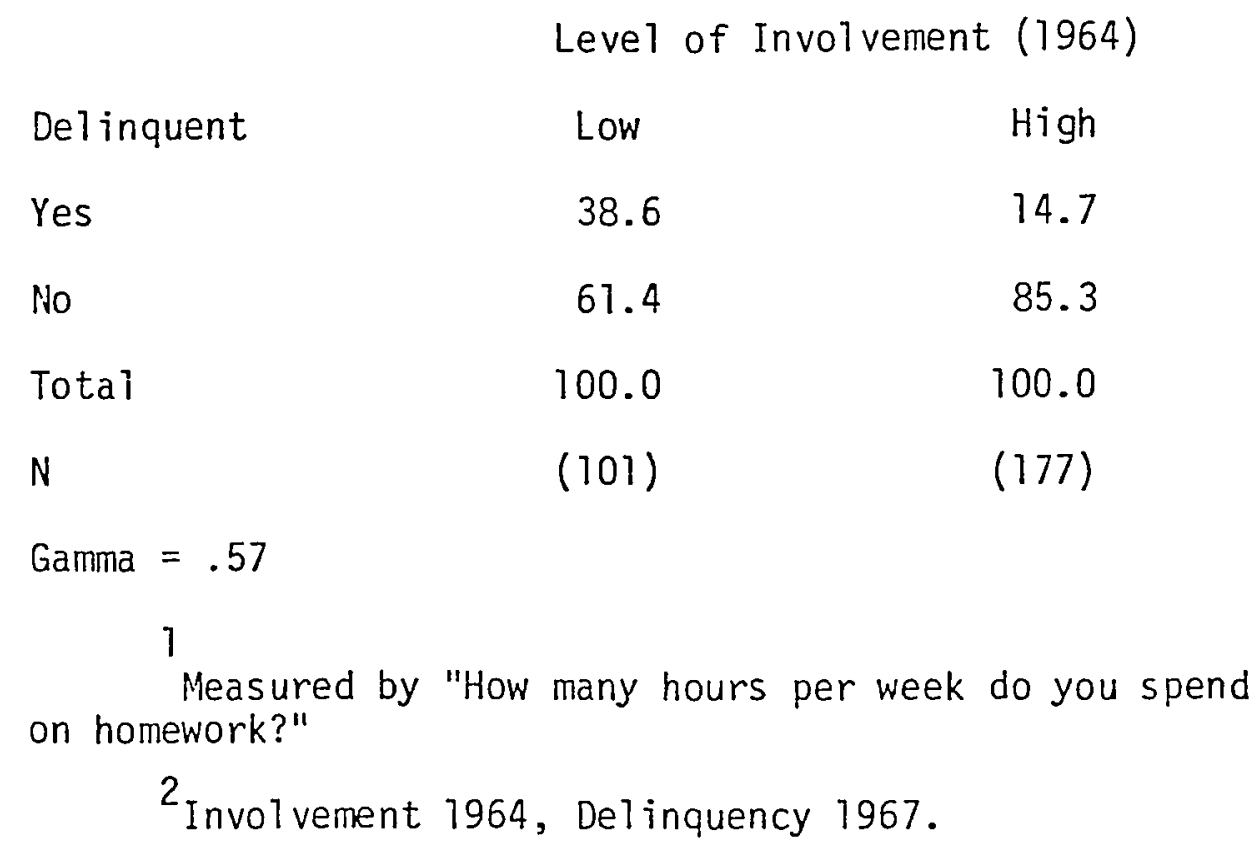

\section{TABLE VIII}

LEVEL OF SELF-REPORTED DELINQUENCY AND LEVEL OF INVOLVEMENT, CAUSES OF DELINQUENCY

Level of Involvement

Time Spent on Homework per Day

\begin{tabular}{|c|c|c|c|c|}
\hline \multirow[b]{2}{*}{ DeTinquent } & \multicolumn{2}{|l|}{ Low } & \multicolumn{2}{|r|}{ High } \\
\hline & $\begin{array}{l}\text { Less Than } \\
\text { One-Half Hour }\end{array}$ & $\begin{array}{c}\text { One-Half } \\
\text { Hour }\end{array}$ & One Hour & $\begin{array}{c}\text { One and One-Half } \\
\text { Hours or More }\end{array}$ \\
\hline Yes & 64 & 52 & 48 & 34 \\
\hline No & 36 & 48 & 52 & 64 \\
\hline Total & 100 & 100 & 100 & 100 \\
\hline $\mathrm{N}$ & (117) & (199) & $(361)$ & (593) \\
\hline
\end{tabular}


In the Marion County Youth Study, it was found that 38.6 percent of the low involvement youths were delinquent compared with 14.7 percent of the high involvement youths. In Hirschi's research, 64 percent of the males who spent less than one-half hour per day on homework were delinquent while 52 percent of those who spent one-half hour, 48 percent of those who spent one hour, and 34 percent of those who spent one and one-half hours or more on homework became delinquent.

The findings of the present study (Tabie VII) indicated that the strength of the relationship between the level of involvement and delinquency was important and stronger than the relationship obtained in Hirschi's study (gamma $=.57$ compared to gamma $=.301$ ). Knowledge of the level of involvement reduced the error in predicting delinquency by 57 percent in the Marion County Study and 30.1 percent in Hirschi's study. Thus there was a strong relation between the time students spent studying and participation in delinquency.

\section{BELIEF IN THE SOCIAL VALUE SYSTEM}

The final element of the bond is belief. Hirschi's conception of belief involved the willingness of a youth to relate his behavior to the prevailing conception of morality as reflected in the legal system. Allegiance to moral norms is acquired in the family.

The person closely attached to his parents is rewarded for conformity by approval and esteem of those he admires. If such attachments are absent, there is no reward for conformity and only weak punishments. Lack of concern for the reactions of such persons as parents is generalized as a lack of concern for the approval of persons in positions of impersonal authority. The child who does not need the love and approval of his parents will not need the love and approval of others and thus will be free to reject the normative pattern "they" attempt to impose (Hirschi, 1969:200). 
In both the present study and in Hirschi's earlier investigation, the "they" referred to are the official agents of social control in a community, principally the police. In the present study, those who agreed with the statement "From what I know, the police around here treat you fairly" were much less likely to have been involved with delinquency. In Marion County (Table IX), 38.5 percent of the youths with low levels of belief were delinquent while the corresponding figure was 27.5 percent for those with a high level. The range of percentage differences was much wider in Hirschi's study (Table $X$ ). of those who agreed with the statement "I have a lot of respect for the Richmond Police," 71 percent had committed no self-reported acts of delinguency compared to 34 percent of those who strongly disagreed. Similarly, 45 percent of those who strongly disagreed had committed two or more delinquent acts while the figure was 12 percent for those males who strongly agreed.

This research found that the relationship between belief and delinquency for Marion County youngsters was gamma $=.39$ indicating that the level of belief was important in predicting subsequent delinquency. Hirschi also found a similar relationship (gamma $=.338$, Table $X$ ) in which those who did not respect the police were most likely to show involvement in delinquency. In his study, by knowing the level of belief, error could be reduced in predicting delinquency by 33.8 percent. 
TABLE IX

LEVEL OF DELINQUENCY INVOLVEMENT BY LEVEL OF BELIEF, 1 MARION COUNTY YOUTH STUDY?

$\begin{array}{lrr}\begin{array}{l}\text { Le rinquent } \\ \text { (1967) }\end{array} & \text { Low } & \text { High } \\ \text { Yes } & 38.5 & 27.5 \\ \text { No } & 61.5 & 78.5 \\ \text { Total } & 100.0 & 100.0 \\ \text { N } & (39) & (242) \\ \text { Gamma }=.39 & & \end{array}$
$1_{\text {Measured by "From what I know the police treat }}$ you fairly."
2Belief 1967, Delinquency 1967.

TABLE $X$

LEVEL OF DELINQUENCY INVOLVEMENT BY LEVEL OF BELIEF, 1 CAUSES OF DELINQUENCY (IN PERCENT)

Level of Belief

\begin{tabular}{lccccc} 
& Low & & & High \\
Self-Reported & Sirongly & & & Strongly \\
Acts & Disagree & Disagree & Undecided & Agree & Agree \\
Two or more & 45 & 33 & 22 & 13 & 12 \\
One & 21 & 26 & 32 & 25 & 17 \\
None & 34 & 42 & 46 & 62 & 71 \\
Total & 100 & 101 & 100 & 100 & 100 \\
N & $(89)$ & $(98)$ & $(325)$ & $(496)$ & $(273)$ \\
Gamma $=.338$ & & & & & \\
\multicolumn{2}{l}{$T_{\text {Measured by }}$} & &
\end{tabular}




\section{DISCUSSION}

The purpose of the preceding section was to determine if the formulation of social control theory advanced by Hirschi could be replicated. Hirschi's conclusions were substantially supported on the basis of the strengths of association found between the elements of the bond and delinquency in the Marion County Youth Study data.

The research findings of the present study were not consistent with those of Hirschi in one area. He found that committed youths, that is, those who wanted to go to college, were less likely to become delinquent, while no such relationship emerged in this study. Given the hypothesized correlation in social control theory between commitment to higher education and involvement as measured by time spent on homework, the failure of the association to emerge is especialty serious. One possible explanation for this failure relates to the fact that in Hirschi's study the sample consisted of high school juniors and seniors, while in Marion County, the sample was first surveyed when the youths were sophomores. The attitudes of sophomores about attending college might not have yet crystallized to produce a bond effect. It may well be that Hirschi's contention that the element of commitment is formed in the family is correct. But, if so, attention should be directed as to why commitment emerges relatively late while the youth is in high school and possibly in response to the decision to prepare for an adult career. Perhaps many youngsters form solid intentions to attend college only during the last two years of high school. Since this study looked at the youths 
first as sophomores and later as seniors, it was possible to determine if increases in the level of commitment occurred as youngsters approached graduation. Findings to be examined in the next chapter indicated that those changes did in fact occur.

SOCIAL CLASS IN RELATION TO SOCIAL BOND AND DELINQUENCY INVOLVEMENT

Social ciass was not considered to be an important explanatory factor in Causes of Delinquency. Hirschi presented evidence which indicated that there was little or no relationship between social ciass and delinquency (Table XI, gamma $=.051$ ). He concluded that:

The percentage differences and/or number of cases in extreme categories are, however, so sma11, in fact, that we need not control social class in subsequent analys is (Hirschi, 1969:75).

The present study used officially reported delinquency as a basis for examining the relationship between social class and delinquency and an important association was found (Table XII, gamma $=.313$ ), indicating that knowledge of the youngster's social class would reduce error in predicting subsequent delinquency by more than 31 percent. In Marion county the percentage differences between white and blue collar youths was significant. It was found that 18.1 percent of the white collar youths were adjudicated delinnuent while the corresponding figure for the blue collar youths was 29.7 percent. The relationship between social class and delinquency in this study parallels the conclusions of other research (Wolfgang, Figlio and Sellin, 1972). 
TABLE XI

LEVEL OF SELF-REPORTED DELINQUENT ACTS BY OCCUPATION OF FATHER (IN PERCENT), CAUSES OF DELINQUENCY

\begin{tabular}{|c|c|c|c|c|c|}
\hline \multirow[b]{3}{*}{ Self-Reported Acts } & \multicolumn{5}{|c|}{ Father's 0ccupation? } \\
\hline & Lon & & & & High \\
\hline & 1 & 2 & 3 & 4 & 5 \\
\hline Two or More & 23 & 21 & 19 & 23 & 14 \\
\hline One & 16 & 26 & 25 & 28 & 25 \\
\hline None & 62 & 53 & 56 & 49 & 61 \\
\hline Totals & 101 & 100 & 100 & 100 & 100 \\
\hline Gamma $=.057$ & & & & & \\
\hline
\end{tabular}

TABLE XII

DELINQUENCY INVOLVEMENT BY FATHER'S SOCIOECONOMIC STATUS, 1 MARION COUNTY YOUTH STUDY

Father's Socioeconomic Status

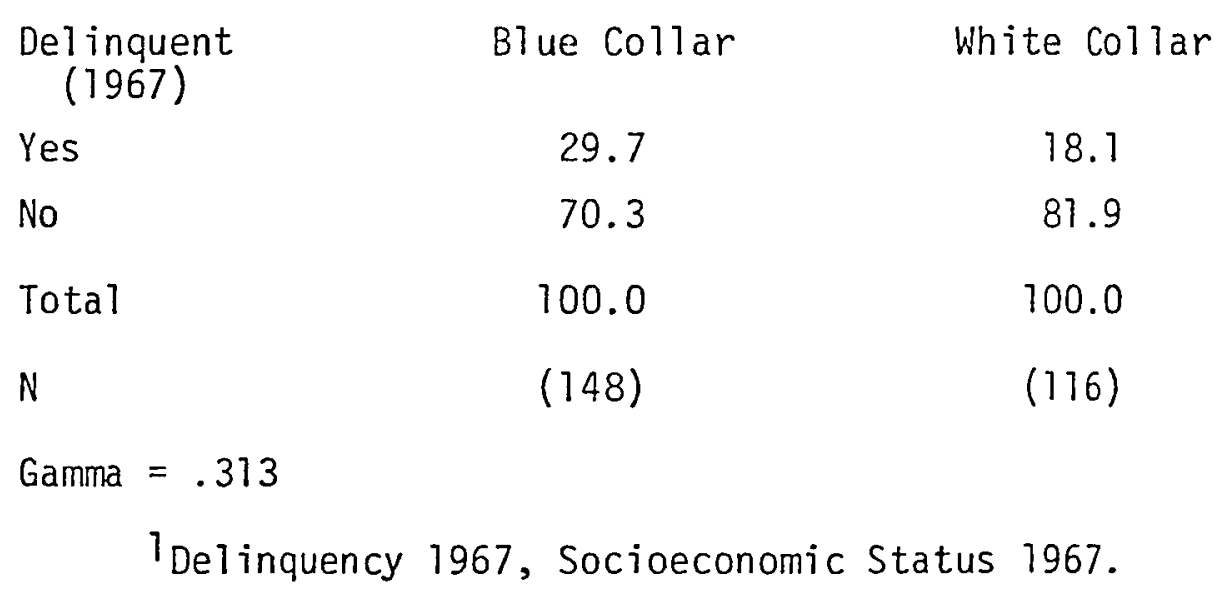


SOCIAL CLASS AND BOND

Hirschi stated that there was no relationship between social class and the elements of the bond. He argued that while variation in bond exists within social classes, variations between classes do not exist. The relationship between social class and social bond was investigated in this study. The evidence supported a version of social control theory located within a social structural perspective. The data from this research indicated that some elements of the bond are related to social class and certain others are not, although the scope of this part of the research was narrow and the results should be interpreted cautiously. Attachment and belief were not strongly related to social class (Table XIII, gamma $=.13$ and Table XIV, gamma $=.18$, respectively) as reflected in the small percentage differences for those elements of the bond. For attachment, 50.7 percent of the blue collar group was classified as low on attachment, while 44.1 percent of the white collar group was low on this dimension. The remainder of each group was high on attachment. Similarly 15.6 percent of the blue collar group was low on belief while the corresponding figure for the white collar group was 11.4 percent. Thus knowledge of social class position would reduce the Error by only 13 percent in predicting the levels of attachment and by 18 percent for the level of belief.

These findings are important in several ways. First, they offer little support for the contention that lower class families raise their children differently than middle class families along these 
TABLE XIII

FATHER'S SOCIOECONOMIC STATUS AND LEVEL OF ATTACHMENT, 1
MARION COUNTY YOUTH STUDY 2

Socioeconomic Status

Level of Attachment

Blue Collar White Collar (1964)

Low

50.7

44.7

High

49.3

55.9

Total

100.0

100.0

N

(142)

(111)

Gamma $=.13$

$1^{1}$ Attachment measured by "My parents usually know where I am and what I am doing."

2 Attachment 1964, Socioeconomic Status 1967.

\section{TABLE XIV}

FATHER'S SOCIOECONOMIC STATUS AND LEVEL OF BELIEF,
MARION COUNTY YOUTH STUDY2

Socioeconomic Status

Level of Belief

Blue Collar White Collar

Low

15.6

11.4

High

84.4

88.6

Total

100.0

100.0

N

Gamma $=.18$

1 Belief measured by "From what I know the police treat you fairly."

${ }^{2}$ Bel ief 1967, Socioeconomic Status 1967. 
two dimensions investigated in this study. Secondly, the lack of a relationship between social class and belief suggests that there is equal support throughout the social class structure for the moral validity of the social value system and that a separate lower class value system, as subcultural theorists would propose, does not exist, at least along these two dimensions tapped in this study.

A strong relationship was observed between commitment and social class and involvement and social class. The findings indicate that a large proportion of youths from white collar backgrounds wanted to go to college than did those youngsters from the working class (Table XV, gamma $=.53$ ) and they were more likely to study than their blue collar counterparts (Table XVI, gamma $=.41$ ). Knowledge of social class thus reduced the error in predicting the level of commitment and involvement by 53 and 41 percent respectively. The percentage differences between the classes were also found to be important. Of the blue collar males, 33.1 percent had a low level of commitment while 13.2 percent of the white collar youngsters were clussified in the low group. The percentage differences were equally significant for involvement, with 44.1 percent of the working class adolescents low on involvement while only 24.8 percent of the working class adolescents were deemed to be low in this dimension.

A question which might be asked is whether these findings indicate that class-related variations exist due to class differences in socialization or whether they simply reflect the realities of the respective positions of the groups in the class structure. Perhaps the relationship between involvement and commitment and social class 


\section{TABLE XV}

FATHER'S SOCIOECONOMIC STATUS AND LEVEL OF COMMITMENT,
MARION COUNTY YOUTH STUDY2

Socioeconomic Status

Level of Commitment

Low

High

Total

N

Gamma $=.53$

${ }^{7}$ Commitment measured by "What do you think about going to college?"

${ }^{2}$ Commitment 1964, Socioeconomic Status 1967.

TABLE XVI

FATHER'S SOCIOECONOMIC STATUS AND LEVEL OF INVOLVEMENT, 1 MARION COUNTY YOUTH STUDY ${ }^{2}$

Socioeconomic Status

Level of Involvement

Low

Bive Collar

44.1

White Collar

High

55.9

24.8

Total

100.0

(145)

Gamma $=.41$

${ }^{1}$ Involvement measured by "How many hours per week do you spend on homework?"

${ }^{2}$ Invorvement 1964, Socioeconomic Status 1967. 
arises not because white collar parents value education more, but simply because they have the financial resources to assist their children in pursuing higher education as a means of social mobility. Conversely, youths from the lower class may be compelled to make an early decision about their careers and realistically do not view school as a means of obtaining a good job. They may reatize that they will have to choose from a selection of unskilled and semiskilled jobs which require neither college nor extensive high school level preparation. There is little point to homework if there is little likelihood that one will attend college or otherwise have the chance of achieving a high status occupation.

The person who would reconcile social-psychological and social structural theories of delinquent behavior is confronted with the issue of college attendance and social mobility and why it is that white collar youths more frequently want to go to college than do blue collar youths. It could be argued that middle class youths are more likely to be college material because of the attitudes of their parents being transmitted to them while blue collar parents do not value education to the same extent. But, there is another explanation as well. Anderson has noted that

.. the probability of low socioeconomic-level high school students in the second-from-the-top ability quartile of going to college is less than that of high-socioeconomic students in the lowest ability quartile (Anderson, 1975:140).

Thus, it may be that the attitudes toward attending college reflect the realities of the respective class positions. If social class is a factor, then it is only because youths do not have the resources to 
pursue their educations. In either case, social class works to restrict the access of qualified youths to higher status positions in the ciass structure.

\section{CHANGES IN THE BOND}

The next part of this study involved an examination of the relation of the elements of the bond to each other at two points in time and to subsequent delinquency involvement. The analysis differed from Hirschi's formulation of social control theory in which the level of bond was treated as a stable social-psychological characteristic which represented the strength of a person's relationship to the social system. His study failed to address the processual nature of adolescence in which the educational system and a hierarchicallyshaped social class structure may alter the level of social bond that was initially formed in the family environment. In this section, information will be presented regarding the level of bond at two points in teme and delinqeunet behavior, with the exception of belief for which information in 1964 could not be obtained.

The reformulation of social control theory that informed this research endeavor conceded that initial social-psychological characteristics are important, but that in adolescence, forces in the educational system and the class structure work differentially to facilitate entry into the occupational and social structure while effectively blocking entry for others.

The theoretical position of this thesis differs from Hirschi's treatment of the effects of the educational system and the social 
class structure which were viewed as being essentially benign; that is to say, he held that doing poorly in school or coming from a lower class background can cause the youth no harm. His discussion of the role of education centered upon the adjustment which youths of differing abilities make toward school. Those youths who have a low grade point average (GPA) but who feel that they are performing to the best of their abilities are less likely to be delinquent than those who are not doing well or who do not like school (Hirschi, 1969:131). In contrast, it was argued in this study that practices such as ability grouping, tracking and grading are equally important in determining the "adjustments" which the youngsters make and therefore how well or poorly they do in school. Grading was used as a measure of the reaction of the school and society toward the individual in that the "rewards" associated with school are denied low GPA youths and so, too, are the opportunities to move to more advanced training and establish investments in conventional behavior. As Hirschi observed, there is a strong relationship between investments in conventional behavior and nonparticipation in delinquency. Therefore, the closing of those options via grading policies must be examined closely in terms of the associated costs of increased delinquency involvement.

Several authors (Gintis and BowTes, 1976; Rosenbaum, 1976) have noted that the educational system may act not only as an agent of socialization but also as a "gate keeper" which regulates entry into the university level educational system and high status adult roles. These authors observed that there is little support for the argument that "ability" as measured by intelligence tests is related to 
achieved social class position. Thus the practices of grading may be serving purposes other than the efficient allocation of scarce human resources.

Gintis and Bowles (1976) contended that social class rather than grade point average is a strong predictor of achieved social class position. This claim stands in contrast to the arguments that social roles are allocated on the basis of ability. An explanation of this phenomenon is that white collar parents perpetuate their children's class position primarity through the financial resources which are available to educate their children. The expanded social control analys is presented in this study paralleled that of Gintis and Bowles (1976) and Rosenbaum (1976). Lower class youths who have ability equal to that of their white collar counterparts are not as likely to be able to go to college; thus it is logical that they would be less involved with high school and more likely to become delinquent. Accordingly, social class should be examined as a factor which may produce changes in the initial level of bond.

Among those from a white collar as opposed to a blue collar background, success or failure in school should result in differentials in delinquency involvement. Youths who are low on social bond and who come from a blue collar background or who are failures in school should have the highest rates of delinquent behavior because of their limited ability to make investments in their future career. Next should be those youths whose levels of bond were initially high but who later came to experience school failure or whose social class background precludes their going to college. Their initially high 
levels of bond should serve, somewhat, to prevent them from participating in delinquent behavior. However, that effect should decrease with unsuccessful school experiences or if their lower class background deprives them of access to opportunities, making "drift" into delinquency more likely. Delinquency rates should be next to the lowest for those whose level of bond was initially low but which increased. Finally, the rates should be lowest for those whose level of bond was consistently high and who did well in school and/or who came from white collar backgrounds.

The data on bond elements reveal a considerable number of changes in individual levers of bond between the two time periods of this study. Thus the research which depicts social-psychological characteristics of individuals as unchanging once they are established through early socialization may not be valid in their basic assumptions about the nature of those personality characteristics.

In the following sections, two matters are discussed. The first involves a description of the changes in the level of bond and is interiwined with the second, a discussion of the relationship of those changes to delinquency involvement.

\section{CHANGES IN ATTACHMENT}

In 1964, of the 284 youths for whom responses could be obtained, 46.5 percent were classified as having low attachment, while 53.5 percent showed high attachment. In 1967 (Table XVII), of those who were initially low, 66.9 percent remained so, while the remainder increased from low to high. For the 146 who were initially classified as high, 
TABLE XVII

CHANGES IN LEVEL OF ATTACHMENT FROM 1964 TO $1967^{1}$

Level of Attachment (1964)

Level of Attachment (1967)

Low High

Low

66.9

37.0

High

33.1

63.0

Total

100.0

100.0

N

Gamma $=.55$

7 Measured in 1964 and 1967 by "My parents usually know where I am and what I am doing."

63 percent remained high while 37 percent decreased. The relationship between the level of attachment in 1964 and 1967 was gamma $=.55$ which means that knowledge of the level of attachment in 1964 reduced the error in predicting subsequent attachment by only 55 percent. While this is a strong relationship according to the criteria set earlier, it would be expected under Hirschi's version of social control theory that this coefficient would be considerably higher, that bond in 1964 would be an excellent indicator of bond in 1967 . Yet this was not the case as bond level changed in a large number of cases. Thus, approximately one third of the youths in each group experienced changes in the level of social bond indicating that the level of attachment was not always stable.

The patterns of attachment and delinquency rates were generally in the directions predicted (Table XVIII). Rates in 1967 were highest 
for those whose lever of bond was consistently low (36.5 percent) and next highest (24.1 percent) for those whose level fell from high to low. The remaining rates were only marginally different. They were lowest (11.9 percent) for those whose level of attachment rose from low to high and next to lowest for those whose level remained high (14.1 percent). This pattern would suggest that those who came to be attached to the social system later in adolescence must have formed a relationship to society that was very strong, as far as insulation against delinquency is concerned.

In examining the detailed data showing changes in the level of attachment and delinquency (Table XVIII) for the different analysis groups, it should be noted that the overall relationship between attachment in 1967 and delinquency was gamma $=.52$ (Table XLI, Appendix). Table XVIII indicates that for those whose level of bond was low in 1964, the likelihood of delinquency involvement increased as knowledge of the level attachment in 1967 reduced error in predicting delinquency by 61.8 percent. For those whose level of attachment was high in 1964, knowledge of the level of attachment did not reduce the error comparably to those who were initially low. Indeed, the findings for this group provided some 20 percent less information than in the zero-order relationship indicating that the relationship between delinquency involvement and later atiachment was weaker if the level of bond was initialiy high. 
TABLE XVIII

DELINQUENCY INVOLVEMENT BY INITIAL (1964) AND SUBSEQUENT (1967) LEVEL OF ATTACHMENT'

Low Initial Attachment (1964)

Subsequent Attachment (1967)

$\begin{array}{lrrr}\text { Delinquent. } & \text { Low } & \text { High } & \text { Total } \\ \text { Yes } & 36.5 & 11.9 & 28.4 \\ \text { No } & 63.5 & 88.1 & 71.7 \\ \text { Total } & 100.0 & 100.0 & 100.0 \\ \text { N } & (85) & (42) & (127) \\ \text { Total } & 66.9 & 33.1 & 100.0\end{array}$

High Initial Attachment (1964)

Subsequent Attachment (1967)

Del inquent

Yes

No

Total

N

Total

Gamma $=.316$
Low High Total

$\begin{array}{lll}24.1 & 14.1 & 17.8\end{array}$

$\begin{array}{lll}75.9 & 85.9 & 82.2\end{array}$

$\begin{array}{lll}100.0 & 100.0 & 100.0\end{array}$

$\begin{array}{lll}(54) \quad(92) & \text { (146) }\end{array}$

$\begin{array}{lll}37.0 & 63.0 & 100.0\end{array}$

Gamma $=.618$

1

Measured in 1964 and 1967 by "My parents usualiy know where I am and what I am doing." 
Commitment level in 1964 was much more strongly predictive of subsequent commitment in 1967 (gamma $=.91$ ) than was the case with attachment for these two periods. For the 64 youths who, in 1964, were not planning to attend college (Table XIX), responses could be obtained for 61 of them. Of these youngsters, 80.3 percent still said that they were not going to attend college. Of the 194 youths polled in 1964 who planned to attend college. 84 percent of the 187 responding in 1967 indicated that they were going to attend college. It is interesting to note that almost 20 percent of those who were initially low on commitment later showed an increase on this dimension, while 16 percent of those whose level of bond was initially high showed a decrease, indicating that for relatively large numbers of each group, changes in this element of the bond did take place.

\section{TABLE XIX}

CHANGES IN LEVEL OF COMMITMENT FROM 1964 TO $1967^{1}$

Lever of Commitment (1964)

Lever of Commitment (1967)

Low

High

Total

N

Gamma $=.91$

${ }^{1}$ Measured in 1964 by "What do you think about going to college" and in 1967 by "I expect to go to college." 
The pattern of the delinquency rates which emerged was only partially in the direction predicted (Table XX). Delinquency rates were next to the lowest for those whose level of bond was high in both time periods (20.4 percent), but the rate was highest (40 percent) for those youths who, as they approached graduation, were not going to attend college although they had once planned to do so. The rates for the latter group were even higher than for those who were low on commitment in 1964 and 1967 (26.5 percent). This finding may indicate that those whose level of bond remained low had more or less resigned themselves to a situation where their life options would be limited by their lack of education. In contrast, those youths who had once appeared to be actively competing for higher social status positions were now confronted with a situation in which their life aspirations were broken. Since education is a prerequisite for most high status occupations, these youths may have been suddenly placed in a position where their opportunity to make investments in conventional patterns of behavior had become increasingly difficult. . With relatively little to lose, increased participation in delinquency becomes a viable alternative.

The process described here appears nore plausible than simply reversing the causal argument and speculating that delinquency leads to a decline in commitment. Involvement in delinquency, in and of itself, would not prevent a youth from wanting to go to college. In contrast, if a youngster had not developed an inclination toward attending college or gave up such plans, there would seem to be little which would keep him or her from becoming delinquent. Finally, it 
TABLE XX

DELINQUENCY INVOLVEMENT BY INITIAL (1964) AND SUBSEQUENT (1967) LEVEL OF COMMITMENT ${ }^{\text {' }}$

Low Initial Commitment (1964)

Subsequent Commitment (1967)

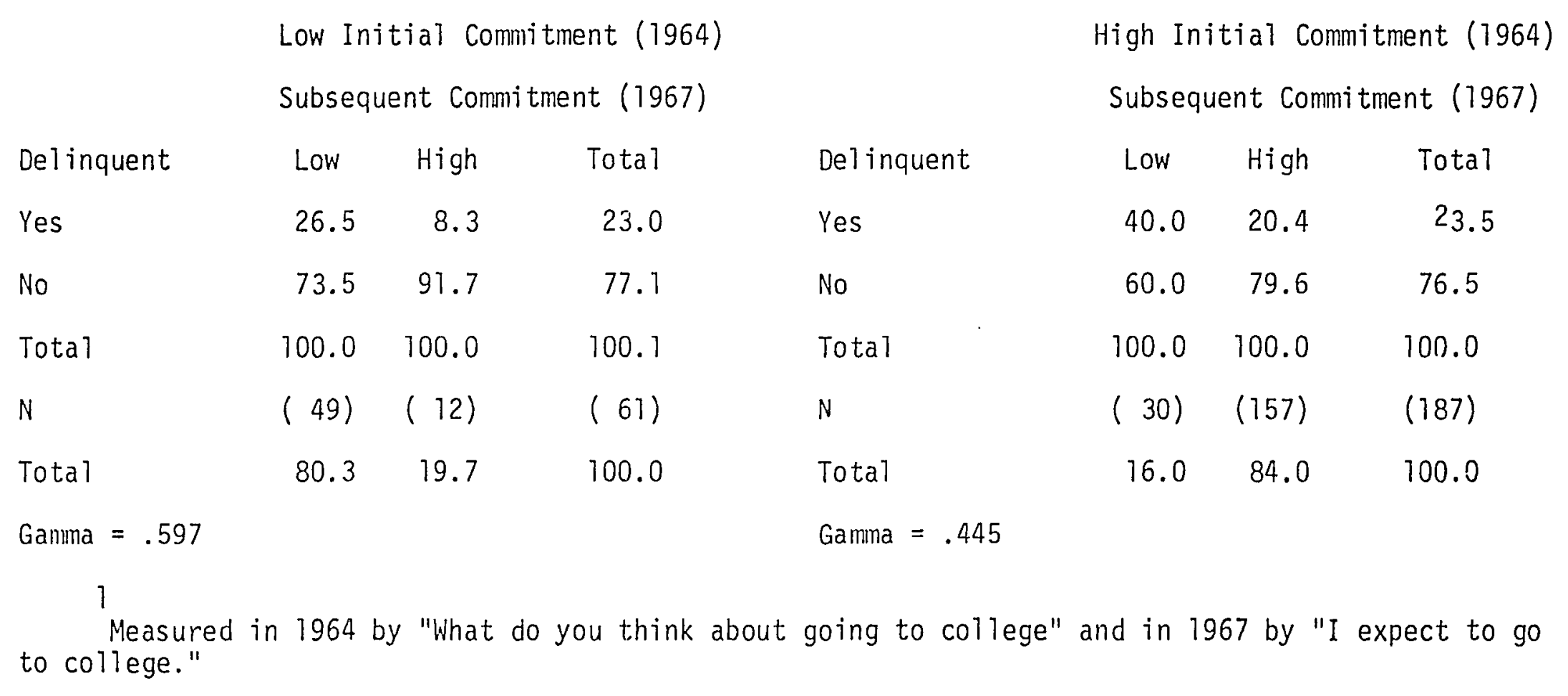

High Initial Commitment (1964)

Subsequent Commitment (1967) 
should be noted that while the number of individuals was small, of the 12 youths who were initially low in their level of bond in 1964, only one of them became delinquent. This was in marked contrast to the Targe difference compared to the rate for the group which consistently remained high on commitment.

The pattern observed in the discussion of changes in attachment also generally emerged for commitment. The relationship between the level of commitment in 1967 and delinquency was significant (gamma = .25, Table XLII, Appendix). In both cases, in the first order relationships, knowledge of the initial level of bond in 1964 provides better predictability of subsequent delinquency than simply knowing the level of bond in 1967. For the group that was initially low on commitment in 1964, error was reduced by almost 60 percent (gamma $=$ .597), while for the group which was initially high, delinquency was also more predictable, although the error, in contrast, was reduced by 44.5 percent (gamma $=.445)$.

\section{CHANGES IN INVOLVEMENT}

As with the other elements of the bond for which an analysis of changes could be made, the instability of involvement is also worth noting: 48.7 percent of the 78 youths who were low on the measure in 1964 were classified as high in 1967 (TabTe XXI). Conversely, 12.7 perceni of the 165 males who showed high scores in 1964 experienced a decieased level of involvement. It is interesting to note that five out of every ten boys who were originally low on commitment increased their participation in school as they approached graduation. 
TABLE XXI

CHANGES IN LEVEL OF INVOLVEMENT FROM 1964 TO $1967^{1}$

Lever of Involvement (1964)

Level of Involvement (1967)

Low

$\mathrm{High}$

Total

Gamma $=.756$
Low

51.3

48.7

100.0

$N=78$
High

12.7

87.3

100.0

165

1

Measured in 1964 and 1967 by number of hours

per week spent on homework.

This finding is consistent with the arguments developed in this study which view adolescence and the high school experience as preparing youths for adult social roles. Thus the adolescents who were initially high on involvement tended to remain at that level, while those who were low were more likely to increase the amount of time spent on homework. The level of the gamma (.756) indicates that the initial level of involvement was strongly related to subsequent involvement, but even so there was a large shift among those who were initially low. The effect of the increased involvement in homework among those who were initially low in 1964 on this measure was reflected in the rates of delinquency (Table XXII). While 50 percent of those who were consistently low became delinquent, the rate was 23.7 percent among those who went from low to high commitment, while the rate was 11.8 percent for those who remained high. The rate among those who fell from high to 10 was 28.6 percent indicating that the effects of the 
TABLE XXII

DELINQUENCY INVOLVEMEN:- BY INITIAL (1964) AND SUBSEQUENT (1967) LEVEL INVOLVEMENT ${ }^{1}$

\begin{tabular}{|c|c|c|c|c|c|c|c|}
\hline \multicolumn{5}{|c|}{ Low Initial Involyement (1964) } & \multicolumn{3}{|c|}{ High Initial Involvement (1964) } \\
\hline & Subsequ & t Invol & nt $(196$ & & Subseq & t Invol & nt (1967) \\
\hline Delinquent & Low & High & Total & Del inquent & Low & High & Total \\
\hline Yes & 50.0 & 23.7 & 37.2 & Yes & 28.6 & 11.8 & 13.9 \\
\hline No & 50.0 & 76.3 & 62.8 & No & 71.4 & 88.2 & 86.7 \\
\hline Total & 100.0 & 100.0 & 100.0 & Total & 100.0 & 100.0 & 100.0 \\
\hline N & $(40)$ & $(38)$ & $(78)$ & $\mathrm{N}$ & $(27)$ & $(144)$ & $(165)$ \\
\hline Total & 51.3 & 48.7 & 100.0 & Total & 12.7 & 87.3 & 100.0 \\
\hline Gamma $=.526$ & & & & Gamma $=.498$ & & & \\
\hline
\end{tabular}


attenuated bond manifested themselves in increased level of delinquency participation. Their rates, however, were lower than those who had consistentiy weak levels of involvement.

Involvement was strongly associated with delinquency in 1967 (Table XLIII, Appendix, gamma $=.67$ ). But differently than in the case of attachment and commitment, knowledge of the level of involvement in 1964 did not improve the predictability of delinquency. For those who were low on involvement in 1964, knowing the level of involvement in 1967 reduced the error in predicting subsequent delinquency by 52.6 percent (gamma $=.526$ ) while for the high group in 1964, error was reduced by almost 50 percent (gamma $=.498)$. Thus knowledge of the initial level of bond was not important in improving the predictability of delinquency.

\section{SUMMARY}

The first portion of this chapter reported upon a replication of Hirschi's research which related the level of bond to del inquency involvement. This study demonstrated substantial support for Hirschi's theory. Next, it was argued Hirschi's model failed to capture the processual nature of adolescence. Departure from the family milieu and entrance into another environment where structural factors predominate may affect the initial levels of bond formed by the youth. When the level of bond was examined at two points in time, it was found that the assumption that it is a fixed social-psychological attribute did not seem accurate. 
Third, the need was shown for a model more complex than that employed in Hirschi's analysis. Attitudes about self-control (attachment) and the social value system (belief) were not class-related, while attitudes toward access to the social class structure were strongly class-related. Accordingly, it appears that all classes of society may subscribe equally to the thesis that social behavior should be governed by the principles of social reciprocity and they hold allegiance to a single social value systme. On the other hand, white collar youths seem more lik y to believe in both social mobility and the socially prescribed means for obtaining that mobility than do blue collar youths.

Finally, two aspects about the behavior of the social bond over time were revealed. The relationship of the individual to society was found to be very dynamic. That is to say, the social affiliation of some persons was found to fluctuate or change, while for others it remained stable. Secondly, the amount of change and stability for the different analysis groups was reflected by the variation in the delinquency rates. With the exceptions noted in the main text, the rates were highest for those whose bond was consistently low, next to highest for those whose level of bond fell from high to low, next to lowest for those whose bond rose from low to high and lowest for those who remained consistently high on social bond. 


\section{CHAPTER V}

\section{EXPLAINING CHANGES IN THE LEVEL OF BOND}

This chapter is concerned with the relationship between changes in the level of social bond, social class position, and educational achievement. Changes in bond levels have already been shown in Chapter IV to be related to delinquency. The purpose of the analys is in this chapter is to uncover the factors that are linked to changes in bond levels.

The theoretical position being advanced here has already been outlined. Differences in social class and school experiences may alter the initial level of social bond formed in primary group interaction. Those who come from a white collar background or who attained a high grade point average should be most likely to increase the level of bond if it was initially low or show little change if the level of bond was initially high. Those who come from a working class backgroung or who are doing poorly in school should be most likely to decrease in the level of bond if it was initially high or exhibit little change if it was initially low. Those general hypotheses are reviewed below:

1. Youths from white collar backgrounds will be less likely to show a decline in the level of bond if it was initially high and will be more likely to show an increase if it was initially low than their working class counterparts. 
2. Youths with a high grade point average will be less likely to show a decline in the level of bond if it was initially high and will be more likely to show an increase if it was initially low than their lower GPA counterparts.

The reader should note that in the following partial tables the youths initially shared the same level of bond. Attention should then be directed at the effects of social class and grade point average on subsequent change or ability in the initial level of bond.

\section{CHANGES IN ATTACHMENT}

It will be recalled that 66.9 percent of those who were initially low on attachment remained low in 1967, while 33.1 percent changed on bond level (Table XVII). For those youths who were initially high, 37 percent were low in 1967, while the remainder exhibited an unchanged level. The effects of social class were smal1, though in the direction which was predicted. It can be seen in Table XXIII that of those who were initially low on attachment, 72.2 percent of those from blue collar backgrounds remained so, while among those from white collar backgrounds, 59.2 percent remained unchanged. In each group the remainder increase their level of bond, indicating that those from a working class background were more likely to remain low on attachment inan their middle class counterparts. For those who were initially aigh on attachment, more than a third experienced a decrease in their level of bond, but the differences between social classes were small. 
TABLE XXIII

INITTIAL (1964) AND SUBSEQUENT (1967) LEVEL OF ATTACHMENT AND SOCIAL CLASS ${ }^{\top}$

Low Economic Status

Initial Attachment (1964)

Subsequent

Attachment (1967)

Low

High

Total

$N$

Total

Gamma $=.647$
High Socioeconomic Status

Initial Attachment (1964)

Subsequent

Attachment (1967) Low High Total

Low

$\begin{array}{lll}59.2 & 38.7 \quad 47.8\end{array}$

$\begin{array}{lll}40.8 & 61.3 & 52.3\end{array}$

$100.0 \quad 100.0^{\circ} \quad 100.1$

$(49) \quad(62) \quad(111)$

$\begin{array}{lll}44.1 & 55.9 & 100.0\end{array}$
Total

N

Tota 1

Gamma $=.393$

1 lleasured in 1964 and 1967 by "My parents usually know where I am and what I am doing." 
In the partial tables the original the gamma $=.55$ between initial and subsequent attachment (Table XVII) increased to gamma $=.647$ for blue collar youths and decreased to gama $=.323$ for the white collar adolescents. This pattern indicates that for the bive collar youths, knowledge of the initial level of bond increased the ability to predict subsequent attachment by 9.4 percent, while for the white collar males, the relationship was not as strong demonstrating they were more likely to change than level of bond. What this means, translated into nonstatistical terms is that social class tends to keep more lower class youngsters low on social bond, while a larger proportion of the middle class youths changed from low to high on attachment.

The effects of grade point average on those who were initially low on attachment were small, but consistently in the predicted directions. Of those who were initially low and who had a low grade point average, 76.8 percent remained low, while for those with a high grade point average only 50 percent remained low on attachment. This indicates that there is a significant relationship between the youths doing well in school and subsequent increases in the level of attachment (Tabie XXIV).

School success appears to be option-opening and to raise bond levels, while school failure operates to reinforce an initial low level of bond. The youngsters who were doing poorly in school were almost twice as likely (gamma $=.674$ ) to remain at their initial level of bond as those who were doing well in school (gamma $=.323$ ). In summary, partial support exists for the hypotheses of this study. For those with initially low attachment, educational success 
TABLE XXIV

INITIAL (1964) AND SUBS EQUENT (1967) LEVEL OF ATTACHMENT AND GRADE POINT AVERAGE

Low Grade Point Average
Initial Attachment (1964)

Subsequent

Attachment (196\%)

Low

High

Total

N

Total

Gamma $=.674$

$\begin{array}{lll}76.8 & 39.2 & 59.0\end{array}$

23.26018

$100.0 \quad 100.0 \quad 100.0$
High Grade Point Average

Initial Attachment (1964)

Subsequent

Attachment (1967) Low High Total

Low

$\begin{array}{lll}50.0 & 33.8 & 40.0\end{array}$

$41.0 \quad$ High

Total

$50.0 \quad 66.2 \quad 60.0$

(82) (74) (156) N

(82) (74) (156) N

$100.0 \quad 100.0 \quad 100.0$

$\begin{array}{llll}52.6 & 47.4 & 100.0 & \text { Tota }\end{array}$

$(44) \quad(71) \quad(115)$

$\begin{array}{lll}38.3 & 61.7 & 100.0\end{array}$

Gamma $=.323$

1

Measured in 1964 and 1967 by "My parents usualiy know where I am and what I am doing." 
and a white collar background were related to small increases in the level of attachment, as predicted. For those whose level of attachment was initially high, the influences of class and grade point average were lass marked as evidenced by the minor changes in the levels of attachment. The effects of grade point average on those who were initially low in attachment are particularly important, suggesting that policies in the school system which encourage success have potentially significant effects on those who dod not have strong ties to relevant others. Success in school apparently operates to bring some youths into conformity with society. These data suggest that with doing well in school being related to an increase in attachment there is a very large social cost associated with the practice of faiting students in school. The opportunity to bind to society those students whose "social" attachment might otherwise be gained is lost.

\section{CHANGES IN COMMITMENT}

The revel of commitment in 1954 was a strong predictor of subsequent commitment (Table XVIII, gamma $=.91$ ). Nonetheless, while 80.3 percent of those who were initially low remained low, one out of every five students increased their commitment to society. Similarly, one out of six (16 percent) of those who were high decreased their level of commitment to low in 1967.

Social class had little effect on those whose level of cominiment was initially low (Table XXV). This finding indicates that while the level of commitment was subject to change, the zero order rates were not affected by socioeconomic status. The gammas in the partial 
TABLE XXV

INITIAL (1964) AND SUBSEQUENT (1967) LEVELS OF COMMITMENT AND SOCIOECONOMIC STATUS ${ }^{1}$

\begin{tabular}{|c|c|c|c|c|c|c|c|}
\hline \multirow[b]{3}{*}{$\begin{array}{l}\text { Subsequent } \\
\text { Commitment (1967) }\end{array}$} & \multicolumn{3}{|c|}{ Low Socioeconomic Status } & \multicolumn{4}{|c|}{ High Scoioeconomic Status } \\
\hline & Initia & Commit & $t(1964)$ & & Initia & Commit & $t(1964)$ \\
\hline & Low & High & Total & $\begin{array}{l}\text { Subsequent } \\
\text { Commitment (1967) }\end{array}$ & Low & High & Tota 1 \\
\hline Low & 87.4 & 20.7 & 40.8 & Low & 76.9 & 17.7 & 19.4 \\
\hline $\mathrm{High}$ & 18.6 & 79.3 & 59.2 & High & 23.1 & 88.9 & 80.6 \\
\hline Total & 100.0 & 100.0 & 100.0 & Total & 100.0 & 100.0 & 100.0 \\
\hline N & $(43)$ & $(87)$ & $(130)$ & $N$ & $(13)$ & $(90)$ & $(103)$ \\
\hline Total & 33.1 & 66.9 & 100.0 & Total & 12.6 & 87.4 & 100.0 \\
\hline Gamma $=.887$ & & & & Gamma $=.927$ & & & \\
\hline
\end{tabular}


tables of .887 for the blue collar group and .927 for the white collar group reflect the lack of change. Youths whose level of commitment was initially high and who came from a white collar background were most ?ikely to remain high on commitment. But, 11.1 percent of the white collar youngsters experienced a decrease in commitment, whereas for those from a lower class background, 20.7 percent experienced a decrease in commitment.

The effects of grade point average on the level of commitment were more important (Table XXVI). Of the group with a low grade point average, 17.3 percent had their level of commitment increase while the figure was 33.3 percent for those with a high grade point average. The impact of a low grade point average on decreases in the level of commitment was also quite pronounced. Among the group with a low grade point average and high commitment in $1964,27.8$ percent experienced a decline in commitment while only 5.2 percent of the high grade point average group showed a decline. The correlations for the partial tables indicate that low GPA students were somewhat more likely to change their level of commitment (gamma $=.85$ ) than the high GPA males (gamma $=946$ ). The finding that the decision to go to college is related to school performance was not surprising. But it does indicate that society pays a price in the form of a lessened relationship to the social system when youths are precluded from going to conege by their failure to do well in high school. This is particularly true when it will be recalled that a key element of commitment was the orientation of the youth towards conventional behavior and achievement of high status occupations. Access to, and investments in conventional 
TABLE XXVI

INITIAL (1964) AND SUBSEQUENT (1967) LEVEL OF COMMITMENT BY GRADE POINT AVERAGE ${ }^{\prime}$

Subsequent

Commitment (1967)

Low

High

Total

N

\section{Total}

Gamma $=.85$

1

Measured in 1964 by "What do you think about going to college" and in 1967 by "I expect to go to college."
Low Grade Point Average

Initial Commitment (1964)

High Grade Point Average

Initial Commitment (1964)

Subsequent

Low High Total

$\begin{array}{llll}82.7 & 27.8 & 47.9 & \text { Low }\end{array}$

$\begin{array}{lll}66.7 & 5.2 & 10.5\end{array}$

$\begin{array}{llll}17.3 & 72.2 & 52.1 & \text { High }\end{array}$

$\begin{array}{lll}33.3 & 94.8 & 89.5\end{array}$

$\begin{array}{llll}100.0 & 100.0 & 100.0 & \text { Total }\end{array}$

$100.0 \quad 100.0 \quad 100.0$

$\left(\begin{array}{lll}52 & (90) \quad(142) \quad N\end{array}\right.$

(9) (96) (105)

$\begin{array}{llll}36.3 & 63.4 & 100.0 & \text { Total }\end{array}$

$\begin{array}{lll}8.6 & 94.4 & 100.0\end{array}$

Gamma $=.946$
Commitment (1967)

4)


behavior should be smaller for those youths who do not intend to go to college. Thus we can expect to see the increases in the participation in delinquent behavior which were demonstrated earlier.

\section{CHANGES IN INVOLVEMENT}

Iivolvement levels were subject to a large amount of change. It will be recalled that 48.7 percent of those initially low on involvement showed a high level in 1967 (Table XXI). Conversely, one youth out of eight (12.7 percent) decreased on the amount of homework done. But, the findings on changes in involvement and social class were not consistent with the hypotheses presented earlier. Table XXVII shows that those from a working class background were somewhat less likely to remain low on involvement than those youths from a white collar background who were more likely to remain low. Of the lower class youths who were originally low on involvement, 44.9 percent remained low, while 56.5 percent of those from a white collar background remained low on involvement. In short, those from blue collar backgrounds were more likely to increase the amount of time they spent un homework than their white collar counterparts. While one explanation is that white collar youths find school easier, it is possibly the case that working class youths are preparing for career decisions which middle class adolescents can delay. At any rate, this finding is especially difficult to reconcile with the earlier observation that in 1964, white collar youths spent mure time on homework than did lower class males. In contrast, declines in the level of involvement were slightly related to social class. The data show that 13.5 percent of 
TABLE XXVII

INITIAL (1964) AND SUBSEQUENT (1967) LEVEL OF INVOLVEMENT AND SOCIOECONOMIC STATUS ${ }^{\top}$

Low Socioeconomic Status

Initial Involvement (1964)

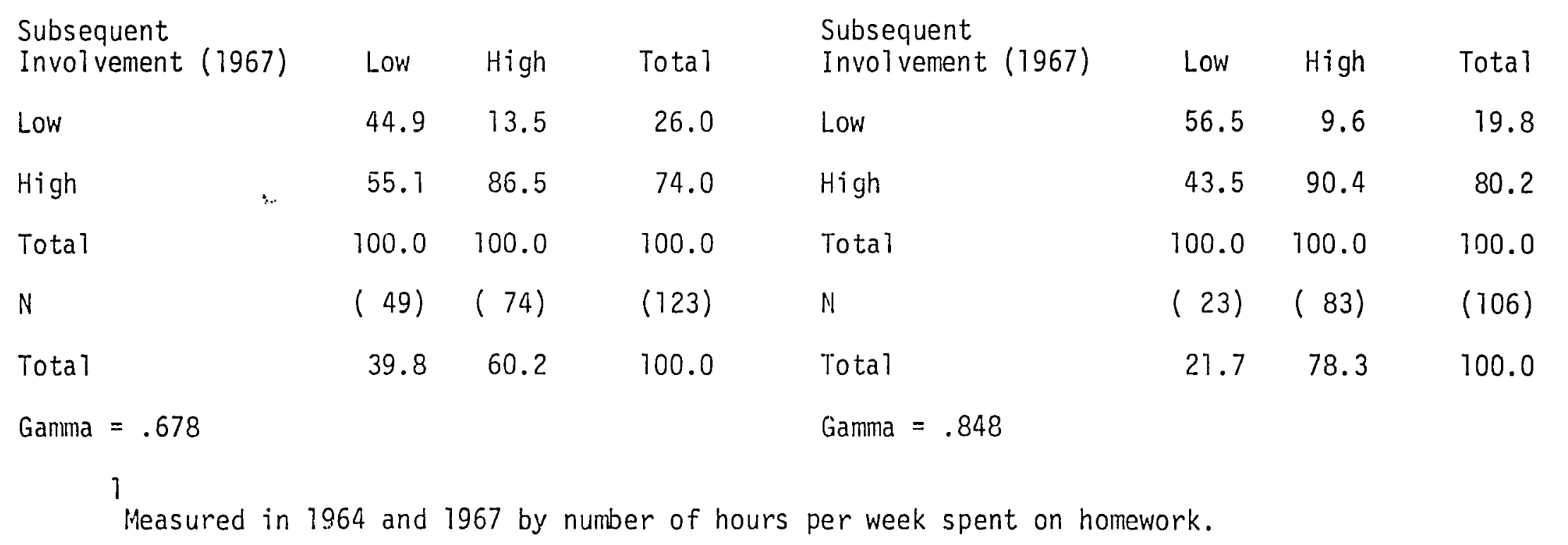

High Socioeconomic Status Initial Involvement (1964) 
those from a lower class background declined in involvement as did 9.6 percent of those from a middle class background.

The overall correlation between initial and subsequent involvement was gamma $=.756$. The correlation coefficients indicate that for the working class boys the predictability of subsequent levels of involvement was not increased, and the amount of error was higher (gamma $=.678$ ) while for the middle class youths, the initial level of bond was a better predictor of the level of bond in 1967 with error being reduced by 84.8 percent (gamma $=.848$ ) .

The effects of grade point average on the level of involvement were important and in the predicted directions (Table XXVIII). The reader will recall that a large number of youngsters responding in 1967 showed an altered level of involvement from 1964. In Table XXVIII it can be seen that increases in involvement were related to doing well in school. Of those youths who did well in school, 61.9 percent increased their level of bond while for those who did poorly, the corresponding figure was 42.9 percent. While the figure is high for both groups, it is clear that compared to the zero order rates where 48.7 percent increased their level of involvement, males who were doing well in school were more likely to go from low to high than their Iow GPA counterparts.

There are two alternative interpretations which can be advanced to explain the changes in the lever of bond. The first, an essentially social-psychological explanation, parallels that of Hirschi who attributes the changes in the level of involvement to the youth's attitudes towards school work. The second reflects the institutional 
TABLE XXVIII

INITIAL (1964) AND SUBSEQUENT (1967) LEVELS OF INVOLVEMENT AND GRADE POINT AVERAGE ${ }^{\top}$

Low Grade Point Average

Initial Involvement (1964)

Subsequent

Involvement (1967)

Low

High

Total

N

Total

Ganma $=.697$

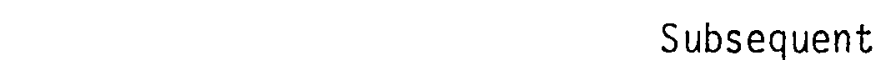

Low High Total

$57.1 \quad 19.2$

35.7

$42.9 \quad 80.8$

64.3

$\begin{array}{lll}100.0 & 100.0 \quad 100.0\end{array}$

(56) (73)

(129)

43.4

56.6

100.0

Subsequent

Low
High Grade Point Average

Initial Involvement (1964)

Involvement (1967) Low High Total

$38.1 \quad 7.6 \quad 13.3$

$\begin{array}{lll}61.9 & 92.4 & 86.7\end{array}$

$100.0 \quad 100.0 \quad 100.0$

(21) (92) (173)

$\begin{array}{lll}18.6 & 81.4 \quad 100.0\end{array}$

1

Measured in 1964 and 1967 by number of hours per week spent on homework. 
or social-structural perspective developed in this research and argues that schools encourage or discourage levels of commitment. Accordingly, school practices should be an object of social policy because of the manner in which failure is translated into a decreased relationship to society, and later, it will be seen, into increased delinquency involvement. While certainly the failure to do better in school can be ascribed to individual youths, the failure to develop effective social policy to deal with the aggregate situation necessitates the view of institutional failure as being responsible for the problem.

In this study a low GPA was associated with a decline in involvement, for those whose initial involvement was high. Of those with a low grade point average, 19.2 percent showed a decline in involvement, while 7.6 percent of those doing well experienced a similar decline. Therefore compared to the base rate of 12.7 percent, doing poorly in school was associated with a decline in involvement while those doing well were somewhat more likely to increase their level of involvement. The gammas for the partial tables reflect the change for the low GPA group. For them, the initial level of bond was not as good a predictor of subsequent bond as for the high GPA group. For the low GPA youths, knowledge of the initial level of bond reduced the error in predicting subsequent bond by 69.7 percent while for the high GPA group error was reduced by 76.3 percent (gamma $=.697$ and .763 respectively).

\section{SUMMARY}

In viewing these data it is important to note that support seems to exist for the hypotheses which predicted that changes in the level 
of bond would be related to social structural situations in which youths are embedded. These interrelationships are undoubtedly quite complex and the pattern of relations between the elements of the bond and changes in the level of bond remain unexplored. Even so, the findings generally support the arguments which were made for an expanded conception of social control theory. Social control theory which is restricted to a set of stable social-psychological properties invoked to explain individual behavior is incomplete. A person's relationship to society does change, and part of those changes are related to the social class background of the youth and how we 11 he does in school.

\section{CHANGES IN THE LEVEL OF BOND AND DELINQUENT BEHAVIOR}

The final section of this study was concerned with examining the rhanges which took place in the level of bond and the effects of school performance and parental social class in relation to changes in delinquency involvement. School performance as represented by high school grade point average and parental socioeconomic status were introduced as control variables to determine how the original first order relationships between changes in bond and delinquency would be affected. As will be recalled, a hypothesis regarding the differential effects of social class and grade point average in relation to changes in the level of bond and delinquency involvements was presented. That hypothes is is detailed below.

Youths with a white collar background and good school performance will be less likely to be involved in delinquency than are those with a working class background and poor school performance. Furthermore, 
regardless of whether the level of bond increased or decreased between Time 1 and Time 2, white collar boys and those with better grades will show less delinquency than will low socioeconomic status youths and those with low grades.

This hypothesis will be discussed below in relation to each element of the social bond. This study was concerned primarily with the pattern and strength of the findings as predicted in the reformulated version of social control theory. Interpretations will be offered for the percentage changes in delinquency involvement. From a practical viewpoint, this method of presenting data is valuable in that it is easily interpretable. In the area of delinquency research, relationships beteween variables tend to be small and differences are more easily understood when expressed as percentages. Similarly, the effects of control variables can be seen as increases or decreases in the original rate of delinquency for the analys is groups.

\section{CHANGES IN THE LEVEL OF ATTACHMENT AND THE RELATION TO DELINQUENCY}

The data show that school success and failure and social class background were important in terms of how rates of delinquency were affected. First of all, it will be recalled that the rates of del inquency involvement were highest (Table XVIII, 36.5 percent) for those whose level of attachment was low in 1964 and 1967 and lowest (11.3 percent) for those whose level increased from low to high. The next lowest rate ( 14.1 percent) was for those who were consistently high, and for those who fell from high to low, the rates were next to the highest (24.1 percent). 
In Table XXIX attention should be directed at the consistent effects of grade point average on the delinquency rates of the analys is groups. Regardless of the level of attachment in 1964 and 1967 and regardless of the changes in the levels of attachment from 1964 to 1967, when the first order delinquency rates for the analys is groups are examined, in every instance the rates are much higher for the low GPA youths than for the high GPA students. Additionally, the percentage differences were important, ranging from 10 to 18.8 percent in the first order rates for the analys is groups. Thus support exists for the hypothesis that structural effects represented by grading and tracking practices within the education system do result in differences in the delinquency rates for the two groups.

With grade point average controlled (Table XXIX), delinquency rates were slightly higher, 41.3 percent (a 4.8 percent increase from the 36.5 percent overal1 rate) for those low on attachment in both time periods wille for those with a high grade point average the del inquency rate was 22.7 percent, almost 13 percent lower. ' For those with a low grade point average whose level of bond increased from 1964

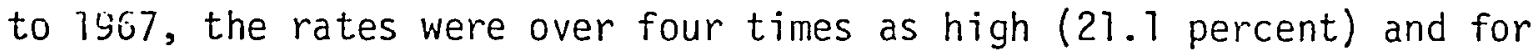
those with a high grade point average the rate was 4.5 percent.

1

The changes in the rates in this and subsequent sections represent the effect of GPA and social class on the delinquency rates of those groups whose level of bond remained constant or changed in comparison to the first order delinquency rate. By examining the direction of the changes, it can be determined whether or not the hypothes is was rejected. The rates should decrease for those from a white collar background or with a high GPA, and increase for those from a lower class background or with a low GPA. The references to increases and decreases are in relation to the rates cited at the beginning of each section. 
TABLE XXIX

DELINQUENCY INVOLVEMENT BY CHANGES IN THE LEVEL OF ATTACHMENT ${ }^{\top}$ BY GRADE POINT AVERAGE

\begin{tabular}{|c|c|c|c|c|c|}
\hline \multirow[b]{2}{*}{ Delinquent } & \multicolumn{5}{|c|}{$\begin{array}{l}\text { Low Grade Point Average } \\
\text { of Attachment in } 1964 \text { and } 1967\end{array}$} \\
\hline & $\begin{array}{l}\text { Low } 1964 \\
\text { Low } 1967\end{array}$ & $\begin{array}{l}\text { High } 1964 \\
\text { Low } 1967\end{array}$ & $\begin{array}{l}\text { Low } 1964 \\
\text { High } 1967\end{array}$ & $\begin{array}{l}\text { High } 1964 \\
\text { High } 1967\end{array}$ & Total \\
\hline Yes & 41.3 & 27.6 & 21.7 & 22.2 & 30.7 \\
\hline No & 58.7 & 72.4 & 78.9 & 78.8 & 69.3 \\
\hline Total & 100.0 & 100.0 & 100.0 & 100.0 & 100.0 \\
\hline$N$ & ( 63) & ( 29) & ( 19) & $(45)$ & $(156)$ \\
\hline
\end{tabular}

Gamma $=.309$

High Grade Point Average

Lever of Attachment in 1964 and 1967

Low 1964 High 1964 Low 1964 High 1964

Delinquent Low 1967 Low 1967 High 1967 High 1967 Total

$\begin{array}{llllll}\text { Yes } & 22.7 & 16.7 & 4.5 & 6.4 & 11.9\end{array}$

No

77.3

83.3

95.5

93.6

88.1

Total

100.0

100.0

700.0

100.0

100.0

N

(22)

(24)

( 22)

(47)

Gamma $=.446$

1

Measured in 1964 and 1967 by "My parents usually know where I am and what I am doing." 
The same general pattern of findings emerged when grade point average was examined in relation to those whose level of bond fell from high to low or remained consistently high. The delinquency rate for those whose level of bond decreased and who had a low GPA rose to 27.6 percent (2.9 percent higher) while for the same group with a high GPA the rate fell to 16.7 percent (7.4 percent lower). Similarly, for those whose level of bond remained high, the rate for those with a low grade point average was 22.2 percent (an 8.1 percent increase) while a high GPA was associated with a rate of 6.4 percent (a 7.7 percent decrease).

When attachment was examined at two points in time with socioeconomic status introduced as a theoretically important control, the pattern which emerged in relation to grade point average reappeared. In general, social class background did affect the delinquency rates as predicted. When the delinquency rates for the analysis groups were partialled according to social class, the rates for the blue collar groups were consistently higher than for the comparable white collar groups. In contrast, the percentage differences for the analys is groups were smaller with the control added, ranging from 3 to 25 percent. Thus, variations in social class background do result in different rates of delinquency involvement. This finding runs counter to Hirschi's view that social class is not important in explaining delinquent behaivor.

The delinquency rates (Table $X X X$ ) were highest for those low on attachment and from lower class backgrounds. While the rate rose slightly less than 5 percent from the base rate of 36.5 percent to 40.4 percent for those who were low in bond both time periods and from 
TABLE $X X X$

DELINQUENCY INVOLVEMENT BY CHANGES IN THE LEVEL OF ATTACHMENT ${ }^{1}$ BY SOCIOECONOMIC STATUS

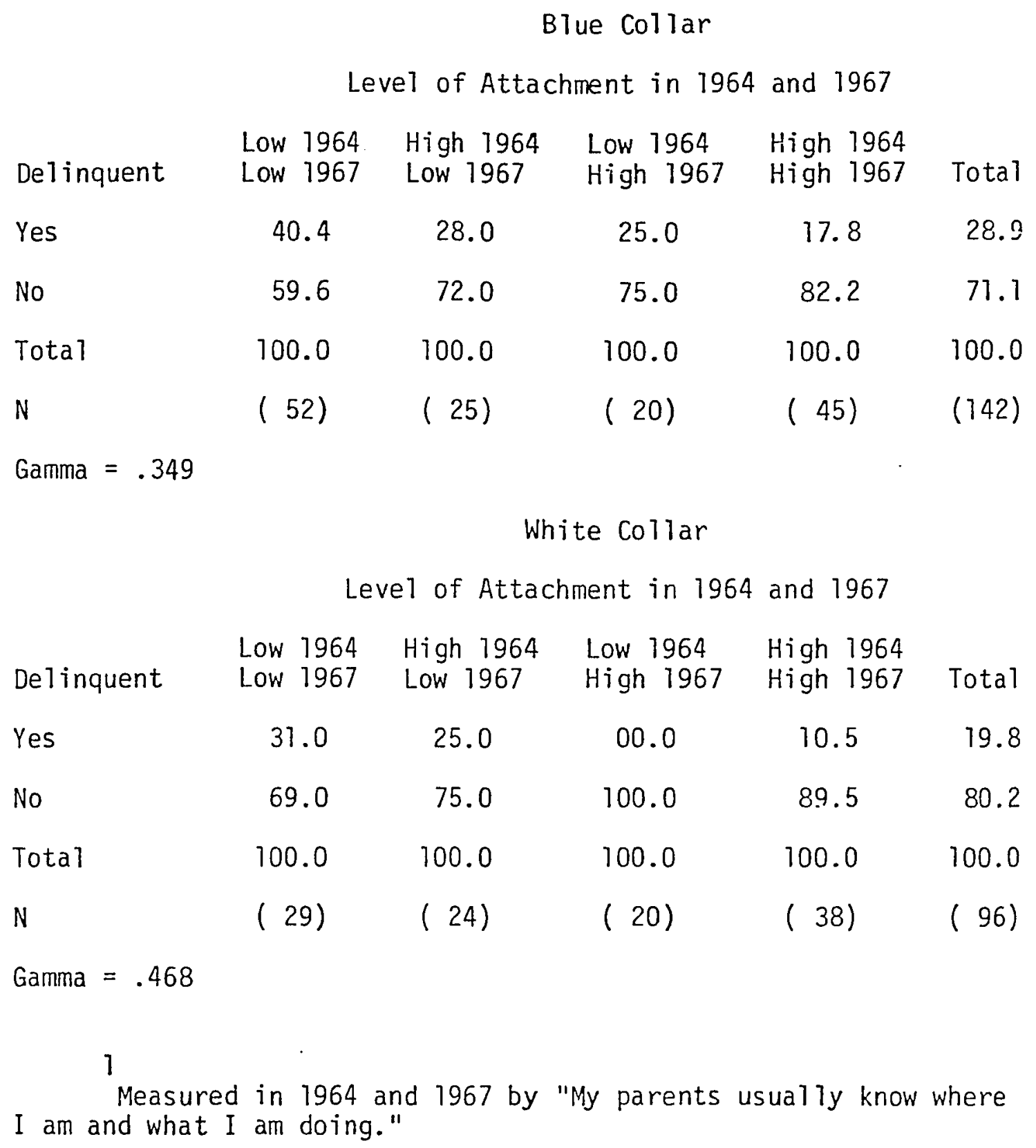


a working class background, there was a slightly larger decrease (5.5 percent) for those from a white collar background to 31 percent. For those whose level of attachment increased from low to high, a lower class background was related to a rate of 25 percent (a 13.1 percent increase from the base of 11.9 percent), while none of the white collar youths became delinquent. For those whose level of bond fell, the delinquency rate was 28 percent (3.9 percent higher than the base rate of 24.1 percent) for those youths from a working class background while the rate was unaffected for those white collar youngsters. For those whose level of attachment was consistently higher, with social class controlled, there were small departures of equal magnitude in the predicted directions from the base of 14.1 percent to 17.8 percent and 10.5 percent for those youths from lower and middle class backgrounds respectively.

\section{CHANGES IN COMMITMENT AND THE RELATION TO DELINQUENCY}

College aspirations loom large in social control theory because they reflect the decision of the individual to become oriented towards conventional social goals and the means of achieving those goals. Initially, (Table XIX), 75 percent of the sample indicated that they wanted to attend college. Yet it was shown that 16 percent of those responding in 1967 were no longer oriented towards attending college, while 20 percent of those who had originally not decided to attend now intended to do so. The rates of del inquency (Table $X X$ ) were highest for those who were no longer college oriented ( 40 percent). The next highest rates were for those low in bond during both time periods 
(26.5 percent). Finaliy, as with attachment the rates were lowest for those whose level of bond increased from low to high ( 8.3 percent), while they were next to the lowest for those whose level remained high (20.4 percent), indicating that those showing delayed commitment form an especially strong social bond.

When the relationship between changes in bond and delinquency involvement was controlled by grade point average and social class, the findings were generally consistent with the hypotheses. With grade point average introduced as a control, the rates of delinquency for the analysis groups generally increased for the low GPA sub-groups while they were lower for comparable high GPA youths (Table XXXI). The percentage differences for the analys is groups with the control introduced ranged from 11.2 percent to 24.4 percent. This finding therefore suggests that nonprimary group factors do differentially affect delinquency involvement. The changes in delinquency rates were small in a number of cells, but were in the direction predicted. Nonetheless, the effects of grade point average in several cells deserved special comment. For those with high levels of commitment in both years and with a high grade point average, the rate of de 1 inquency was 10.9 percent compared with the first order rate of 20.4 percent. In contrast, the comparable group with a low GPA had a rate of 33.9 percent. The changes are understandable in that going to college is predicated on high grades and school failure concomitantly precludes students from going to college. The failure of educational commitment to be developed may be interpreted as an indication that youths realize that a whole set of life options are no longer available 
TABLE XXXI

DELINQUENCY INVOLVEMENT BY CHANGES IN THE LEVEL OF COMMITMENT ${ }^{7}$ BY GRADE POINT AVERAGE

\begin{tabular}{lccccc}
\multicolumn{7}{c}{ Low Grade Point Average } \\
\multicolumn{5}{c}{ Level of Commitment in 1964 and 1967 } \\
Delinquent & Low 1964 & High 1964 & Low 1964 & High 1964 \\
Yes & 27.9 & 44.4 & 11.1 & 33.9 & 32.3 \\
No & 72.1 & 55.6 & 88.9 & 66.1 & 67.7 \\
Tota1 & 100.0 & 100.0 & 100.0 & 100.0 & 100.0 \\
N & $(43)$ & $(25)$ & $(9)$ & $(65)$ & (142) \\
Gamma $=-.057$ & & & & &
\end{tabular}

High Grade Point Average

Lever of Commitment in 1964 and 1967

$\begin{array}{lccccc}\text { Delinquent } & \text { Low 1964 } & \text { High 1964 } & \text { Low 1964 } & \text { High 1964 } & \\ \text { Yes } & \text { Low 1967 } & \text { High 1967 } & \text { High 1967 } & \text { Total } \\ \text { No } & 82.7 & 20.0 & 00.0 & 10.9 & 10.4 \\ \text { Total } & 100.0 & 100.0 & 100.0 & 100.0 & 100.0 \\ \text { N } & (6) & (5) & (3) & (91) & (115) \\ \text { Gamma }=.158 & & & & & \end{array}$

1 Measured in 1964 by "What do you think about going to college" and in 1967 by "I expect to go to college." 
and with decreased commitment to conventional behavior, delinquency becomes a viable alternative activity.

The rates were essentially unchanged from the general rate of 26.5 percent for those with a low GPA who were consistently low on commitment and slightly higher for those whose level went from low to high (a 2.8 percent increase over the base rate of 8.3 percent to 11.1 percent). For the first group, expectations of future success may be lowered, and this fact, coupled with decreased access to higher positions in the class structure may be a partial explanation of the relatively low delinquency rates. In contrast, for those with a high GPA who were consistentiy low on commitment, the delinquency rate declined almost 10 percent to 16.7 percent. Additionally, none of the three youths whose level of commitment rose from low to high and who had a high GPA became delinquent.

Finally, for the group whose level of commitment fell from high to low and who had a high grade point average, the delinquency rate was 20 percent, a decline of 20 percent from the first order rate of 40 percent. The corresponding rate for the low GPA group was 44 percent, a 4.4 percent increase. This is an indication that while the commitment to conventional goals may not exist, it is important that the option to engage in those goals at a later date not be closed off through school failure.

The importance of access to conventional goals as options therefore emerges as a critical factor in this revised model of social control theory. While conventional social control theory such as Hirschi's version implies that the individual is free to choose his or her 
behavior, it is important to realize that the legitimate behavioral options which are available to a person with a high grade point average are greater than those available to a youth with a low grade point average. Thus a person with a low level of commitment but with a high GPA can always decide to go to college and would probably do well, whereas a person with a low grade point average would experience considerable difficulty in doing well in a college enviornment.

The effects of socioeconomic status were not as cons istent with respect to commitment as were those of grade point average (Table $X X X I I)$. While it was hypothesized that the delinquency rates would be higher for the youths from blue collar backgrounds than those from white collar backgrounds, this turned out to be not entirely the case. While the number of cases was small, particularly for the blue collar adoiescents whose level of commitment rose from low to high, their level of delinquency participation fell. The rate declined for white collar boys who were consistently high in commitment

For those low on commitment in both years, and from a Tow SES background, the delinquency rate was 37.1 percent, which was 10.6 percent higher than the first order rate of 26.5 percent. None of the white collar youths who were low in both years became delinquent. For the remainder of those initially low on bond, the small number of cell frequencies mikes it difficult to substantiate assertions about the effect of socioeconomic status on changes in the level of bond and delinquency. For those who were initially high and whose level of bond decreased, the effects of socioeconomic status as a control were more 
TABLE XXXII

DELINQUENCY INVOLVEMENT BY CHANGES IN THE LEVEL OF COMMITMENT ${ }^{1}$ BY SOCIOECONOMIC STATUS

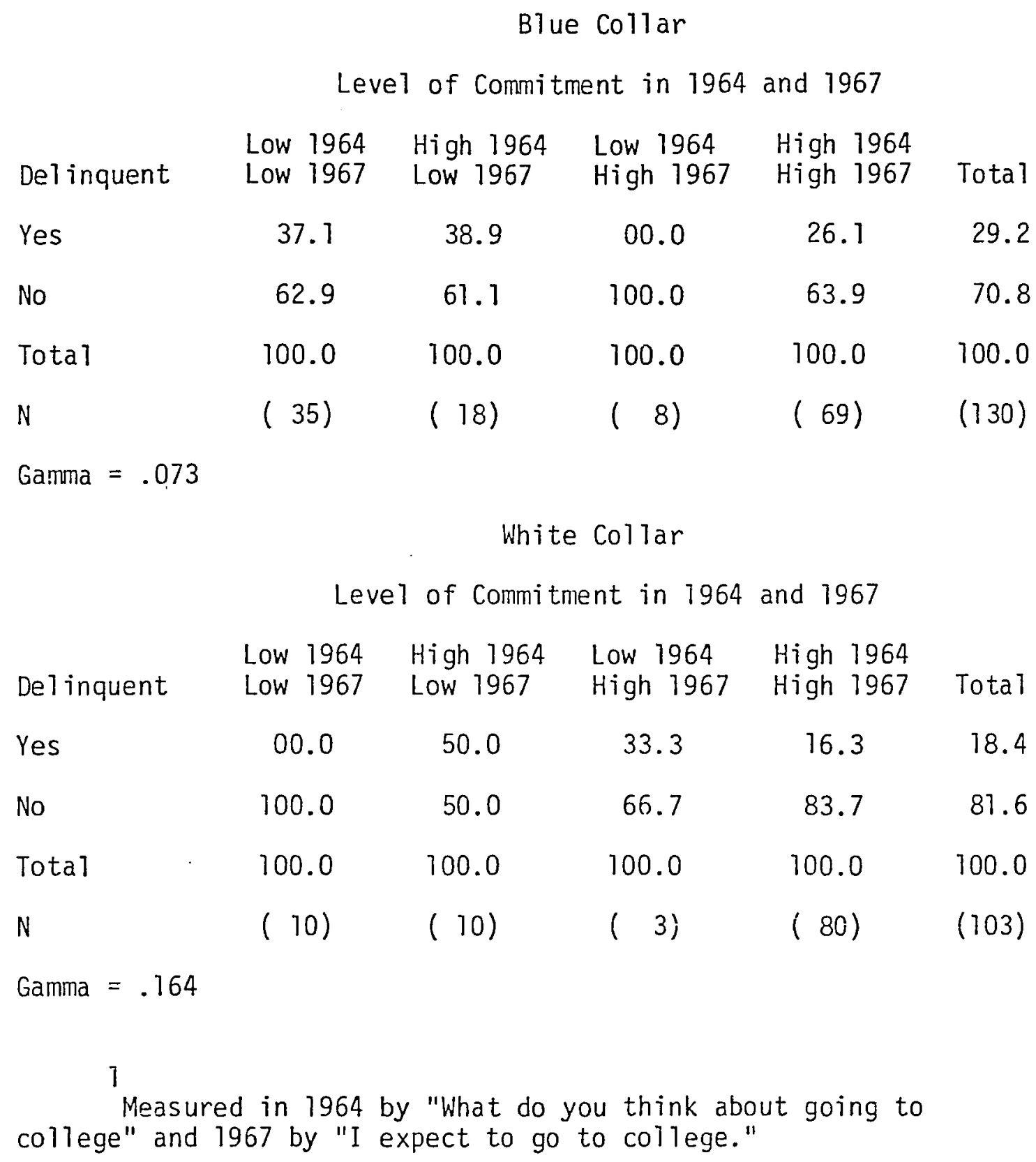


mixed. For the low SES group the delinquency rate essentialiy remained constant while it increased 10 percent for the high SES group to 50 percent.

The rates for those whose level of commitment was high in both years changed in the predicted directions. The rates were 5.7 percent higher than the base rate of 20.4 percent for the low SES group, an increase to 26.1 percent, and 4.1 percent lower, a decrease to 16.3 percent for the high SES group. While the number of cases is sma11, it should be noted that none of the eight low SES boys whose level of commitment increased from low to high became delinquent while one of the three high SES boys became delinquent.

CHANGES IN THE LEVEL OF INVOLVEMENT AND THE RELATION TO DELINQUENCY

It will be recalled that almost half of those who were low on involvement in 1964 and who responded in 1967 changed their level of involvement from low to high. Of those who were initially high in 1964, it was determined that in 196712.7 percent of the 165 had changed their level of involvement from high to low. The rates of delinquency involvement were in the directions predicted. Of those low in both periods, half were delinquent, while for those who were consistently high the rate was 11.8 percent. For those whose level changed from low to high the rate was 23.7 percent, while for those whose level decreased from high to low the rate was 28.6 percent. The delinquency rates (Table XXXIII) were higher for the subgroups of the low GPA youths than comparable involvemerit subgroups with a high GPA, with one exception, regardless of the level of 
TABLE XXXIII

DEL INQUENCY INVOLVEMENT BY CHANGES IN THE LEVEL OF INVOLVEMENT ${ }^{1}$ BY GRADE POINT AVERAGE.

\begin{tabular}{|c|c|c|c|c|c|}
\hline \multirow[b]{2}{*}{ Del inquent } & \multicolumn{5}{|c|}{ Low Grade Point Average } \\
\hline & $\begin{array}{l}\text { Low } 1964 \\
\text { Low } 1967\end{array}$ & $\begin{array}{l}\text { High } 1964 \\
\text { Low } 1967\end{array}$ & $\begin{array}{l}\text { Low } 1964 \\
\text { High } 1967\end{array}$ & $\begin{array}{l}\text { High } 1964 \\
\text { High } 1967\end{array}$ & Total \\
\hline Yes & 56.3 & 28.6 & 25.0 & 18.6 & 30.2 \\
\hline No & 43.7 & 71.4 & 75.0 & 81.4 & 69.8 \\
\hline Total & 100.0 & 100.0 & 100.0 & 100.0 & 100.0 \\
\hline N & $(32)$ & $(14)$ & $(24)$ & ( 59$)$ & (129) \\
\hline \multicolumn{6}{|l|}{ Gamma $=.328$} \\
\hline & \multicolumn{5}{|c|}{ High Grade Point Average } \\
\hline Delinquent & $\begin{array}{l}\text { Low } 1964 \\
\text { Low } 1967\end{array}$ & $\begin{array}{l}\text { High } 1964 \\
\text { Low } 1967\end{array}$ & $\begin{array}{l}\text { Low } 1964 \\
\text { High } 1967\end{array}$ & $\begin{array}{l}\text { High } 1964 \\
\text { High } 1967\end{array}$ & Total \\
\hline Yes & 25.0 & 28.6 & 23.1 & 7.1 & 11.5 \\
\hline No & 75.0 & 71.4 & 76.9 & 92.9 & 88.5 \\
\hline Total & 100.0 & 100.0 & 100.0 & 100.0 & 100.0 \\
\hline N & $(8)$ & $(7)$ & $(13)$ & $(85)$ & $(173)$ \\
\hline Gamma $=.488$ & & & & & \\
\hline
\end{tabular}


involvement in 1964 and 1967, and regardless of the changes in the level of involvement from 1964 to 1967 although in some cases the changes were relatively small. The one exception can be termed minor in that the rates were unchanged for youths whose level of involvement fell from high to low. In short, the predicted structural effect emerged, indicated by the variation in the rates for the low and high GPA groups.

However, the differences in the delinquency rates for low and high GPA youths did not consistently emerge as predicted (Table XXXIII). In only two of four instances did a low grade point average result in rates which were much higher than in the high GPA group. For those youths who were low in both periods, the low GPA group had a rate of 56.3 percent, which is 6.3 percent higher than in the first order relationship, compared to 25 percent for the high GPA students. For the group consistentiy high, the low GPA adolescents had a delinquency rate of 18.6 percent, which was 7.8 percent higher than in the base rate. For the corresponding high GPA males the rate was 4.7 percent lower for a rate of 7.1 percent.

The effects of socioeconomic status on the level of involvement were also mixed. This inconsistency and lack of large changes makes it difficult to make definitive assertions about the effects of socioeconomic status on involvement. In part, this is due to the previously discussed strong relationship between socioeconomic status and involvement in 1967.

The failure of the relationships to emerge was, in part, also due to the same measure of social class being used to represent two 
different concepts. In the first, social class was used to describe the background of the youths, while the second refers more directly to the differences in life options between white collar and blue collar adolescents which assist middle class youths in being upwardly socially mobile. Even though these terms are used in a conceptually different sense, the degree of overlap in part may be distorting the strength of the relationship which actually exists.

With one exception the delinquency rates were higher for the blue collar youths than those from white collar backgrounds. Although in some cells the changes were quite small, the rate was higher for the latter group of boys who fell from high to low in involvement than their lower class counterparts. Again, if Hirschi's formulation of social control theory was correct, this type of class related variation in delinquency rates should not exist.

For those adolescents who were low in involvement both years (Table XXXIV), the delinquency rates were nigher for those from both blue collar and white collar backgrounds. The rates were 54.6 percent for the former group and 53.9 percent for the latter which represented small increases of 4.6 and 3.9 percent respectively over the first order rate of 50 percent. When the level of involvement increased from low to high, the predicted differential effects of class emerged, but again the small cell frequencies made it difficult to place a great dea 7 of credence in the interpretation of the data. For those whose levei of involvement fell, the probiem of small cell sizes emerged, with the total number of cases in the two cells being six. When involvement was consistently higher, the effect of class was also 
TABLE XXXIV

DEL INQUENCY INVOLVEMENT BY CHANGES IN THE LEVEL OF INVOLVEMENT ${ }^{\top}$ BY SOCIOECONOMIC STATUS

\begin{tabular}{|c|c|c|c|c|c|}
\hline \multirow[b]{2}{*}{ Delinquent } & \multicolumn{5}{|c|}{ Blue Collar } \\
\hline & $\begin{array}{l}\text { Low } 1964 \\
\text { Low } 1967\end{array}$ & $\begin{array}{l}\text { High } 1964 \\
\text { Low } 1967\end{array}$ & $\begin{array}{l}\text { Low } 1964 \\
\text { High } 1967\end{array}$ & $\begin{array}{l}\text { High } 1964 \\
\text { High } 1967\end{array}$ & Total \\
\hline Yes & 54.6 & 30.0 & 29.6 & 17.2 & 27.8 \\
\hline No & 45.4 & 70.0 & 70.4 & 82.8 & 72.2 \\
\hline Total & 100.0 & 100.0 & 100.0 & 100.0 & 100.0 \\
\hline N & $(22)$ & $(10)$ & $(19)$ & $(64)$ & $(115)$ \\
\hline \multicolumn{6}{|l|}{ Gamma $=.497$} \\
\hline & \multicolumn{5}{|c|}{ White Collar } \\
\hline & \multicolumn{5}{|c|}{ Level of Involvement in 1964 and 1967} \\
\hline Del inquent & $\begin{array}{l}\text { Low } 1964 \\
\text { Low } 1967\end{array}$ & $\begin{array}{l}\text { High } 1964 \\
\text { Low } 1967\end{array}$ & $\begin{array}{l}\text { Low } 1964 \\
\text { High } 1967\end{array}$ & $\begin{array}{l}\text { High } 1964 \\
\text { High } 1967\end{array}$ & Total \\
\hline Yes & 53.9 & 37.5 & 10.0 & 8.0 & 14.2 \\
\hline No & 46.1 & 62.5 & 90.0 & 92.0 & 85.8 \\
\hline Total & 100.0 & 100.0 & 100.0 & 100.0 & 100.0 \\
\hline N & $(13)$ & $(8)$ & $(10)$ & $(75)$ & $(106)$ \\
\hline Gamma $=.700$ & & & & & \\
\hline
\end{tabular}


and in the directions predicted. For the blue collar group, the rate was 17.2 percent, while for the white collar group the rate was 8 percent, indicating that social class affected the relationship from the base rate of 11.8 percent as hypothesized.

\section{BELIEF AND THE EFFECTS OF SOCIAL CLASS AND EDUCATIONAL PRACTICES}

Unlike the other three elements of the bond, it was not possible to obtain measures of belief at two points in time. However, an important relationship between belief measured in 1964 and delinquency (Table VIII, gamma $=.39$ ) was observed. Translated into percentages, 38.5 percent of those low on belief were delinquent while 21.5 percent of those high on belief were delinquent, a difference of 17 percent.

The effects of social class on the zero order relationships bear some examination. For those with a working class background (Table $X X X V)$, the rate of delinquency was 5.0 percentage points higher for those who were low on bel ief and 5.9 percentage points higher for those who were high on belief. For the blue collar youths error in predicting delinquency was reduced to 34 percent (gamma $=.34$ ). In contrast, for middle class youths, delinquency rates were unaltered for those low in belief but were 5.7 percentage points lower for those who were high on this dimension. Information about social class background for the white collar group resulted in the predictability of delinquency increasing to gamma $=.537$, or alternatively stated, error being reduced by 53.7 percent. This finding requires some explanation because it was noted earlier that there was only a small relationship between social class and belief. The higher rate for the group which 
TABLE XXXV

PERCENT OFFICIALLY DELINQUENT AND LEVEL OF BELIEF (1967) AND SOCIOECONOMIC STATUS ${ }^{1}$

\begin{tabular}{|c|c|c|c|c|c|c|c|}
\hline \multirow[b]{3}{*}{ Delinquent } & \multicolumn{3}{|c|}{ Blue Collar } & \multicolumn{4}{|c|}{ White Collar } \\
\hline & \multicolumn{3}{|c|}{ Level of Betief (1967) } & \multirow[b]{2}{*}{ Delinquent } & \multicolumn{3}{|c|}{ Level of Belief (1967) } \\
\hline & Low & High & Total & & Low & High & Total \\
\hline Yes & 43.4 & 27.4 & 29.9 & Yes & 38.5 & 15.8 & 18.4 \\
\hline No & 56.5 & 72.6 & 70.7 & No & 61.5 & 84.2 & 81.6 \\
\hline Total & 100.0 & 100.0 & 100.0 & Total & 100.0 & 100.0 & 100.0 \\
\hline N & $(23)$ & (124) & $(747)$ & $N$ & $(13)$ & $(101)$ & (114) \\
\hline Total & 15.7 & 84.4 & 100.0 & Total & 11.4 & 88.6 & 100.0 \\
\hline Gamma $=.34$ & & & & Gamma $=.537$ & & & \\
\hline
\end{tabular}


was from a lower social class background and which had a high level of belief appears to challenge the view that no special structural strains are needed to explain delinquency (Hirschi, 1969:23-26). There appears to be something which operates in relation to social class to account for the higher rates among those who are from a working class background but who are bonded to the social system.

Belief was intended to represent the relation of the youths to the social value system, focusing upon the norms regulating socially proscribed behavior. A lower social class position, therefore, places a youngster from that background in an undesirable situation. Working class boys are expected to play by the rules of the game in the competition for scarce social goods, yet they also have one hand tied behind their backs. When, by virtue of their social class position, they find they cannot compete on an equal basis with white coliar adolescents, they have a decreased relationship to society and a higher rate of delinquency. To continue the metaphor, for those who are from a middle class background, since they are presumably able to use both hands, the rate does not increase. Thus where this class related perspective is present, the differential effects of class in relation to legitimate and illegitimate goals appears to be valid.

In contrast, with grade point average controlled, the rates of delinquency were as predicted (Table XXXVI). For those low in belief, Iow GPA was associated with a rate 9.5 percentage points higher than the zero order figure, while for those who were high the rate was 7.8 percentage points higher. High GPA was associated with a rate 17.1 percentage points lower for those who were initially low on belief 
TABLE XXXVI

PERCENT OFFICIALLY DELINQUENT AND LEVEL OF BELIEF (1967) AND GRADE POINT AVERAGE ${ }^{1}$

\begin{tabular}{|c|c|c|c|c|c|c|c|}
\hline \multicolumn{5}{|c|}{ Low Grade Point Average } & \multicolumn{3}{|c|}{ High Grade Point Average } \\
\hline & Leve & of Beli & 1967) & & Leve & of Beli & 1967) \\
\hline Del inquent & Low & High & Total & Del inquent & Low & High & Total \\
\hline Yes & 48.0 & 29.3 & 32.1 & Yes & 27.4 & 10.0 & 11.4 \\
\hline No & 52.0 & 70.7 & 67.9 & No & 78.5 & 90.0 & 88.6 \\
\hline Total & 100.0 & 100.0 & 100.0 & Total & 100.0 & 100.0 & 100.0 \\
\hline N & $(25)$ & $(140)$ & $(165)$ & $N$ & $(14)$ & $(100)$ & $(114)$ \\
\hline Total & 15.2 & 84.9 & 100.1 & Total & 12.3 & 87,7 & 100.0 \\
\hline Gamma $=.38$ & & & & Gamma $=.42$ & & & \\
\hline
\end{tabular}


and 11.5 percentage points lower for those who were initially high. The gammas for the partial tables show that knowledge of GPA resulted in relatively little additional information about delinquency involvement when the level of bond was known. The gammas were .38 for the low GPA group and .42 for the high GPA youths.

\section{CONCLUSION}

In reviewing and summarizing the research to this point, severa? observations can be made. Consistent findings emerged with respect to the effects of social class and the educational system on the social bond. This study supported the contention that it is accurate to view both those factors as intervening at very specific points in the lives of young peopie and therefore affecting their level of bond and rates of delinquency involvement. Delinquency rates consistently varied in the directions predicted when those variables were introduced as controls. This was especially true when the changes were compared to the rates for each element of the bond before the controls were introduced.

The problem of the causal ordering of variables has atready been addressed. This research assumed that the educational system and the social class structure can work to change the individual's initial relationship to society. In marked contrast, it could be argued that an increase in bond should result in an increased affiliation to conventional goals and activities. Youths then would study harder and be more oriented toward competing for a high status job. Certainly as the youngster approaches graduation, he or she may decide to make 
investments in conventional behavior which result in a higher social bond. Reversing the causal order, though, provides little explanation fo why youths suddenty become "unbonded" to society. The role of the school as a gate-keeper and the aspects of the social class structure which assist some youths and deny others entry into higher education with the attendant rewards provides a much more satisfactory explanation of the increases, decreases and stability in the level of bond and del inquency involvement. 



\section{CHAPTER VI}

\section{CONCLUSIONS}

The tasks of this study were accomplished in several stages. First, the applicability of the delinquency theory developed by Hirschi was examined in a new research setting. Next, the argument was made that the interaction of socialization with social structure and social institutions was inadequately conceived in Hirschi's study. Since this study was concerned with the impact of social structure on socialization, the level of bond was then explored in relation to social class. Also, bond levels were scrutinized at two points in time to determine if they remained constant or changed over time. Next, the changes that were observed were examined in relation to social class and grade point average to determine if those variables could account for the alterations in bond levels. Finally, the changes were examined in reiation to delinquency, with controls then added, first for social class and then for grade point average to determine if the rates of delinquency varied in the directions predicted for the respective groups.

\section{REPLICATION OF CAUSES OF DELINQUENCY}

This research found substantial support for the thes is presented by Hirschi that the level of bond is related to the likelihood that a 
youth will come into contact with the juvenile justice system (Table XXXVII). Three of the four elements of the social bond: attachment, involvement and belief, were found to be related to delinquency. The higher the level of bond, the less likely that a youth was an adjudicated delinquent. No relation to delinquency was found for the fourth element of the bond; commitment or the decision to go to college and subsequentiy pursue a high status occupation. A possible explanation for the failure of the predicted relationship to emerge was offered. The youths initially questioned in this study were sophomores and in Hirschi's study they were juniors and seniors. It may be that the bonding effect of commitment to conventional goals does not come into operation until much later in adolescence as it was found that a large proportion of the population later made the decision to attend college. In summary, these data generally mirrored Hirschi's findings.

TABLE XXXVII

CORRELATIONS BETWEEN DELINQUENCY AND THE ELEMENTS OF THE BOND

Attachment Comultment Involvement Belief

$\begin{array}{lllll}\text { Delinquent } & .292 & -.002 & .57 & .39\end{array}$

(1967)

LEVEL OF BOND AND DELINQUENCY AND SOCIAL CLASS

Hirschi did not consider it important to analyze the level of bond in relation to social class partly because no relationship was found between social class and delinquency in his study. The present 
research did find a relationship between social class and delinquency and therefore examined the impact of social class on the level of bond (Table XXXVIII). The data showed that attachment and belief were not strongly related to social class. Youths from the middle class were much more likely to want to go to college, and more of them studied more intensively than their lower-class counterparts. The findings may simply reflect the reality of the respective positions of the youths in the social class system. Other studies have shown that for youths of equal ability, those from the middle and upper class are much more likely to go to college than their lower class counterparts. Thus the relationship of commitment and involvement to social class may simply mean that the lower class youths recognize that their class position consigns them to a future which simply has fewer life options and fewer rewards for conforming behavior and consequently do not form that element of the bond.

TABLE XXXVIII

CORRELATION BETWEEN SOCIAL CLASS AND DELINQUENCY AND ELEMENTS OF THE BOND Delinquency Attachment Commitment Involvement Belief $\begin{array}{llllll}\text { Social Class } & .373 & .13 & .53 & .47 & .18\end{array}$ CHANGES IN THE LEVEL OF BOND

The view of the social bond which emerged in this study was considerably more complex than that developed by Hirschi. He argued that a youth's relationship to society is determined by the success 
of the adolescent's interaction with his or her parents in early childhood and that the level of bond should, therefore, be fixed by the time the youth entered high school. In contrast, this research assumed that while the level of bond may be formed in primary group interaction, factors related to the social class structure and the secondary school system may act with an intensity similar to that of the primary group to alter the bond which has been developed.

It was first necessary to determine if the bond levels did change. This analysis could be conducted only for attachment, commitment and involvement, as data for measuring belief did not exist in 1964 when the survey instrument was first administered.

From a social control perspective, the level of bond should be stable from one year to the next, that is, the correlation coefficients should be very high (Table XXXIX). Looking at the correlation coefficients it can be seen that attachment exhibited a large amount of instability while the level of commitment in 1964 was an excellent predictor of the level of commitment in 1967. The level of involvement, in contrast, had a coefficient of $r=.76$ indicating that some change did take place.

\section{TABLE XXXIX}

CORRELATION BETWEEN ELEMENTS OF THE BOND IN 1964 AND $1967^{1}$

$$
\begin{aligned}
& \text { Attachment in } 1964 \text { and 1967, } r=.55 \\
& \text { Commitment in } 1964 \text { and 1967, } r=.91 \\
& \text { Involvement in } 1964 \text { and 1967, } r=.76 \\
& \text { Data for Belief were not available in } 1964 .
\end{aligned}
$$$$
1
$$ 
Earlier it was hypothesized that the changes in the level of bond might be related to either social class or educational stratification factors. When the partial correlations in Table $X X X X$ are viewed in relation to the zero order correlations of Table XXXIX, only partial support was generated for the hypotheses of this research with only one element of the bond behaving as as predicted, another being slightly affected and the third unchanged.

\section{TABLE XXXX}

CORRELATION BETWEEN THE LEVEL OF BOND IN 1967 AND 1967 CONTROLL ING FOR SOCIAL CLASS AND GRADE POINT AVERAGE

$$
\text { LOW SES High SES Low SES High SES }
$$

Attachment

.647

.393

.674

.323

Commitment

.887

.927

.85

.946

Involvement

.678

.848

.697

.763

It can be seen that under the conditions of a lower class background or low GPA the level of attachment remained stable, while for the adolescents from a white collar background or who were doing well in school, change in the level of bond was more likely to occur. The level of commitment was unaffected by social class and grade point average. Finally, with involvement, under the conditions of a low GPA or Tow SES the level of bond was less stable, while it remained stable for high SES youths and was unaffected for high GPA males. 
EXPLAINING THE CHANGES IN THE LEVEL OF BOND

This research departed from earlier studies which emphasized the social psychological approach to social control because it considered the impact of nonprimary group variables on the level of bond. Doing well in school or coming from an upper class background should be related to stability in the level of bond if it was initially high or $i$ ts subsequent increase if the level of bond was initially low. Conversely, if the youth was doing poorly in school or came from a lower social class background, then those factors ought to be related to continued low levels of bond or decreases if the level was initially high. In the following discussion the proportions of the youths who changed their level of bond by social class and grade point average controlling for the initial level of bond is examined (Tabie XLI).

In examining attachment, those who were low in 1964 were more likely to increase their level of attachment if they were from a high SES background, while for those who were high in 1964 more than a third decreased their level of attachment, but there was no difference between the low and nigh status groups.

The same pattern emerged when the effects of grade point average were examined. Youths who were initially low in attachment were more than twice as likely to increase their level of bond if they had a high rather than a low liPA. Conversely, while a iarge proportion of those who were initially high decreased their level of bond, there was only a small difference between the two groups indicating that school performance was not related to declines in the level of attachment. 
TABLE XLI

FERCENT OF YOUTHS WHO CHANGED THEIR LEVEL OF BOND BY SOCIAL CLASS AND GRADE POINT AVERAGE CONTROL: ING FOR THE INITIAL LEVEL OF BOND IN 1964

\begin{tabular}{cccc}
$\begin{array}{c}\text { Initial } \\
\text { Low Bond }\end{array}$ & $\begin{array}{c}\text { Initial } \\
\text { High Bond }\end{array}$ & $\begin{array}{c}\text { Initial } \\
\text { Low Bond }\end{array}$ & $\begin{array}{c}\text { Initial } \\
\text { High Bond }\end{array}$ \\
LOW SES Hi SES & LOW SES Hi SES & LOW GPA Hi GPA & LOW GPA Hi GPA \\
\hline
\end{tabular}

Percent Who Change Level of Attachment $27.8 \quad 40.0$

35.7

38.7

23.250 .0

$39.2 \quad 33.8$

Percent Who Change Level of Commitment 18.
23.1

20.7

11.1

17.3

33.3

27.8

5.2

Percent Who Change Level of Involvement

$\begin{array}{llll}55.1 & 43.5 & 13.5 & 9.6\end{array}$

$42.9 \quad 61.9$

19.2

7.6 
Looking at commitment, it is important to remember that this element of the social bond remained stable for the years 1964 and 1967. For those boys who were low in 1964, almost a fifth increased their level of bond, but the increases were not related to differences in social status. Similariy, declines in bond were not related to social class.

For those youths with low levels of commitment in 1964, those with a high GPA were somewhat more likely to increase their level of bond than those with a low GPA. In contrast, those with a low GPA were much more likely to decline than their high GPA counterparts. With involvement, for those youths who were initially low, a large number of the adolescents changed their level of bond with lower status youths being slightly more likely to go from low to high than the high status males. For those who were initially high, only a small number decreased in involvement and those decreases were not related to social class. Finally, for those who were initially low in involvement, increases were related to doing well in school while those who did poorly were more likely to decline in the level of involvement.

CHANGES IN THE LEVEL OF BOND AND DELINQUENCY

This study predicted that changes in the level of bond ought to be related to different rates of delinquency for those youths whose level of bond exhibited stability at a high or low level or upward or downward change. The rates should be highest for those youths whose levels were consistently low, intermediate for those 
whose levels fell from high to low or increased from low to high, and lowest for those who were consistently bonded to saciety. With minor exceptions the patterns were in the predicted directions (see Tables $X V I I, X I X, X X I)$.

Social class and success in school were thought to be important factors accounting for the changed level of a youth's bond to society. The analysis of changes in the revel of bond and delinquency with social class and grade point average controlled, demonstrated that school success and the social class background of the youths were related to increases and decreases in the delinquency rates when compared to the first order correlations. With minor exceptions, the rates were higher between comparable groups for those with a low GPA or lower social class background than for those who were doing well in school (see Tables XXVIII through XXXII).

\section{SUMMARY}

The issue of the impact of social structural factors on an individual's relationship to society is by no means resolved in this research. Yet, aside from the attempts of labeling theorists to describe the effects of institutional reaction on an individual's personality structure, the schism between the social structural and social psychological traditions remains unbridged.

An emergent metaphor or theme in sociology is that social institutions do need to be examined critically to determine if they are operating well. Depending on the criteria which are chosen to represent institutional "health" or "illness," it is apparent that 
social institutions (the economy, educational structures, health care systems, criminal justice) do manifest a side range of deleterious social impacts (Ryan, 1976; Duberman, 1976 and Gordon, 1971). The specific relevance of dysfunctional institutional effects broached in this research is the extent to which poorly functioning schools and social inequality is increasing the likelihood that an individual will become delinquent. Whatever the rationale for a social institution, if it can be demonstrated that it is harming an individual's relationship to society and affecting the likelihood that a youth will become involved with the criminal justice system, then the operation of that institution should be examined closely.

The contribution of social control theory and this research has been first to define the nature of the relationship of a youth to society and then to attempt to articulate the linkage between dysfunctional social institutions, decreased relationships to society and delinquency involvement. If adolescence is viewed as part of a maturation process with the end goal being the integration of the youth into adult social roles as control theory would suggest, then the role of research should be to investigate problems associated with successful socialization. 


\section{APPENDIX}

The data which were collected in 1967 in the Marion County Youth Study could be treated as cross sectional data and compared with the findings presented in Causes of Deinquency. Such an analysis, it might be argued, represents a more accurate comparison of the two populations since the youths from Marion County were seniors in 1967 and the youths in Hirschi's research were juniors and seniors. It will be recalled that the initial comparison of the two groups was made when the Marion County Youths were sophomores. This variation, however, should not be important if Hirschi is correct about his contention of the importance of early childhood socialization.

When the data are viewed cross-sectionally, for each element of the bond for which data were obtained at two points in time, the strength of the bond was stronger in 1967 than in 1964. For commitment, in 1964 the relationship to delinquency did not exist, but by 1967 the decision not to go to college was strongly related to de Tinquency.

In 1964 the relationship between attachment and delinquency in the Marion County Youth Study was gamma $=.292$, while for Hirschi's research the measure was gamma $=.294$. In 1967 when the Marion County youths were seniors, the relationship was gamma $=.52$ (Table XLII). The increase between the two years would lend considerable support to the contention that those youths who are no longer under the control 
of their parents are much more involved with delinquent behavior. A7so, as the youths approach graduation, if they have not formed attachment, and ties to conventional significant others, they appear to be especially free to deviate.

The emergence of a relationship between commitment in 1967 and delinquency is important, because it was noted that the relationship between the decision to attend college and law breaking behavior did not exist in 1964. This would possibly indicate that commitment was formed outside the family and in secondary group relations. The relationship between commitment and delinquent behavior is relatively strong (gamma $=.251$, Table XLIII). It appears that between 1964 and 1967 many youths directly confronted the need to make decisions about their careers and future education plans. Those who did not intend to go to college, for whatever reasons, reacted to the closure of that means of investment in their future and increasing their stakes in conformity through delinquent behavior. Thus, the failure to orient youths towards college manifested itself in delinquency irvuivement.

Involvement in 1964 was strongly related to delinquent behavior (gamma $=.57)$. In 1967 the relationship was only slightly stronger (ganma $=.61$, Table XLIV). When this finding is contrasted against the newly formed relationship between commitment and delinquency it is interesting to observe how initially homework prevents the youths from becoming involved with delinquency. However, for more of the adolescents, that work is a goal in itself. Only in high school do 
TABLE XLII

DELINQUENCY INVOLVEMENT BY LEVEL OF ATTACHMENT ${ }^{\top}$ FROM THE MARION COUNTY YOUTH STUDY

\begin{tabular}{lccr} 
& \multicolumn{3}{c}{ Level of Attachment (1967) } \\
De1 inquent (1967) & Low & High & Total \\
Yes & 33.3 & 13.6 & 23.6 \\
No & 66.7 & 86.4 & 76.4 \\
Total & 100.0 & 100.0 & 100.0 \\
N & $(144)$ & $(140)$ & $(284)$ \\
Total & 50.7 & 49.3 & 100.0 \\
Gamma $=.52$ & & & \\
\multicolumn{1}{l}{ T Attachment 1967, del inquency } & 1967.
\end{tabular}

TABLE XLIII

DELINQUENCY INVOLVEMENT BY LEVEL OF COMMITMENT ${ }^{\top}$ FROM THE MARION COUNTY YOUTH STUDY

\begin{tabular}{lccr} 
& \multicolumn{3}{c}{ Lever of Commitment (1967) } \\
Delinquent (1967) & Low & High & Total \\
Yes & 29.8 & 20.2 & 23.5 \\
No & 70.2 & 79.8 & 76.5 \\
Total & 100.0 & 100.0 & 100.0 \\
N & $(94)$ & $(178)$ & (272) \\
Total & 34.6 & 65.5 & 100.0 \\
Gamma $=.25$ & & & \\
\multicolumn{1}{c}{ 1 Commitment 1967, del inquency } & 1967.
\end{tabular}


TABLE XLIV

DEL INQUENCY INVOLVEMENT BY LEVEL OF INVOLVEMENT ${ }^{\top}$ FROM THE MARION COUNTY YOUTH STUDY

\begin{tabular}{lccr} 
& \multicolumn{3}{c}{ Level of Involvement (1967) } \\
Del inquent (1967) & Low & High & Total \\
Yes & 40.6 & 14.2 & 21.1 \\
No & 59.4 & 85.7 & 78.9 \\
Total & 100.0 & 100.0 & 100.0 \\
N & $(64)$ & $(182)$ & $(246)$ \\
Total & 26.0 & 74.0 & 100.0 \\
Gamma $=.61$ & & & \\
\multicolumn{1}{c}{1 Involvement 1967, delinquency } & 1967.
\end{tabular}

youths acquire the "commitment" to conventional goals which Hirschi deems important, and only then does commitment function as an element of the social bond.

The main body of this study dealt with the dynamic nature of the social bond. This brief analysis, which treated part of the information as cross-sectional data, showed the sirength of Hirschi:s pustulates. Additionally, one of the elements of the bond which was to be formed in the family, was, in fact, formed between the youth's sophomore and senior years indicating that the processes involved with adolescence may be much more powerfully associated with the emergence of commitment and delinquency than hitherto thought. 


\section{REFERENCES}

Anderson, Charles H. 1974. The Political Economy of Social Class, Englewood Cliffs, New Jersey: Prentice-HalT.

Banton, Michael 1964. The Policeman in the Community, New York: Basic Books.

B1ake, Gerald Francis 1973. School Dropouts: A Study of the Antecedents and Consequences of Dropping Out of High School, Unpublished Ph.D. Dissertation, University of Oregon.

Bittner, Egon 1967. "The Police in Skid-Row; A Study of Peace Keeping," American Sociological Review, XXXII, 699-715.

Bordua, David J. 1967. "Recent Trends: Deviant Behavior and Social Control," Annals of the American Academy of Political and Social Science, CCCLXIX, 149-163.

Bowles, Samuel and Herbert Gintis 1976. Schooling in Capitalist America: Educational Reform and the Contradictions of Economic Life, New York: Basic Books.

Cicourel, Aaron V. 1968. The Social Organization of Juvenile Justice, New York: John Wiley and Sons.

Clark, Alexander and Jack P. Gibbs 1965. "Social Control: A Reformulation," Social Problems, XII, 398-414.

Cloward, Richard A. and Lloyd E. Ohl in 1960. Del inquency and Opportunity, New York: The Free Press.

Cohen, Albert K. 1955. Delinquent Boys, New York: The Free Press.

Cooley, Charles H. 1902. Human Nature and the Social Order, New York: Charles scribner's Sons.

Costner, Herbert L. 1965. "Criteria for "leasures of Association," American Sociological Review, XXX, 341-353.

Davis, Nannette J. 1975. Sociological Constructions of Deviance, Dubuque, Iowa: W. C. Brown Co. 
Dentler, Robert A. and Lawrence J. Monroe 1961. "Sociological Correlates of Early Adolescent Theft," American Sociological Review, XXIII, 733-743.

Duberman, Lucile 1976. Social Inequality, Lippincott: Philadelphia.

Eubanks, Earle Edward 1932. The Concepts of Sociology, New York: D. C. Heath.

Frease, Dean C. 1969. The Schools, Self-Concept and Delinquency, Unpublished Ph.D. Dissertation, University of Oregon.

Gibbons, Don C. 1976. Delinquent Behavior, 2nd Edition, Englewood Cliffs, New Jersey: Prentice-Hail.

Gibbons, Don C. and Joseph F. Jones 1975. The Study of Deviance, Englewood Cliffs, New Jersey: Prentice-Ha17.

Glueck, Sheldon and Eleanor 1976. Unraveling Juvenile Delinquency, Cambridge, Massachusetts: Harvard University Press.

Gordon, David 1971. Problems in Political Economy, Lexington, Mass.: D. C. Heath.

Gordon, David 1974. "Capitalism, Class and Crime in America," in Charles E. Reasons (editor) The Criminologist: Crime and the Criminal, Pacific Pal isades, California: Goodyear Publishing Company.

Gouldner, Alvin W. 1962. "Anti-Minotaur: The Myth of a Value-Free Social Science, Social Problems, IX, 199-213.

Gusfield, Joseph R. 1963. Symbolic Crusade, Urbana, Illinois: University of Ilinois Press.

Hepburn, John R. 1963. "Testing Alternative M̉odels of Delinquency Causation," Journal of Criminal Law and Criminology, LXVII, $450-459$.

Hindelang, Michael J. 1973. "Causes of Delinquency: A Partial Replication and Extension," Social Problems, XX, 471-487.

Hirschi, Travis 1969. Causes of Delinquency, Berkeley, California: Universjty of California Press.

Hollingshead, August B. 1941. "The Concept of Social Control," American Sociological Review, VI, 217-224.

Hopkins, Andrew 1975. "On the Sociology of Criminal Law," Social Problems, XXII, 608-619. 
Janowitz, Morris 1975. "Sociologicai Theory and Social Control," American Journal of Sociology, LXXXI, 82-106.

Janowitz, Morris 1976. Social Control of the Welfare State, New York: Elsevier Scientific Publishing Company.

Jensen, Gary 1976. "Inner Containment and Delinquency," Journal of Criminal Law and Criminology, LXIV, 464-470.

Kelley, Delos 1970. Social Class, School Status, and Self-Evaluation as Related to Adolescent Values, Success, and Deviance, Unpublished Ph.D. Dissertation, University of Oregon.

Kerlinger, Frederick Nicholas 1964. Foundations of Behavioral Research, New York: Holt, Rinehard and Winston.

Kova7, John Patrick 1967. The Drifters and the Directed: An Anatomy. of Educational Involvement, Unpublished Ph.D. Dissertation, University of Oregon.

Landis, Paul H. 1956. Social Control, Chicago: J. B. Lippincott.

LaPiere, Richard J. 1954. A Theory of Social Control, New York: McGraw-Hi11.

Lemert, Edwin M. 1967. Human Deviance, Social Problems and Social Control, Englewood Cliffs, New Jersey: Prentice-Hall.

Lemert, Edwin M. 1974. "Beyond Mead: The Societal Reaction to Deviance," Social Problems, XXI, 457-468.

Liska, Alten E. 1959. "Interpreting the Causal Structure of Differential Association Theory," Social Problems, XVI, 485-492.

Marsna11, T. F. 1973. "An Investigation of the Delinquency SelfConcept Theory of Reckless and Dinitz," British Journal of Criminology, XIII, 227-236.

Hicad, George Herbert 1925. "The Genes is of Self and Social Control," international Journal of Ethics, XXXV, 257-289.

Merton, Robert 1957. Social Theory and Social Structure, Glencoe, New York: Free Press.

Mueller, John Henry, Karl L. Schuessler and Herbert L. Costner 1970. Statistical Reasoning in Sociology, 2nd Edition, Boston: Houghton Mifflin.

Nettler, Gwynn 1974. Explaining Crime, New York: McGraw-Hill. 
Nye, F. Ivan 1958. Family Relationships and Delinquent Behavior, New York: Wiley.

Orcutt, James D. 1970. "Self-Concept and Insulation Against Delinquency: Some Critical Notes," Sociological Quarterly, $X I, 381-390$.

Parsons, Ta1cott 1951. The Social System, New York: The Free Press of Glencoe.

Polk, Kenneth and F. Lynn Richmond 1972. "Those Who Fail," in Schools and Delinquency edited by Kenneth Polk and Walter E. Schafer, Englewood Cliffs, New Jersey: Prentice-Hall.

Rankin, Joseph H. 1976. "Investigating the Interrelations Among Social Control Variables and Conformity," Journal of Criminal Law and Criminology, LXVII, 470-480.

Reckless, Walter C., Simon Dinitz and Ellen Murray 1956. "Self-Concept as an Insulator Against Delinquency," American Sociological Review, XXI, 744-746.

Reckless, Walter C., Simon Dinitz and Ellen Murray 1957. "The 'Good' Boy in a High Delinquency Area," Journal of Criminal Law, Criminology and Police Science, May-June (48CD), 18-25.

Reckless, Walter C. and Simon Dinitz 1972. The Prevention of Delinquency: An Experiment, Columbus: Ohio University Press.

Reiss, Albert J. 1951. "Delinquency as the Failure of Personal and Social Control," American Sociological Review, XVI, 196-206.

Rosenbaum, James A. 1976. Making Inequality, New York: John Wiley and Sons.

Rosenberg, Morris 1968. The Logic of Survey Analysis, New York: Basic Books.

Ross, Edward A. 1901. Socia? Contro1: A Survey of the Foundations of Order, New York: MacMillan

Ross, Edward A. 1936. 70 Years of It, New York: Appleton.

Ryan, William 1975. Blaming the Victim, New York: Vintage.

Scarpitti, Frank R., Ellen Nurray, Simon Dinitz and Walter C. Reckless 1960. "The 'Good' Boy in a High Delinquency Area: Four Years Later," American Sociological Review, XXV, 555-558. 
Schafer, Walter E., Carol 01exa and Kenneth Polk 1972. "Programmed for Social Class: Tracking and High School" in Schools and Delinquency, edited by Kenneth Polk and Walter E. Schafer, Englewood Cl iffs, New Jersey: Prentice-Hall.

Schafer, Walter E. and Kenneth Polk 1967. "Delinquency and the School," Task Force Report: Juvenile Del inquency and Youth Crime, The President's Commission on Law Enforcement and Administration of Justice, Washington, D.C.: U.S. Government Printing Office.

Schrag, Clarence 1971. Crime and Justice: American Style, Rockville, Maryland: National Institute of Mental Health.

Schur, Edwin M. 1971. Labeling Deviant Behavior: Its Sociologicai Implications, New York: Harper and Row.

Schwartz, Michael and Sandra S. Tangri 1965. "A Note on Self-Concept as an Insulator Against Delinquency," American Sociological Review, XXX, 922-926.

Scott, Robert A. and Arnold Shore 1975. "Sociology and Policy Analysis," The American Sociologist, IX, 51-59.

Short, James F., Jr. 7976. Delinquency, Crime and Society, Chicago: The University of Chicago Press.

Sudnow, David 1965. "Normal Crimes: Sociological Features of the Penal Code in a Public Defender Office," Social Problems, XII, 255-276.

Sykes, Gresham M. and David Matza 1957. "Techniques of Neutralization: A Theory of Delinquency," American Sociological Review, XXII, $664-670$.

Tangri, Sandra S. and Michael Schwartz 1967. "Delinquency Research and the Self-Concept Variable," Journal of Criminal Law, Criminology and Police Science, LXIII, 182-190.

Turner, Ra]ph E. 1967. Robert E. Park: Selected Papers, Chicago: The University of Chicago Press.

Vincent, George 1896. "The Province of Sociology," American Journal of Sociology, I, 473-491.

U.S. Department of Health, Education and Welfare 1950. Report to Congress on Juvenile Delinquency, Washington, D.C.: U.S. Government Printing office.

Wolfgang, Marvin E., Robert Figlio and Thorsten Sellin 1972. Delinquency in a Birth Cohort, Chicago: University of Chicago Press. 
Zald, Mayer N. 1962. "Power Balance and Staff Conflict in Correctional Institutions," Administrative Science Quarterly, VII, 22-49.

Zeisel, Hans 1957. Say It With Figures, New York: Harper and Row. 